\title{
WestVirginiaUniversity
}

THE RESEARCH REPOSITORY @ WVU

Graduate Theses, Dissertations, and Problem Reports

2002

\section{Application evaluation of a prototype backscatter imaging LDV system (BILS)}

Preetanshu Pandey

West Virginia University

Follow this and additional works at: https://researchrepository.wvu.edu/etd

\section{Recommended Citation}

Pandey, Preetanshu, "Application evaluation of a prototype backscatter imaging LDV system (BILS)" (2002). Graduate Theses, Dissertations, and Problem Reports. 1894.

https://researchrepository.wvu.edu/etd/1894

This Thesis is protected by copyright and/or related rights. It has been brought to you by the The Research Repository @ WVU with permission from the rights-holder(s). You are free to use this Thesis in any way that is permitted by the copyright and related rights legislation that applies to your use. For other uses you must obtain permission from the rights-holder(s) directly, unless additional rights are indicated by a Creative Commons license in the record and/ or on the work itself. This Thesis has been accepted for inclusion in WVU Graduate Theses, Dissertations, and Problem Reports collection by an authorized administrator of The Research Repository @ WVU. For more information, please contact researchrepository@mail.wvu.edu. 


\title{
Application Evaluation of a Prototype Backscatter Imaging \\ LDV System (BILS)
}

\author{
Preetanshu Pandey \\ Thesis Submitted to the \\ College of Engineering and Mineral Resources \\ at West Virginia University \\ in partial fulfillment of the requirements \\ for the degree of \\ Master of Science \\ in \\ Chemical Engineering \\ Dr. Richard Turton \\ Dr. Paul Yue \\ Dr. Charter D. Stinespring \\ Department of Chemical Engineering \\ Morgantown, West Virginia \\ 2002
}

Keywords: Fluidized Bed, Laser Doppler Velocimeter, Velocity Profiles, Imaging and

Particle Size, Clusters 


\section{Abstract \\ Application Evaluation of a Prototype Backscatter Imaging LDV System (BILS)}

\section{Preetanshu Pandey}

This study focuses on the application evaluation of a prototype backscatter imaging LDV system (BILS). This non-intrusive instrument has the ability to record particle images and two-dimensional velocity data simultaneously. A series of validation tests were conducted to verify the operation of the system. These included comparing the velocity of a wire, attached to a rotating disc, with known angular frequency (measured by digistrobe), with that measured by the instrument. The results were found to be in good agreement. The imaging part of BILS was calibrated using a target with known dimensions.

The terminal velocities and particle sizes of near-spherical, Nu-pareil sugar particles were investigated using BILS for five different size cuts. The results were in good agreement with the drag curve proposed by Haider and Levenspiel, 1988. The images of the particles obtained were used to estimate the sphericity $(\Phi)$, which was found to be very close to $1(0.98<\Phi<0.99)$. A qualitative study on the effect of particle loading and drop height on the particle velocity was also carried out. In the course of this study, it was observed that the velocity of free falling particles was affected by the solids loading in the particle stream.

After successful validation of both the imaging and the velocity part of the system, it was used to record real-time particle velocity data, near the wall region of a $15 \mathrm{~m}$ high riser section of a cold-flow circulating fluidized bed (CFCFB) located at NETL, Morgantown. The effects of superficial gas velocity and solids circulation rate on the particle velocity were studied for nine different operating conditions. The particle velocity near the wall was found to increase in the upward direction with increasing superficial gas velocity and in the downward direction with increasing solids circulation rate.

The phenomenon of 'clustering' of particles near the wall region was also studied for different operating conditions. A criterion was proposed to define a cluster. Although a more rigorous analysis is recommended for future work, the preliminary results show that the mean velocity of the clusters was between $0.2-1 \mathrm{~m} / \mathrm{s}$ in the downward direction, for most of the operating conditions studied. The average cluster length was found to be about 2 to $4 \mathrm{~cm}$. In addition, it was found that the operating parameters, such as solids circulation rate and superficial gas velocity, effect the distribution of the cluster velocity and cluster length. 


\section{Acknowledgements}

The author would like to take this opportunity to acknowledge the people who assisted with this research, specially the considerable assistance and encouragement given to him by his advisor, Dr. Richard Turton. The author is also grateful to the other committee members, Dr. Paul Yue and Dr. Charter Stinespring.

Thanks are extended to Dr. Lawrence Shadle for his guidance and financial support through the University/NETL partnership program. Joseph Shakal from TSI Inc. MN deserves a special mention for providing the valuable technical help with the instrument. The author also expresses his gratitude to his parents and other members of the family for their support and encouragement. 


\section{Table of Contents}

Application Evaluation of a Prototype Backscatter Imaging LDV System (BILS) ........... i

Table of Contents ..................................................................................................... iv

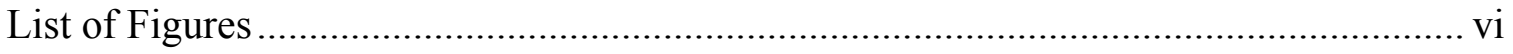

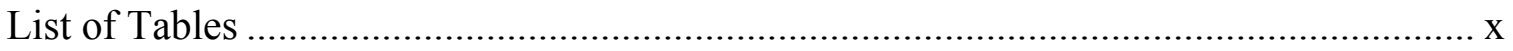

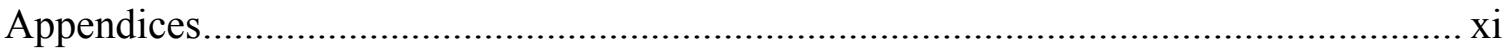

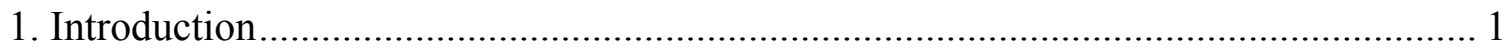

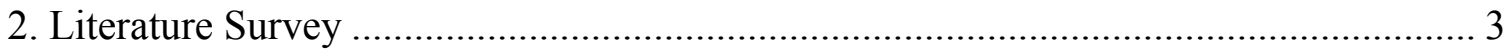

2.1 Previous uses of laser Doppler velocimeter..................................................... 3

2.2 The use of laser Doppler velocimeter and other devices to measure solids velocities in a circulating fluidized bed....................................................... 6

2.3 Studies on particle motion near the wall of a circulating fluidized bed............... 14

3. Components and Operating Principles of BILS ................................................. 21

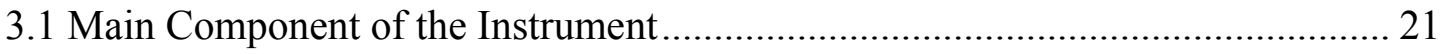

3.2 Basic Operating Principles of the Instrument ............................................... 26

3.2.1 Operating Principles of the LDV component …....................................... 26

3.2.2 Operating Principles of the Imaging component ...................................... 28

3.3 A summary of the Capabilities and Limitations of BILS ................................ 30

4. Instrument Calibration and Validation............................................................ 31

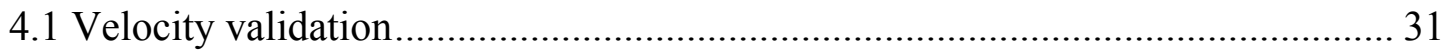

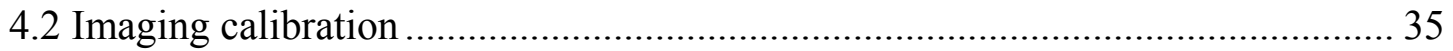

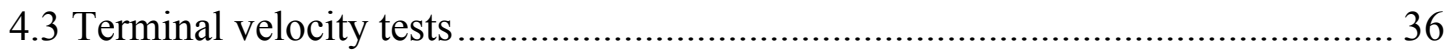

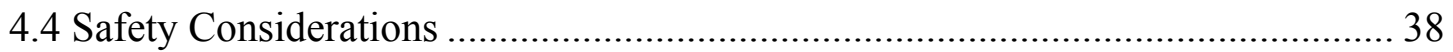




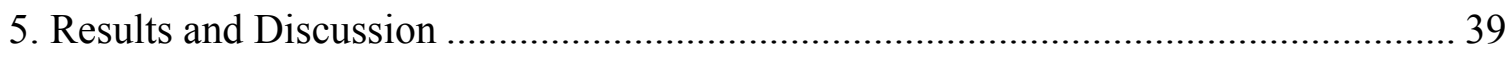

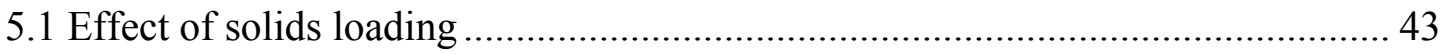

5.2 Terminal velocity and particle size measurements ....................................... 47

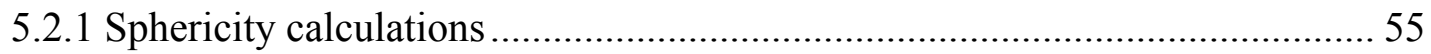

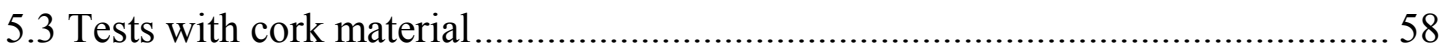

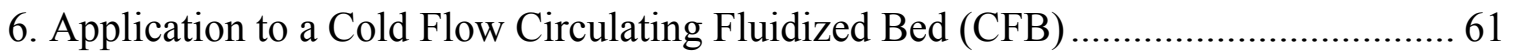

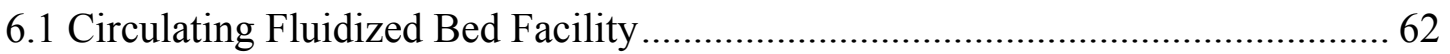

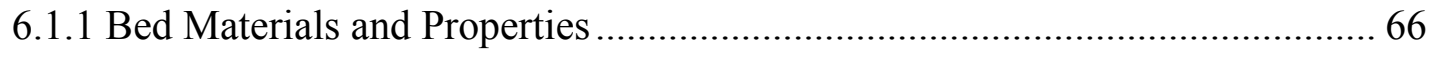

6.2 Data reproducibility in the Circulating Fluidized Bed..................................... 67

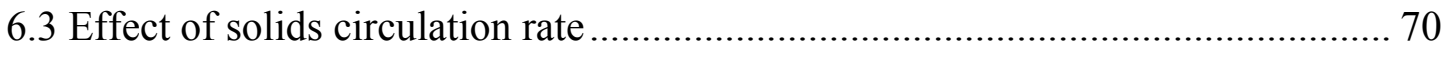

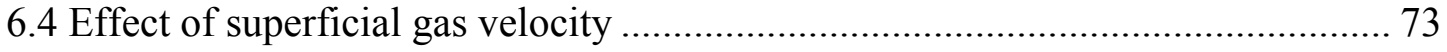

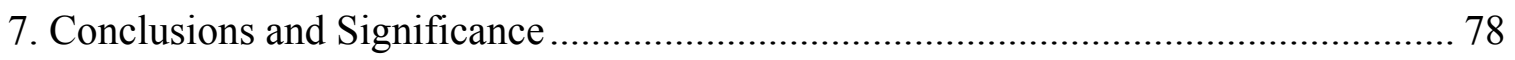

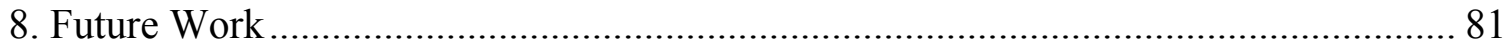

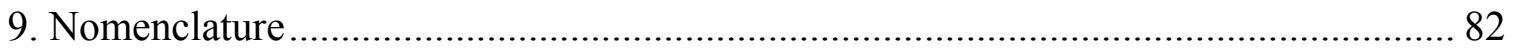

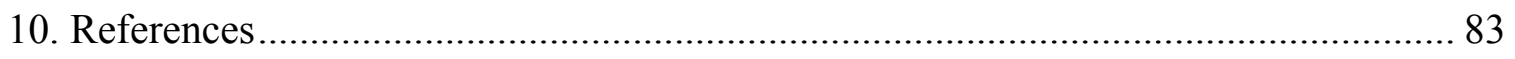




\section{List of Figures}

Figure 2.1 Mean particle velocity distribution in the presence of $200 \mu \mathrm{m}$ particles, Tsuji

et al., [1984]..... 7

Figure 2.2 Velocity profile of local particle velocity for different solid fluxes: $U g=5.5 \mathrm{~m} / \mathrm{s}$, $\mathrm{z}=6.2 \mathrm{~m}, \mathrm{x} / \mathrm{X}=0$, Zhou et al., [1995] 9

Figure 2.3 Radial mean velocity profiles Arastoopour et al., [1996] 9

Figure 2.4 Particle axial velocity at center of the pipe and $Z / H=0.5, U_{g}=1 \mathrm{~m} / \mathrm{s}$, Van den Moortel et al., [1998] 11

Figure 2.5 Comparison of solids velocity profiles of different particles, Wang et al.,

[1998]. 11

Figure 2.6 Radial profiles of particle velocity along axial position, Wei et al., [1998].... 12

Figure 2.7 A comparison of the particle velocity profiles between low and high flux at constant $U_{g}=8 \mathrm{~m} / \mathrm{s}$, Zhu et al., [2001]

Figure 2.8 A picture of particle swarms and vertical strands near the riser wall, Rhodes et al., [1992]. 15

Figure 2.9 Typical cluster velocities and lengths, Soong et al., [1995] 16

Figure 2.10 Comparison of predicted and experimental cluster velocity, Lim et al., [1996]

Figure 2.11 Particle cluster length as a function of radial position x, Van den Moortel and Tadrist, [2002]. 18

Figure 2.12 Comparison of data from various researchers with the correlation suggested, Griffith and Louge, [1998]... 20 
Figure 3.1 Backscatter Imaging LDV System (BILS), TSI Inc. Manual

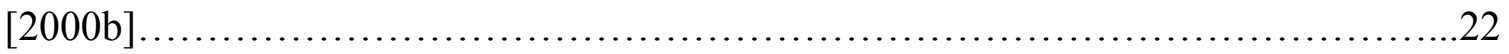

Figure 3.2 The BILS instrument set-up at NETL location, Morgantown....................... 24

Figure 3.3 Basic operating principle of the LDV component of BILS, Dantec Inc........ 27

Figure 3.4 Layout of the Backscatter Imaging System, TSI Inc. Manual [2000b].......... 29

Figure 4.1 Set-up for instrument's data validation ................................................ 31

Figure 4.2 The effect of the position of wire in the measurement volume, for wire

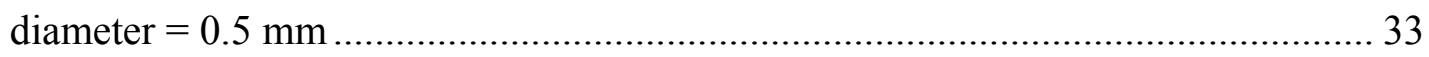

Figure 4.3 Random runs with different wire diameters ............................................ 34

Figure 4.4 Target used for image calibration...................................................... 35

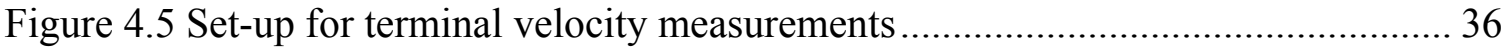

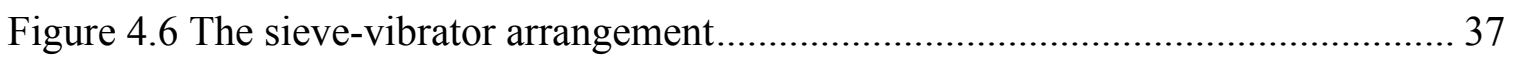

Figure 5.1 Typical velocity vs time data obtained from the DATAVIEW software ....... 40

Figure 5.2 Image of a Nu-Pareil obtained from the camera and its corresponding binary

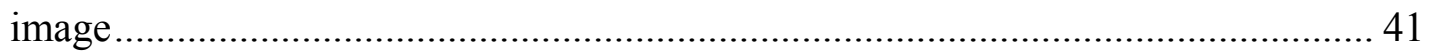

Figure 5.3 The image of a particle not completely within the field of view of camera... 41

Figure 5.4 Variation of velocity with drop height and solids loading ........................... 44

Figure 5.5 Velocity of 500-600 $\mu \mathrm{m}$ particles as a function of drop height and solids loading 45

Figure 5.6 Velocity of 600-700 $\mu \mathrm{m}$ particles as a function of drop height and solids loading 46

Figure 5.7 Experimental terminal velocity versus particle size..... 48 
Figure 5.8 Run 1- Experimental dimensionless particle velocity vs dimensionless

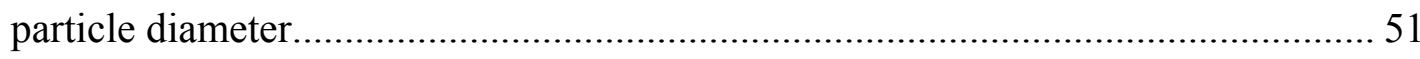

Figure 5.9 Run 1- Mean values and error bars (two standard deviations) ....................... 52

Figure 5.10 Run 2- Experimental dimensionless particle velocity vs dimensionless

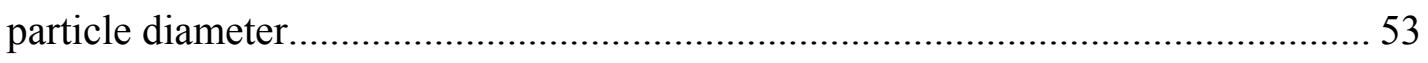

Figure 5.11 Run 2- Mean values and error bars (two standard deviations).................... 54

Figure 5.12 Terminal velocity of cork particles for particle size $1000-1200 \mu \mathrm{m}$............59

Figure 5.13 Velocity variation of cork particle with particle size and solids loading ...... 60

Figure 5.14 Comparison of velocity with and without glass section for three different

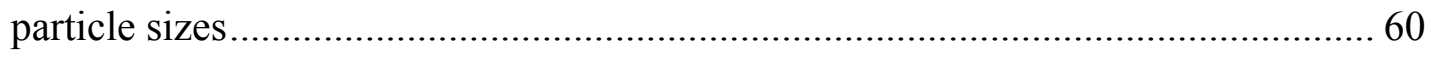

Figure 6.1 Circulating Fluidized Bed set-up at NETL, Morgantown ............................. 64

Figure 6.2 A sketch of the linear positioning system used in the set-up ...................... 65

Figure 6.3 Mean velocity as a function of the measurement volume distance from the wall of the CFB, 68

Figure 6.4 Mean velocity as a function of the measurement volume distance from the wall of the CFB, a repeat of Run 7, $U_{g}=4.58 \mathrm{~m} / \mathrm{s}$ and $M_{s}=2722 \mathrm{~kg} / \mathrm{hr}$

Figure 6.5 Effect of solids circulation rate on the mean velocity near the wall region for superficial gas velocity, $U_{g}=4.58 \mathrm{~m} / \mathrm{s}, M_{s}=907 \mathrm{~kg} / \mathrm{hr}$ (Run 4), $M_{s}=2722 \mathrm{~kg} / \mathrm{hr}$ (Run 7), $M_{s}=4491 \mathrm{~kg} / \mathrm{hr}(\operatorname{Run} 1)$ 71

Figure 6.6 Effect of solids circulation rate on the mean velocity and positive and negative components, 72 
Figure 6.7 Effect of superficial gas velocity on the mean velocity near the wall region for solids circulation rate, $M_{s}=2722 \mathrm{~kg} / \mathrm{hr}: U_{g}=5.4 \mathrm{~m} / \mathrm{s}$ (Run 2), $U_{g}=4.58 \mathrm{~m} / \mathrm{s}$ (Run 7), $U_{g}=3.75 \mathrm{~m} / \mathrm{s}($ Run 9$)$ 75

Figure 6.8 Effect of superficial gas velocity on the mean velocity near the wall region for solids circulation rate, $M_{s}=1439 \mathrm{~kg} / \mathrm{hr}: U_{g}=5.16 \mathrm{~m} / \mathrm{s}$ (Run 6), $U_{g}=3.99 \mathrm{~m} / \mathrm{s}$ (Run 8)

Figure 6.9 Effect of superficial gas velocity on the mean velocity near the wall region for solids circulation rate, $M_{s}=4005 \mathrm{~kg} / \mathrm{hr}: U_{g}=5.16 \mathrm{~m} / \mathrm{s}$ (Run 3), $U_{g}=3.99 \mathrm{~m} / \mathrm{s}$ (Run 5)

Figure A3.1 Clustering of particles for the dense and dilute solids loading.............93

Figure A3.2 Variation of cluster velocity distribution with radial location for $M_{s}=6000$

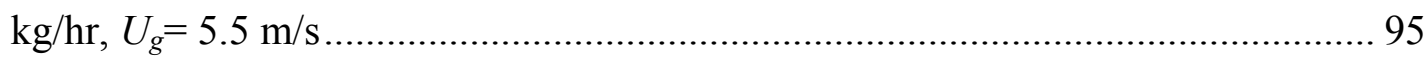

Figure A3.3 Variation of cluster velocity distribution with radial location for $M_{s}=6000$ $\mathrm{kg} / \mathrm{hr}, U_{g}=4.6 \mathrm{~m} / \mathrm{s}$ 96

Figure A3.4 Variation of cluster length distribution with radial location for $M_{S}=6000$ $\mathrm{kg} / \mathrm{hr}, U_{g}=4.6 \mathrm{~m} / \mathrm{s}$ 98

Figure A3.5 Variation of cluster velocity distribution with solids circulation rate for $U_{g}=$ $4.6 \mathrm{~m} / \mathrm{s}$, at the wall of the riser. 99

Figure A3.6 Variation of cluster velocity distribution with superficial gas velocity for $M_{s}=6000 \mathrm{~kg} / \mathrm{hr}$, at the wall of the riser 100 


\section{List of Tables}

Table 2.1 Cluster velocities at the wall obtained by various researcher, Griffith and Louge,

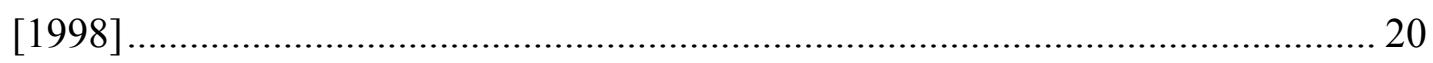

Table 5.1 The main contents of the output file of the BackscaPP software .................... 42

Table 5.2 Terminal velocity of Nu-Pareils for different particle size-cuts ..................... 48

Table 5.3 Sphericity values for different particle size for two runs..............................57

Table 5.4 Mean terminal velocities and standard deviations for different particle sizes of cork material.....................................................59

Table 6.1 The experimental matrix of superficial gas velocities and solids circulation

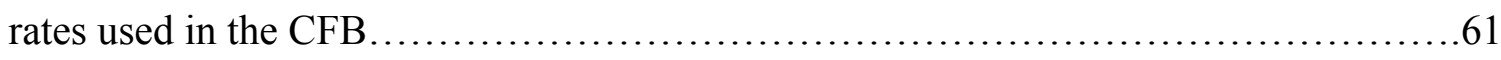

Table A1.1 Velocity data corresponding to Figures $5.4,5.5$ and $5.6 \ldots \ldots \ldots \ldots \ldots \ldots . . . . . .17$

Table A1.2 Experimental data for terminal velocity and particle diameter of Nu-Pareils of

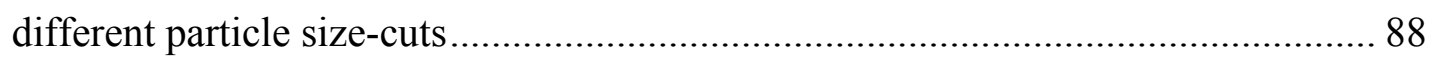

Table A2.1 Mean velocities of particles as a function of distance inside the riser wall for

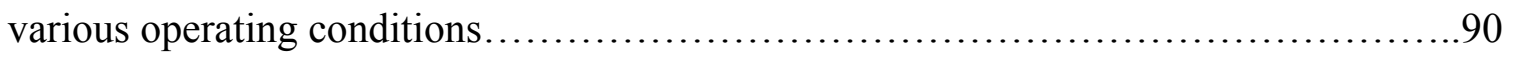

Table A2.2 Dependence of solids velocity on superficial gas velocity and solids circulation rate, at the wall- A statistical study. 91 


\section{Appendices}

Appendix I Variation in velocity of Nu-Pareils with drop height, solids loading and

particle size.......................................................... 87

Appendix II Solids velocity data near the wall of the CFB riser.....................89

Appendix III Results on Solids 'Clusters' ......................................92 


\section{Introduction}

Gas-solid circulating fluidized beds (CFB's) are used widely in many processes in the petroleum and chemical industries and find major application in coal combustors and fluidized catalytic cracking units (FCC). Due to the development of highly active catalysts, circulating fluidized beds have replaced bubbling beds in the Petroleum Industry. Further, circulating fluidized bed combustors are popular because of the potential of burning coal with low $\mathrm{SO}_{2}$ and $\mathrm{NO}_{2}$ emissions, Gidaspow [1994]. Due to this trend, much attention has been paid to the hydrodynamics and mixing behavior of such devices.

The presence of a dispersed phase, i.e. solid particles, bubbles and droplets, not only has an effect on the flow pattern of the continuous phase (gas in a CFB), but also on heat, mass and momentum transfers. Thus characteristics of the dispersed phase, such as particle size and velocity, as well as the continuous phase, directly affect the performance of the bed, Arastoopour et al. [1996]. Considerable effort has been extended to model these systems in order to study parameters such as particle concentration profiles, velocity profiles, and size distribution of solids at the walls and inside the bed. This information is critical in solving the momentum balance.

The particles tend to move in the form of clusters in the near-wall region. To estimate the heat transfer occurring at the walls of the CFB, it is important to have a complete understanding of the hydrodynamics of clusters. Though some research in this area has been done in the past, the issue of defining clusters and their properties is still of great interest. 
The present study focuses on the application evaluation of a prototype backscatter imaging laser Doppler velocimeter (LDV) system (BILS). This instrument was developed by TSI Inc., Shoreview, MN. The goal of this study is to measure the particle velocity in the riser section of a cold flow circulating fluidized bed facility at NETL, Morgantown. The backscatter imaging LDV system (BILS) incorporates and extends the particle velocity measurement ability of the LDV with the ability to measure particle size. In this sense, the BILS may seem to function like a phase Doppler particle analyzer (PDPA). However, this is not the case. Infact, BILS and PDPA serve mutually exclusive applications. PDPA requires the particle to be homogenous and smooth (usually spherical) in order to obtain a meaningful measurement. On the other hand, BILS requires the particles to have rough surfaces in order to obtain non-specular scattering. In addition to obtaining particle size and velocity data, BILS provides particle shape information (aspect ratio and circularity) along with a digital image, TSI Inc. Manual [2000a]. This is an added advantage over a conventional PDPA.

There is a need for a non-intrusive system to record accurately particle velocities near the wall for various operating conditions. This will help to characterize the hydrodynamics of the solids near the wall region of the bed. Also, a more detailed and involved study is required to characterize clusters of particles near the wall. This provided the impetus for the current work. 


\section{Literature Survey}

\subsection{Previous uses of laser Doppler velocimeter}

The use of laser Doppler velocimetry (LDV) for flow measurement was first demonstrated in 1964. Since that time, it has evolved from a laboratory instrument into a practical tool for research and industrial use. The LDV's obvious advantage is its ability to make measurements without perturbing the flow under conditions where other instruments provide questionable results or cannot be used. All the flow field characteristics are retained and hardly any calibration is required. Flow velocity is measured directly and is not strongly dependent on the temperature, density, or composition of the flow medium.

The LDV made its debut in 1964 with the appearance of the paper by Yeh and Cummins. They presented the basic theory for a reference-beam LDV and included excellent data obtained for the laminar velocity profile in a circular tube. The instrument capabilities increased and commercial devices became available as more applications for this instrument were realized. In early investigations, it was often a major accomplishment to obtain a reasonably good Doppler signal.

For many years the fundamental concept of a frequency shift in radiation received from a moving body by a stationary detector has been understood, and used in the Communication and Astronomy Industries. The equation relating the measured frequency difference, $v_{D}$, to the instantaneous velocity can be derived from the Doppler-shift of scattered radiation, from fringe considerations, or from wave theory. It is of the form:

$$
v_{D}=\text { const } * V_{P}
$$


and shows a linear relationship between the frequency difference and the instantaneous velocity $\left(V_{P}\right)$. After the first work by Yeh and Cummins [1964], much progress has been made on the subject. The research effort in laser-Doppler anemometry has thus been directed towards applying a familiar principle in a new way to coherent light sources. Currently, many pre-aligned optical systems are available and they also are adaptable to different flow situations, Durst et al. [1981].

There are three kinds of optical arrangement modes that are used, reference-beam, dual-beam, and the two-scattered beam. The third type is rarely used in commercial devices. The earlier LDV's used the reference beam technique where the reference (incident) beam is split into an intense scattering beam and a weak reference beam. The frequency of the scattered beam is altered by the Doppler effect, and its combination with the reference beam gives rise to a frequency difference, which is proportional to the particle velocity, Durst et al. [1981]. The dual-beam mode is the most widespread because of its simplicity. The two coherent beams interfere to produce fringes in the intersection region. A small particle crossing the fringe pattern scatters light, producing intensity fluctuations at a frequency corresponding to the rate at which the fringes are crossed. The particle scatters the Doppler-shifted light from each beam into the detector. The two optical frequencies are mixed to give a beat note. The frequency of which will depend on the fringe spacing and the velocity component, Kaufman [1986].

There are two kinds of scattering modes that are currently used in LDV systems. These are the forwardscatter mode and the backscatter mode. In the past, the forwardscatter mode was predominantly used, since the signal intensity from the backscatter mode were relatively weak. Generally, forward scattering is used when the 
particles are transparent and the receiver is on the other side of the transmitter. The backscatter mode has the receiving probe on the same side. This helps in implementing the method when access to the flow is limited to one side. The basic optical principle involved in the forwardscatter is refraction and that for the backscatter is reflection.

The introduction of the dual beam mode, Thompson and Stevenson [1978], has increased the use of the backscatter arrangement, so that only a single optical access port (window) to the flow is needed. Flow measurements in large wind tunnels, rotating machinery and combustion chambers are routinely done in the backscatter mode. BILS is also based on the backscatter mode and is an even more advanced version of the instrument in the sense that the transmitter and the receiver probes, which are two separate entities in a conventional LDV, are combined in a single probe called the transceiver. This requires only one optical access port to the flow region. Also, the design is very light and compact design.

The potential applications of the technique range from very low velocity measurements, as in blood flow and other biological flows, to measurements in chemical reacting flows, hypersonic flows, and flows within blade rows in rotating machinery, Menon [1982]. Much research has been done to study the aerodynamic properties of aircraft and land vehicles and to design more efficient turbines and internal combustion engines. The following section shows how the LDV system has been useful in the area of circulating fluidized beds. 


\subsection{The use of laser Doppler velocimeter and other devices to measure solids velocities in a circulating fluidized bed}

The application of interest in this study is the use of LDV principles in a BILS instrument along with the particle size measurements in a circulating fluidized bed. Some research has been done in the analysis of the gas-particle flow using PDPA. The differences in PDPA and BILS have already been discussed. The different flow regimes obtained in a CFB depend on the operating parameters, e.g., the superficial velocity, physical properties of both the phases, solid size distribution, shape and size (diameter) of the riser.

The LDV is able to characterize the velocity profiles in the gas-solid (diphasic) flow system in a CFB. Tsuji et al., [1984] used a LDV system to make velocity measurements in a vertical pipe having two-phase flow. They used a dual beam forward scattering mode with a $15 \mathrm{~mW}$ He-Ne laser and a $100 \mathrm{~mm}$ focal length lens. A typical graph for the velocity profile for spherical $200 \mu \mathrm{m}$ diameter plastic particles, that they generated, is shown in Figure 2.1, where $m$ is defined as the particle-to-air-mass-flowrate, $\bar{u}_{c}$ is the velocity at the pipe center, $D$ is the diameter of the pipe ( $\left.\mathrm{D}=30 \mathrm{~mm}\right), \bar{u}_{m}$ is the mean air velocity and $r$ is the radial distance from the center. They measured both air and particle velocity. Tracer particles for detecting the airflow were ammonium chloride smoke of diameter $0.6 \mu \mathrm{m}$. 


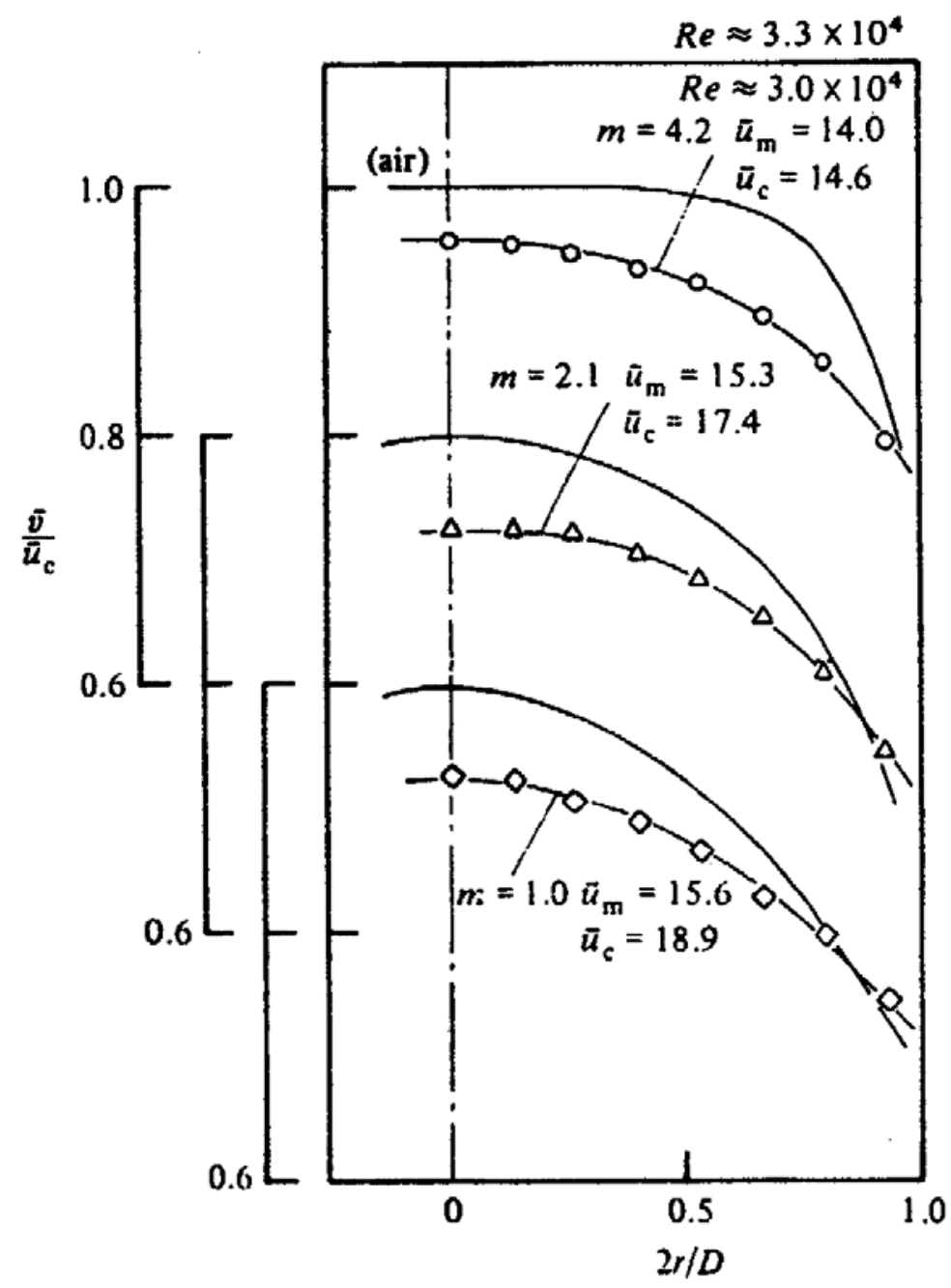

Figure 2.1 Mean particle velocity distribution in the presence of $200 \mu \mathrm{m}$

\section{particles, Tsuji et al., [1984]}

Rhodes and Geldart [1986] observed an exponential decay of the solid concentration with height. Monceaux et al. [1985] showed that a characteristic flow regime in $\mathrm{CFB}$ was a core-annulus configuration in the dilute zone of the riser. The riser bed in the dilute region is described as a rapidly-rising dilute suspension core zone surrounded by a slower falling suspension near the riser walls.

Tadrist and Cattiuw [1993] used a phase Doppler particle analyzer (PDPA) in the dilute zone of the CFB riser to determine solid size, velocity profiles, and local mass 
fluxes. Zhou et al., [1995] developed a five-fiber optical particle velocity measuring system (intrusive in nature). They measured vertical velocities and the fraction of rising and falling particles in a CFB riser section of $146 \mathrm{~mm}$ by $146 \mathrm{~mm}$ square cross section. The particles used were Ottawa sand of mean diameter $213 \mu \mathrm{m}$ and particle density of $2640 \mathrm{~kg} / \mathrm{m}^{3}$. The effects of superficial gas velocity and solid circulation rate on solids velocity were studied. They analyzed these effects on the ascending and descending particles separately. A typical graph obtained for different fluxes is shown in Fig. 2.2, where $G_{s}$ is the solid circulation rate and $y$ is the radial distance. They concluded that, for the operating conditions they explored, the ascending particle velocity increased in the core and decreased near the wall with increasing solid circulation rate and increased with superficial gas velocity. The magnitude of descending particle velocity increased with solid circulation rate, but was almost unaffected by an increase in superficial gas velocity.

Arastoopour et al., [1996] used a laser Doppler anemometer (LDA) to obtain velocity profiles in a CFB. The solid volume concentration used was below 3\%. The riser was a $9 \mathrm{ft}$ high, PVC pipe with a $5 \mathrm{~cm}$ ID. Figure 2.3 shows the radial distribution of the mean velocity at different superficial gas velocities, where $D_{p}$ is the particle diameter. At low gas velocity, the mean particle velocities approached zero between $r / R=0.85$ and the wall. At the wall boundary an instantaneous reversal of flow was observed. A decrease in the wall boundary region with increase in gas velocity was attributed to an increase in the number of collisions between the particles at the wall region and particles in the core region. In their study the results do not show any reversal in sign of velocity near the wall region. 


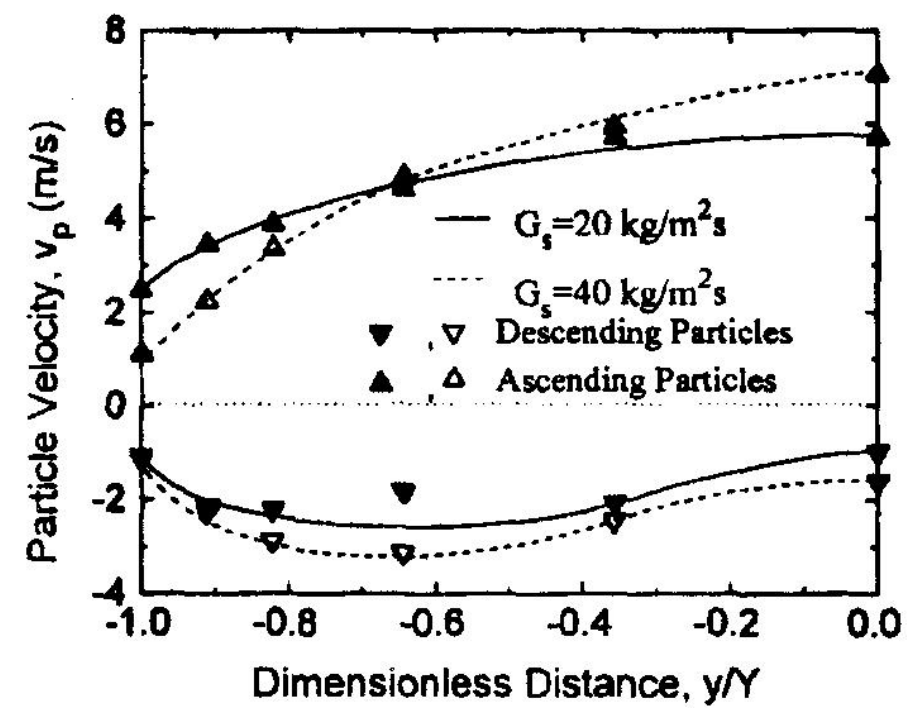

Figure 2.2 Velocity profile of local particle velocity for different solid fluxes: $\mathrm{Ug}=5.5 \mathrm{~m} / \mathrm{s}, \mathrm{z}=6.2 \mathrm{~m}, \mathrm{x} / \mathrm{X}=\mathbf{0}$, Zhou et al., [1995]

$1500 \mathrm{~g}$ Shale Fines Circulating

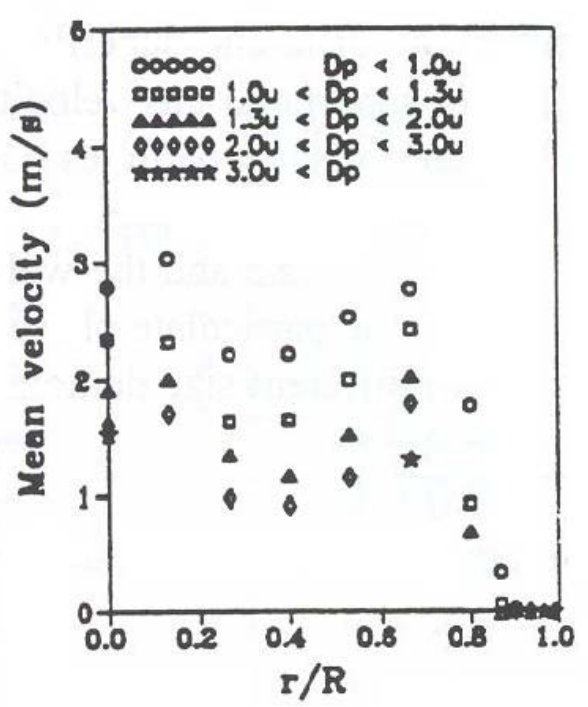

$1500 \mathrm{~g}$ Shale Fines Circulating

$$
\mathrm{Uo}=4.50 \mathrm{~m} / \mathrm{s}
$$

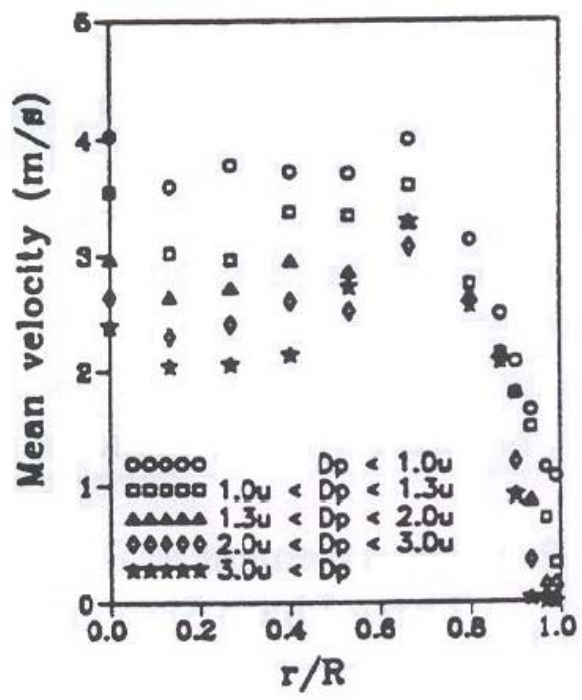

Figure 2.3 Radial mean velocity profiles Arastoopour et al., [1996] 
Van den Moortel et al. [1998] used a one dimensional PDPA and measured the hydrodynamic characteristics of the solid phase (size, axial and transversal velocities) at various heights in the riser. Their study showed a segregation phenomenon and typical velocity profiles for the gas-solid flow in a CFB. They used a CFB with a square crosssection in order to ensure a good quality optical signal for their LDV. Their instrument used a transmitter and a receiver as two separate probes and therefore optical alignment was difficult (this problem is eliminated in the BILS to be used in the current work). Their experiments were carried-out in the dilute zone of the gas-particle flow, where the solid volume fraction does not exceed $1.5 \%$. The riser used was $2 \mathrm{~m}$ high with a $0.2 \mathrm{X} 0.2$ $\mathrm{m}^{2}$ square cross section. The mean size of glass particles (particle density $=2500 \mathrm{~kg} / \mathrm{m}^{3}$ ) used was $120 \mu \mathrm{m}$. A typical velocity profile from their work is shown in Figure 2.4, where $V_{\text {pax }}$ is the particle axial velocity in $\mathrm{m} / \mathrm{s}$ and $N$ is the number of particles validated during the acquisition period. They measured characteristics like size, axial and transversal velocities for the solid phase at different heights in the CFB riser. Their results confirmed core-annulus flow structure in the riser.

Wang et al., [1998] used a TSI built LDV system on a riser of $140 \mathrm{~mm}$ diameter. They compared hydrodynamic differences between conventional FCC catalyst and fine catalyst of $36 \mu \mathrm{m}$. The average solids fraction they used was below 1.3\%. A comparison of solids velocity profiles obtained for two different particle sizes is shown in Figure 2.5. 


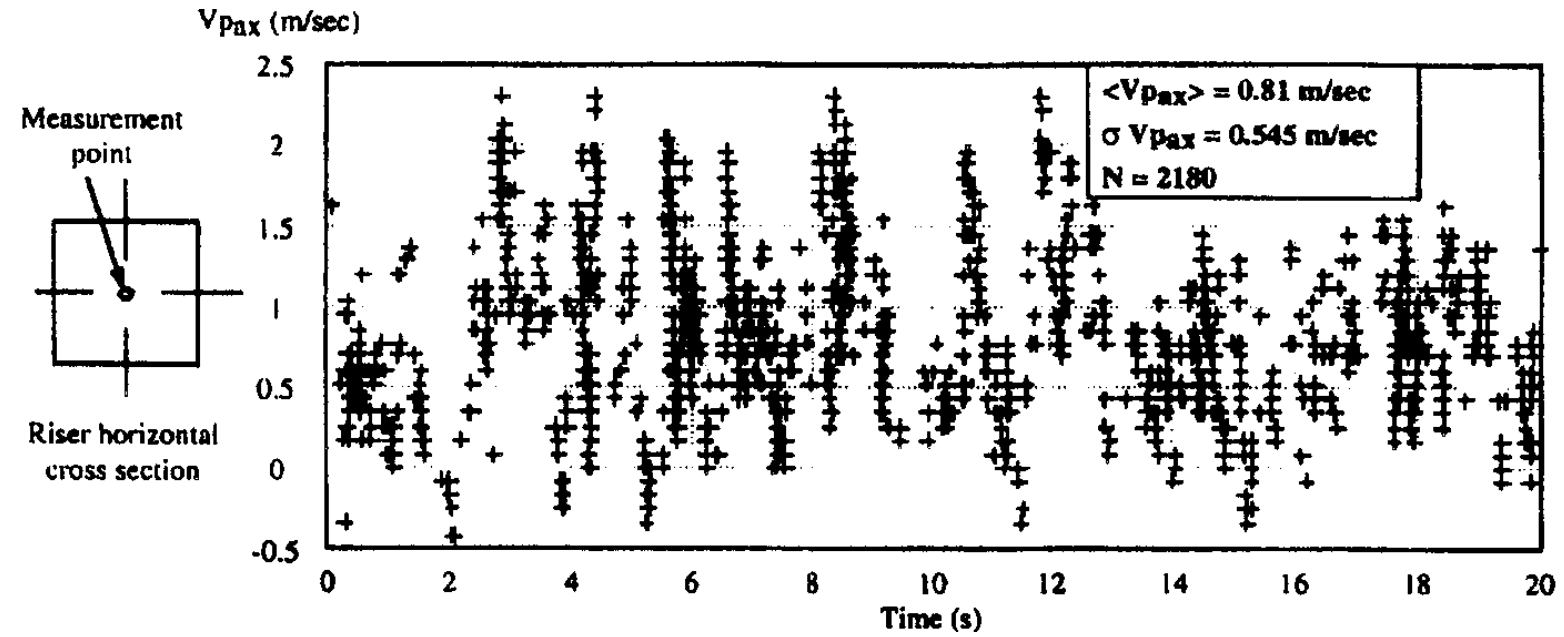

Figure 2.4 Particle axial velocity at center of the pipe and $Z / H=0.5, U_{g}=$ 1m/s, Van den Moortel et al., [1998]

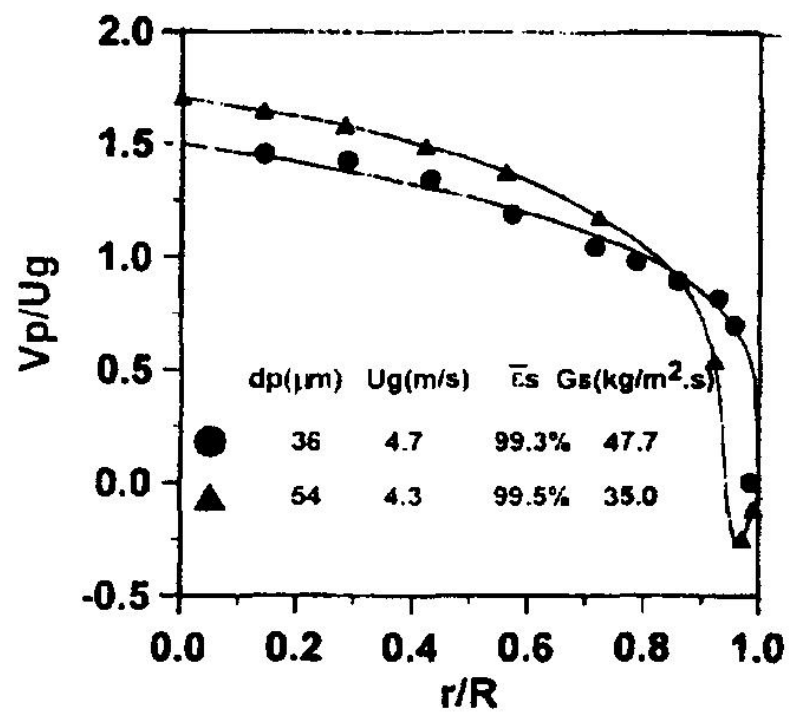

Figure 2.5 Comparison of solids velocity profiles of different particles,

Wang et al., [1998] 
Wei et al, [1998] used a modified TSI LDV system to develop velocity profiles in a riser section $8 \mathrm{~m}$ in height and $186 \mathrm{~mm}$ in diameter. Although the modified LDV lost its 'non-intrusive' nature, it was able to measure higher solids fraction (up to 0.21), which would not be possible otherwise. They carried all experiments at ambient temperature and pressure with air and FCC catalyst $\left(d_{p}=54 \mu \mathrm{m}, \rho_{p}=1398 \mathrm{~kg} / \mathrm{m}^{3}\right)$. They also showed that the shape of the particle velocity profile changes little with changing average solids fraction. Their data fits the Boltzmann function given by:

$$
\frac{(1-\varepsilon)}{(1-\bar{\varepsilon})}=2.2-\frac{2}{1+\exp (10 * r / R-7.665)} \quad \text { for } 0.68<\varepsilon<0.95
$$

where $\varepsilon$ is the local solids fraction and $\bar{\varepsilon}$ is the cross sectional average of voidage.

An example of the velocity profiles developed is shown in Figure 2.6 where $V_{p}$ is the particle velocity in $\mathrm{m} / \mathrm{s}$.
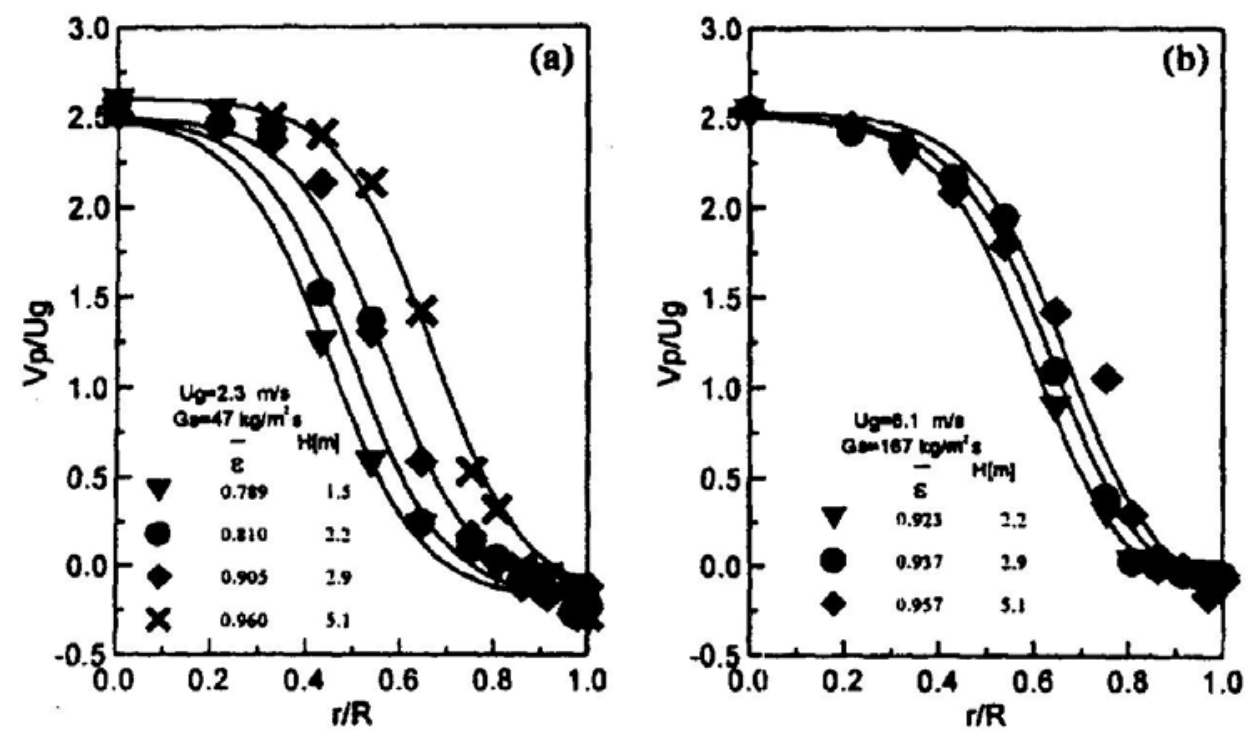

Figure 2.6 Radial profiles of particle velocity along axial position, Wei et
al., $[1998]$ 
Zhu et al., [2001] developed a five-fiber optical probe to measure solids velocity. Care was taken to minimize the intrusive nature of the probe by giving it an aerodynamic shape. The riser used was $10 \mathrm{~m}$ tall and $76 \mathrm{~mm}$ diameter. They measured the radial and axial particle velocity profiles over a wide range of high-flux operating conditions up to $550 \mathrm{~kg} / \mathrm{m}^{2} \mathrm{~s}$. Figure 2.7 shows a comparison of the velocity profiles between low and high flux operating conditions, obtained in their study. Their results show that particle velocity near the wall mostly flow upwards in a high flux riser, contrary to most reported results from low flux risers. They attribute it to the solids concentration and flux both being high in the high-flux riser, thereby impeding the tendency of particles to flow downwards in the wall region. They also conclude that the flow development becomes faster on increasing $U_{g}$ or on decreasing solid circulation rate, but little influence is observed for circulation rates greater than $300 \mathrm{~kg} / \mathrm{m}^{2} \mathrm{~s}$. The bed material used was FCC catalyst.

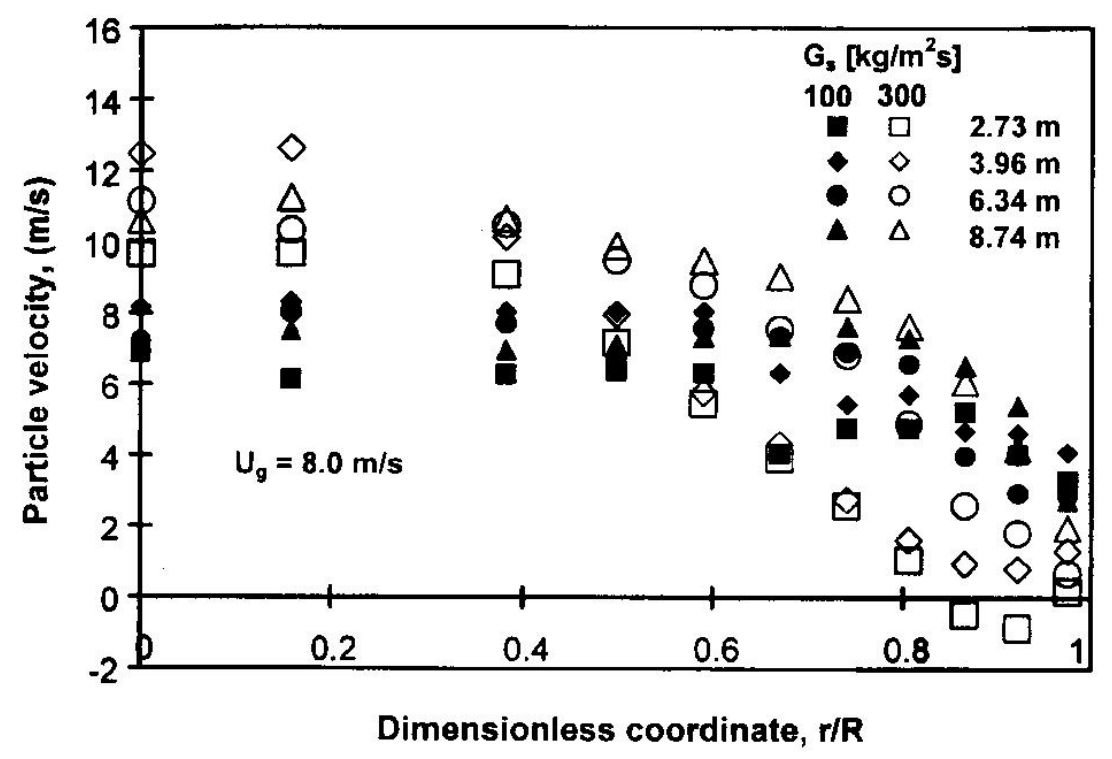

Figure 2.7 A comparison of the particle velocity profiles between low and high flux at constant $U_{g}=8 \mathrm{~m} / \mathrm{s}$, Zhu et al., [2001] 


\subsection{Studies on particle motion near the wall of a circulating fluidized}

bed

The flow in a circulating fluidized bed is generally characterized by a rapidly rising, relatively dilute suspension in the core that is surrounded by a slow-falling, denser suspension towards the wall. It is important to have information on the mechanism of heat transfer from the suspension to the wall, if combustion temperatures are to be maintained as boiler load varies, Rhodes et al., [1992].

Gidaspow et al., [1989] used a high-speed camera to study cluster velocity. Glass beads of $520 \mu \mathrm{m}$ diameter were used in a $7.6 \mathrm{~cm}$ diameter plexiglass tube at a gas

velocity of $5 \mathrm{~m} / \mathrm{s}$ and solid flux of $25 \mathrm{~kg} / \mathrm{m}^{2}$-s. They reported the typical wall clusters to descend at a velocity of $1.1 \mathrm{~m} / \mathrm{s}$ with a cluster size of about 2 to $3 \mathrm{~cm}$. They also observed that the clusters disappear at velocities greater than $5.5 \mathrm{~m} / \mathrm{s}$ except at the wall.

Rhodes et al., [1992] studied the motion of alumina particles of mean size $75 \mu \mathrm{m}$ near the wall of a $305 \mathrm{~mm}$ diameter riser using a high-speed video camera. They concluded that the predominant direction of particle flow near the wall is downward. They termed the particles actually in contact with the wall as 'swarms' with typical velocities in the range of $0.3-0.4 \mathrm{~m} / \mathrm{s}$. They also suggested that, a few $\mathrm{mm}$ away from the wall, there is a steady bulk downflow of particles, which they termed as 'particle strands'. These were found to be descending at a velocity of $\sim 1 \mathrm{~m} / \mathrm{s}$ for suspension densities greater than $5.6 \mathrm{~kg} / \mathrm{m}^{3}$. Figure 2.8 shows an image of a 'swarm' and a 'strand'. 

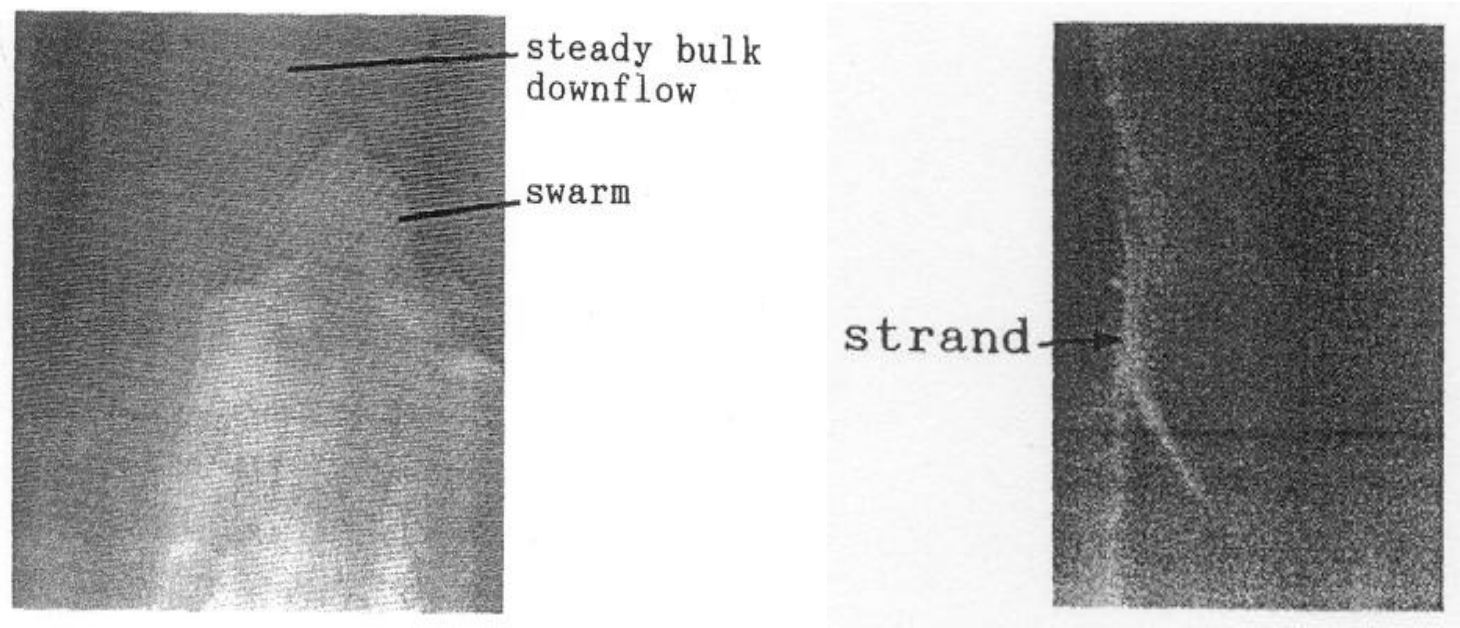

\section{Figure 2.8 A picture of particle swarms and vertical strands near the riser wall, Rhodes et al., [1992]}

Soong et al., [1995] used a dual-sensor capacitance probe to obtain solid concentration measurements in a riser of $7.6 \mathrm{~cm}$ diameter operating with $60 \mu \mathrm{m} \mathrm{FCC}$ particles. These were used to obtain a criterion to identify 'clusters'. They concluded that smaller clusters move upwards in the riser core and larger clusters move downwards at the wall. Figure 2.9 shows typical mean cluster velocities and lengths obtained.

Lim et al., [1996] established a theoretical model to predict the descending velocity of clusters near the walls of a CFB. The results from the model matched well with their experimental measurements obtained by video photography. While they reported a wide scatter, the descending velocity varies with cluster size and lies between 0.5 to $1.7 \mathrm{~m} / \mathrm{s}$. Within their operation range they did not observe any variation of the velocity with operating parameters like superficial gas velocity and solids circulation rate. They reported that the descending particle velocity is higher for sand clusters in 
comparison to FCC particles. Figure 2.10 shows how the model compares to the experimental results, where $E_{r}$ is the aspect ratio.
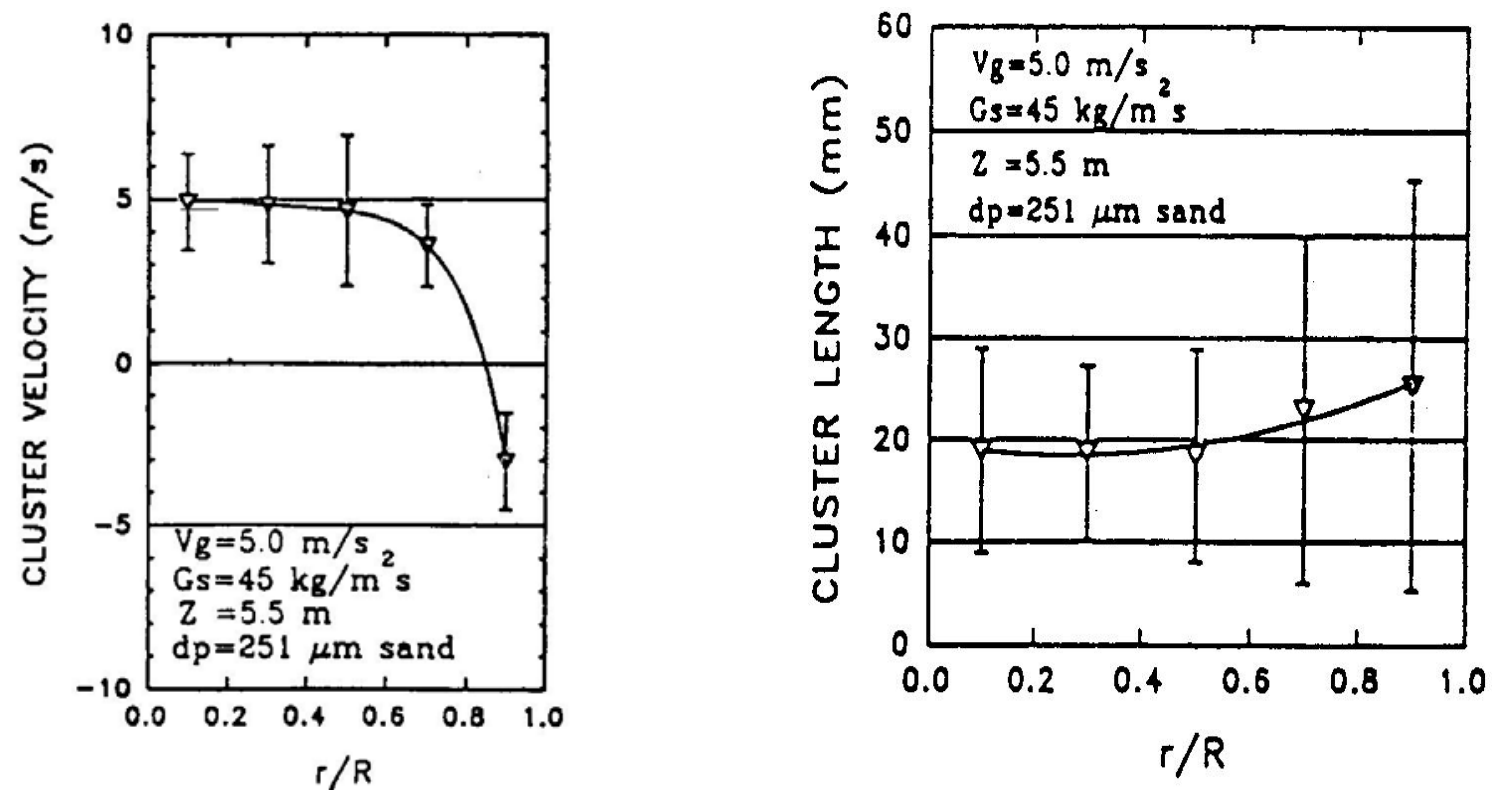

Figure 2.9 Typical cluster velocities and lengths, Soong et al., [1995]

Noymer and Glicksman, [1998] studied the descent velocities of particle clusters at the wall of a CFB. The technique used is called 'thermal image velocimetry' or TIV. It involves heating the cluster of particles at the wall and then using the radiant emission to track their movement. The riser used had a diameter, $D=0.159 \mathrm{~m}$ (square cross-section). The measured cluster velocities were reported to be between 0.9 to $1.2 \mathrm{~m} / \mathrm{s}$. They indicated that the velocities seem independent of the operating conditions (solids and gas flow rates) but also mentioned that whatever variation they observed falls within the range of their experimental uncertainty. They developed a correlation using various assumptions and obtained a fairly simple model that shows good agreement with the past work done on clusters by various researchers. The correlation developed was: 


$$
\frac{u_{c l}}{u_{m f}}=\frac{1000}{\sqrt{A r}}
$$

where $u_{c l}$ is the cluster velocity, $u_{m f}$ is the minimum fluidization velocity and $\mathrm{Ar}$ is the Archimedes number of the gas-solid system.

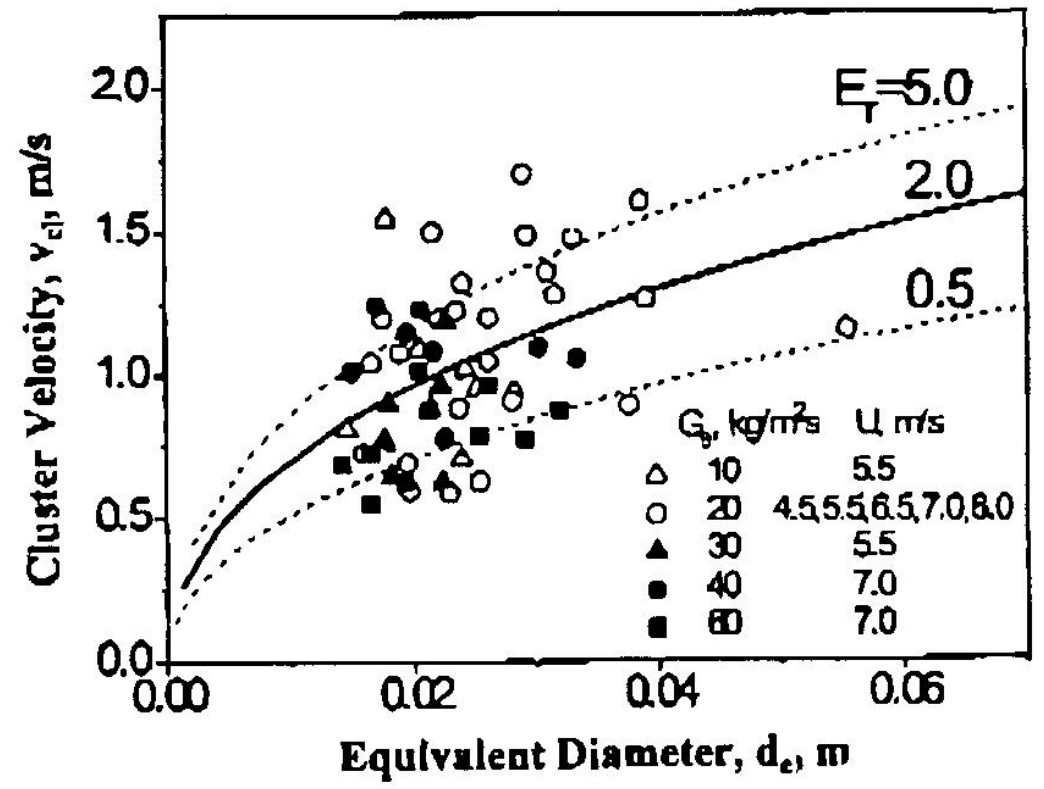

Figure 2.10 Comparison of predicted and experimental cluster velocity,

\section{Lim et al., [1996]}

Sharma et al., [2000] studied the effects of particle size and gas velocity on the cluster characteristics. They used capacitance-probe measurements of local solids concentrations in a $15 \mathrm{~cm}$ diameter fast-fluidized bed. They came up with a criterion to identify a cluster based on the particle concentration. They concluded that the solids volume fraction in clusters was not dependent on particle size but decreased with increasing gas velocity. The duration time of a cluster was found to be in the range of 20- 
$50 \mathrm{~ms}$ for the range of conditions tested. The frequency of cluster occurrence was reported to be from 6 to 11 per second.

Van den Moortel and Tadrist, [2002] used a PDPA, which they had previously used to develop solids velocity profiles in a riser (described in Section 2.2), to study the hydrodynamics of particle clusters. Figure 2.11 shows mean particle cluster lengths obtained in this study, where $L_{a x}$ is the axial length of the cluster. They concluded that the particle cluster sizes are strongly related to the local characteristics of the velocity field.

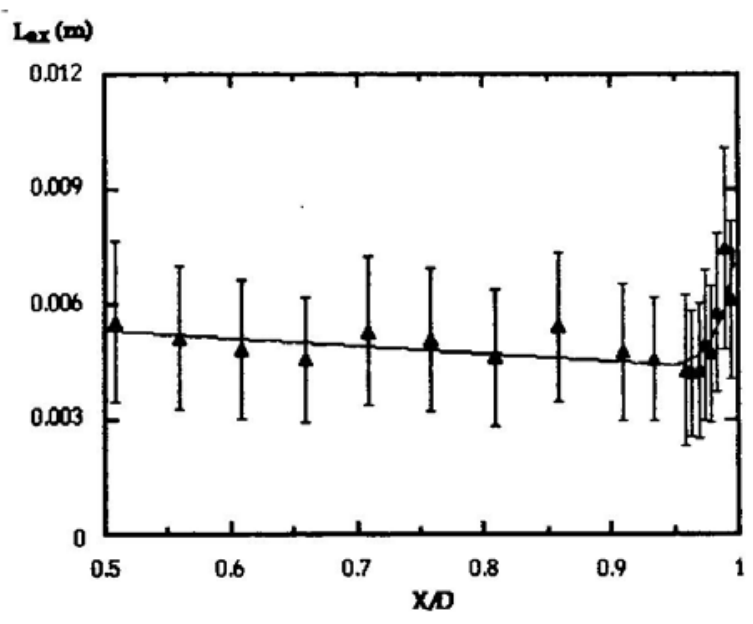

Figure 2.11 Particle cluster length as a function of radial position $x$, Van den Moortel and Tadrist, [2002]

Griffith and Louge, [1998] provided an extensive summary of the studies done on cluster velocities over the past several years and this is shown in Table 2.1. They suggest a very simple correlation relating the cluster velocity $\left(u_{c l}\right)$ and particle diameter $\left(d_{p}\right)$ :

$$
u_{c l} \approx 36 \sqrt{g d p}
$$

Figure 2.12 indicates that this trend is relatively robust considering the vast range of operating conditions, riser geometries and measurement techniques that different 
researchers had. They also stated that most observers have found that cluster velocity very near the wall is relatively insensitive to the solid flux and superficial gas velocity.

It is clear from the literature survey that considerable amount of work has been done in trying to measure velocity profiles in the riser section of a circulating fluidized bed using various techniques. There is still a lot of interest in trying to measure velocities in a non-intrusive way. This study is an effort to evaluate a BILS system and to apply this system to understand the particle behavior near the wall region of a cold flow circulating fluidized bed system. 


\begin{tabular}{|c|c|c|c|c|c|c|c|c|c|}
\hline Authors & $\begin{array}{l}\text { Measurement } \\
\text { technique }\end{array}$ & $\begin{array}{c}U_{\mathrm{cl}} \\
(\mathrm{m} / \mathrm{s})\end{array}$ & $\begin{array}{c}U_{0} \\
(\mathrm{~m} / \mathrm{s})\end{array}$ & $2 / H$ & $\begin{array}{c}G \\
\left(\mathrm{~kg} / \mathrm{m}^{2} \mathrm{~s}\right)\end{array}$ & $\begin{array}{c}T \\
\left({ }^{\circ} \mathrm{C}\right)\end{array}$ & $\begin{array}{c}D \\
(\mathrm{~cm})\end{array}$ & $\underset{\left(\mathrm{kg} / \mathrm{m}^{3}\right)}{\rho_{3}}$ & $\underset{(\mu \mathrm{m})}{d}$ \\
\hline \multicolumn{9}{|l|}{ Glicksman and } & \\
\hline Noymer (1996) & Thermal imaging & $1.1 \pm 0.1$ & $2.3-3.6$ & 0.21 & $8-28$ & 20 & $16^{*}$ & 6980 & 69 \\
\hline $\begin{array}{l}\text { Bader et al. (1988) } \\
\text { Golriz and Leckner }\end{array}$ & Pitot tube & $1.0 \pm 0.2$ & 3.7 & 0.75 & 98 & 20 & 31 & 1714 & 76 \\
\hline (1992) & Thermocouples & $1.8 \pm 0.4$ & $3.6-6.7$ & 0.81 & $\sim 10$ & 850 & $170^{*}$ & 2600 & 260 \\
\hline Horio et al. (1988) & Optical fibers & $0.8 \pm 0.1$ & 1.2 & 0.58 & 11.7 & 20 & 5 & 1000 & 60 \\
\hline Nowak et al. (1991) & Optical fibers & $0.8 \pm 0.2$ & 4.0 & 0.28 & 55.7 & 20 & 21 & 2300 & 46 \\
\hline Hartge et al. (1988) & Optical fibers & $1.2 \pm 0.2$ & 2.9 & 0.56 & 49 & 20 & 40 & 1500 & 85 \\
\hline Wu et al. (1991) & Heat transfer probe & $1.6 \pm 0.5$ & 7.0 & 0.43 & $15-47$ & 20 & 15 & 2650 & 171 \\
\hline Wu et al. (1991) & Video & $1.3 \pm 0.5$ & 7.0 & 0.43 & $15-47$ & 20 & 15 & 2650 & 171 \\
\hline Wirth et al. (1991) & Video & $1.3 \pm 0.2$ & $1.2-1.9$ & 0.73 & - & 20 & $17^{*}$ & 3950 & 50 \\
\hline \multicolumn{10}{|l|}{ Rhodes et al. (1992) } \\
\hline $\begin{array}{l}\text { wall strands } \\
\text { bulk downflow }\end{array}$ & High-speed video & $\begin{array}{c}0.3 \text { to } 0.4 \\
\sim 1\end{array}$ & $3-5$ & 0.53 & $2-80$ & 20 & 31 & 2456 & 75 \\
\hline
\end{tabular}

* Square cross-section.

Table 2.1 Cluster velocities at the wall obtained by various researcher,

Griffith and Louge, [1998]

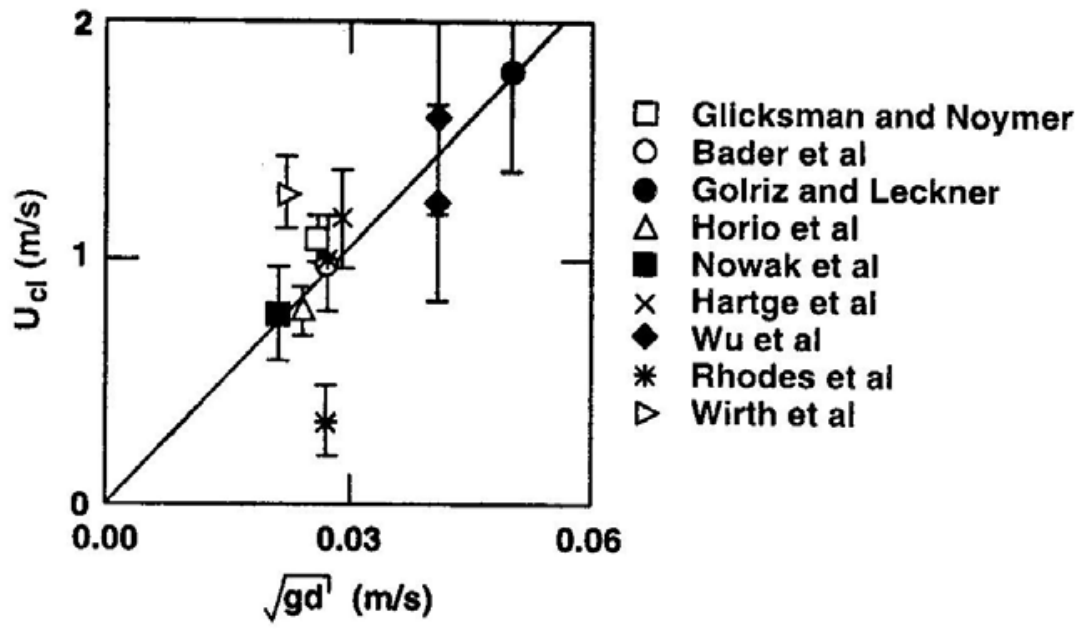

Figure 2.12 Comparison of data from various researchers with the correlation suggested, Griffith and Louge, [1998] 


\section{Components and Operating Principles of BILS}

\subsection{Main Component of the Instrument}

BILS consists of two main components: the LDV system and the imaging system. The LDV used here is different from a conventional LDV in the sense that it has both the probes (transmitter and the receiver) combined into a single probe forming a transceiver.

An overview of the various optical and electronic hardware components in our system is illustrated in Figure 3.1. The first component is the argon ion laser that is the source of the beam. The laser used in this work is a Class IV argon ion laser. It is an aircooled, continuous laser and has a peak output power of $750 \mathrm{~mW}$. Proper safety precautions must be taken to deal with a Class IV laser and these are addressed in Section 4.5. The laser beam is directed to a 2-D fiber drive. The fiber drive manipulates the laser beam before directing the beams into single-mode fibers, TSI Inc. Manual [2000b]. The fiber drive thus provides beam splitting, frequency shifting, and color separation. The laser beam is split into four beams- two green and two blue beams. A Bragg cell is used to split the incoming beam into two beams of equal intensity. Two dispersion prisms that separate the beams into individual colors further manipulate these beams. These are then directed into the optical fibers for transmission. The $40 \mathrm{MHz}$ reference frequency, used to modulate the Bragg cell, is received from the signal processor. The beams directed through the fiber optic cables go to the main transceiver. The transceiver contains all the optics necessary to create the sampling volume for particle velocity measurements. 


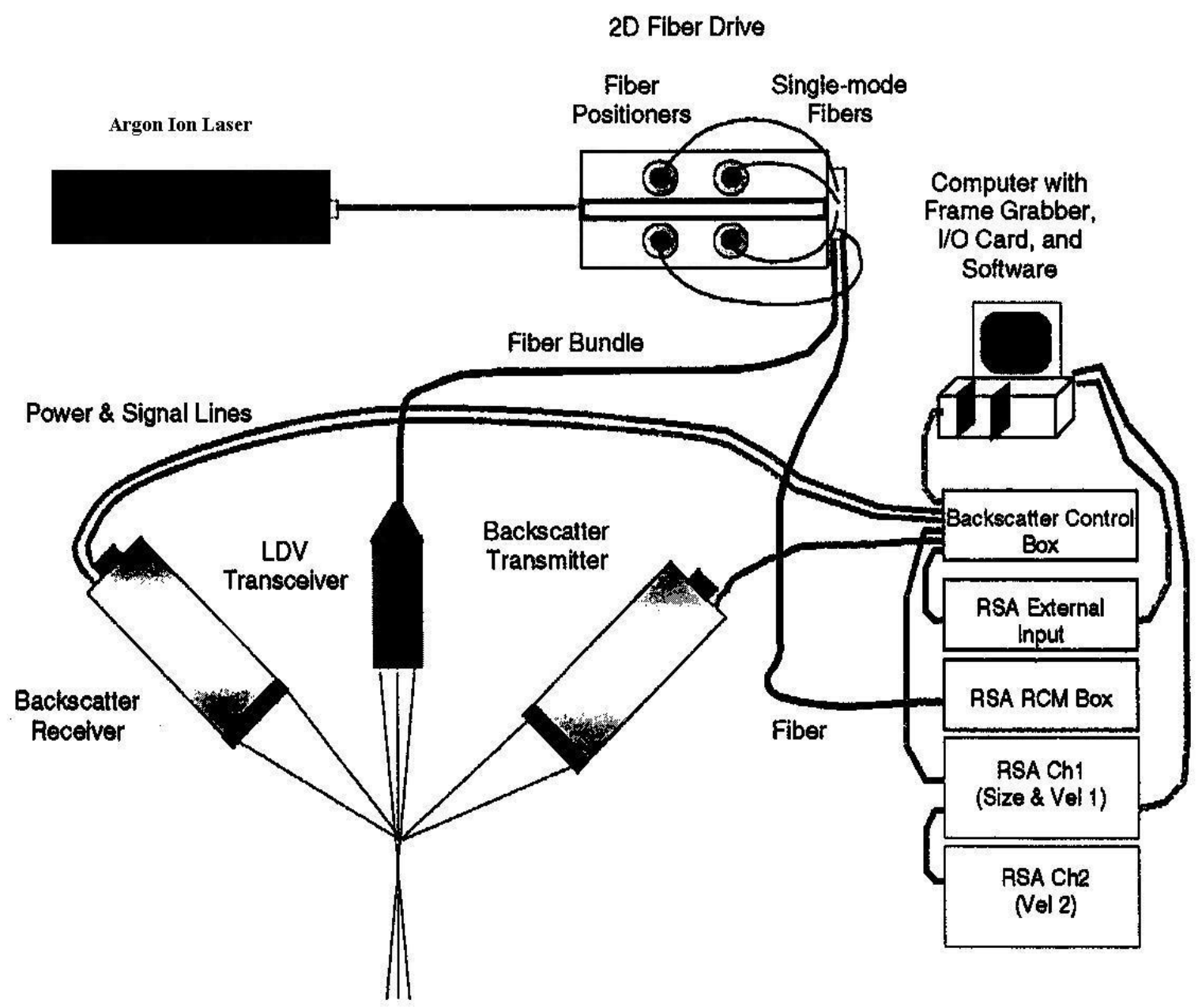

Figure 3.1 Backscatter Imaging LDV System (BILS), TSI Inc. Manual [2000b] 
The transceiver is linked to the rest of the system only by optical fibers, thus providing a convenient, compact, and robust LDV probe for a wide range of applications (Figure 3.2). Because the probe is a transceiver, it has all the optics required to receive the backscattered signals and it uses a series of optical fibers and lenses to transmit laser light. The beam pairs intersect and create a measurement volume at the focal spot. The receiver fiber directs the light away from the probe head, back through the fiberoptic cable and to the receiver module (RCM) for separation and photodetection, TSI Inc. Manual [2000b].

The function of the RCM is to convert phase-Doppler light signals from the receiver optics into electronic signals. The RCM box contains the photomultiplier tubes (PMTs) and the optomechanical hardware for separating the receiver light (by wavelength) and steering it into the PMTs. High voltage setting for the PMT is software controlled and the signals from PMTs are processed in the real-time analyzers (RSAs). There are two RSAs for a two-dimensional velocity system. The BNC terminal labeled RAW is used to monitor the raw signal being sent from the receiver module to the RSA. The terminal labeled COMPUTER is used for connecting the RSA to the controlling computer. Both the RSAs are also interconnected with each other. The RSA is capable of taking precise measurements in test situations where the signal-to-noise ratio is beyond the capability of other processors. The RSA External Input accepts up to 16 channels of data that can be tagged to incoming velocity and/or size measurements. Operation of this external input box is controlled through the RSA software, DataVIEW. The input to the 'external input' is measured at the end of the Doppler Burst from any of the active RSAs. 


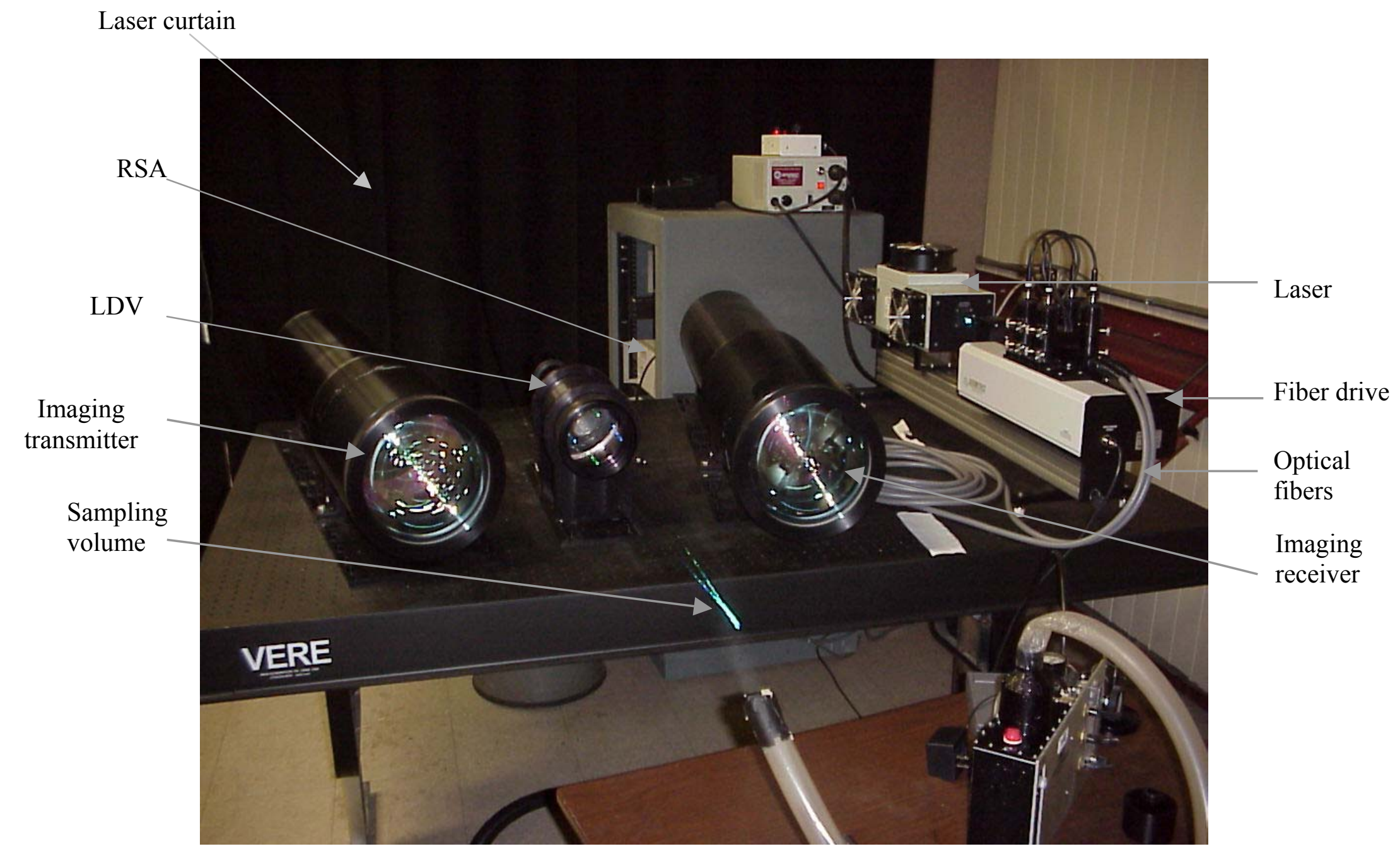

Figure 3.2 The BILS instrument set-up at NETL location, Morgantown 
If a velocity measurement comes from channel 2 and not from channel 1, the external input will measure the input. If both channels give a signal at the same time, the input is also recorded. DataVIEW compares the time for the different RSA channels. If they overlap then the measurements are assumed to be from the same particle and they are linked to the external input measurement at that time. If they don't match then the measurement on the display as well as the external input measurement is removed. The external input is connected directly to the RSA I/O card inside the computer.

The BILS imaging system consists of three main components: the backscatter imaging receiver, the backscatter imaging transmitter, and the backscatter imaging controller. The RSA processors and RSA external input are shared with the LDV component. The backscatter probe volume, a region well under 1 square $\mathrm{mm}$ in size must be aligned both with the backscatter transmitter and receiver as well as the LDV probe volume. Essentially all three probes are 'looking' at the same point in space, through which the measured particles must pass. The transmitter is mounted on the same base plate as the other probes. It contains a diode laser with a wavelength $905 \mathrm{~nm}$ and pulse width $15 \mathrm{~ns}$ and a maximum repetition rate of $5 \mathrm{kHz}$. The focal length of the front lens is $750 \mathrm{~mm}$, TSI Inc. Manual [2000a]. This diode laser illuminates the particle for imaging. 


\subsection{Basic Operating Principles of the Instrument}

\subsubsection{Operating Principles of the LDV component}

An interference pattern is setup in the plane where the two phase-shifted laser beams intersect. The interference pattern is an area of bright and dark fringes. As a particle passes through the bright fringes, it scatters pulses of light, as shown in Figure 3.3. The frequency of the pulses of scattered radiation is proportional to the speed of the particle in the fluid. The interference pattern can be imagined as a picket fence. The bright fringes correspond to the slats, while the dark fringes are the spacing between the slats. If one drags a stick across the slats, a certain frequency of sound is produced. The faster one drags the stick, the higher the frequency. If one imagines the particle in the fluid to be the stick, it is easy to visualize how a faster moving particle would produce a higher frequency signal while a slower moving particle would produce a lower frequency signal. When a particle passes through the fringes, the photomultipliers produce uniform Doppler bursts. These are proportional to the particle velocity component perpendicular to the plane of the fringes. These velocities are calculated using the following equation:

$$
V_{P}=\frac{\lambda_{0}}{2 \sin (\Gamma / 2)} F_{D}
$$

where $\lambda_{0}$ is the wavelength of the laser beam, $F_{D}$ is the Doppler frequency, $V_{P}$ is the particle velocity and $\Gamma$ is the beam-crossing angle. The beam-crossing angle for this instrument is about 8 degrees. The fringe spacing can be obtained from the expression:

$$
d=\frac{\lambda_{0}}{2 \sin (\Gamma / 2)}
$$

where $d$ is the fringe spacing. The blue laser has a wavelength of $488 \mathrm{~nm}$ and the green one has a wavelength of $514 \mathrm{~nm}$. The fringe spacing is of the order of $3.6 \mu \mathrm{m}$. 


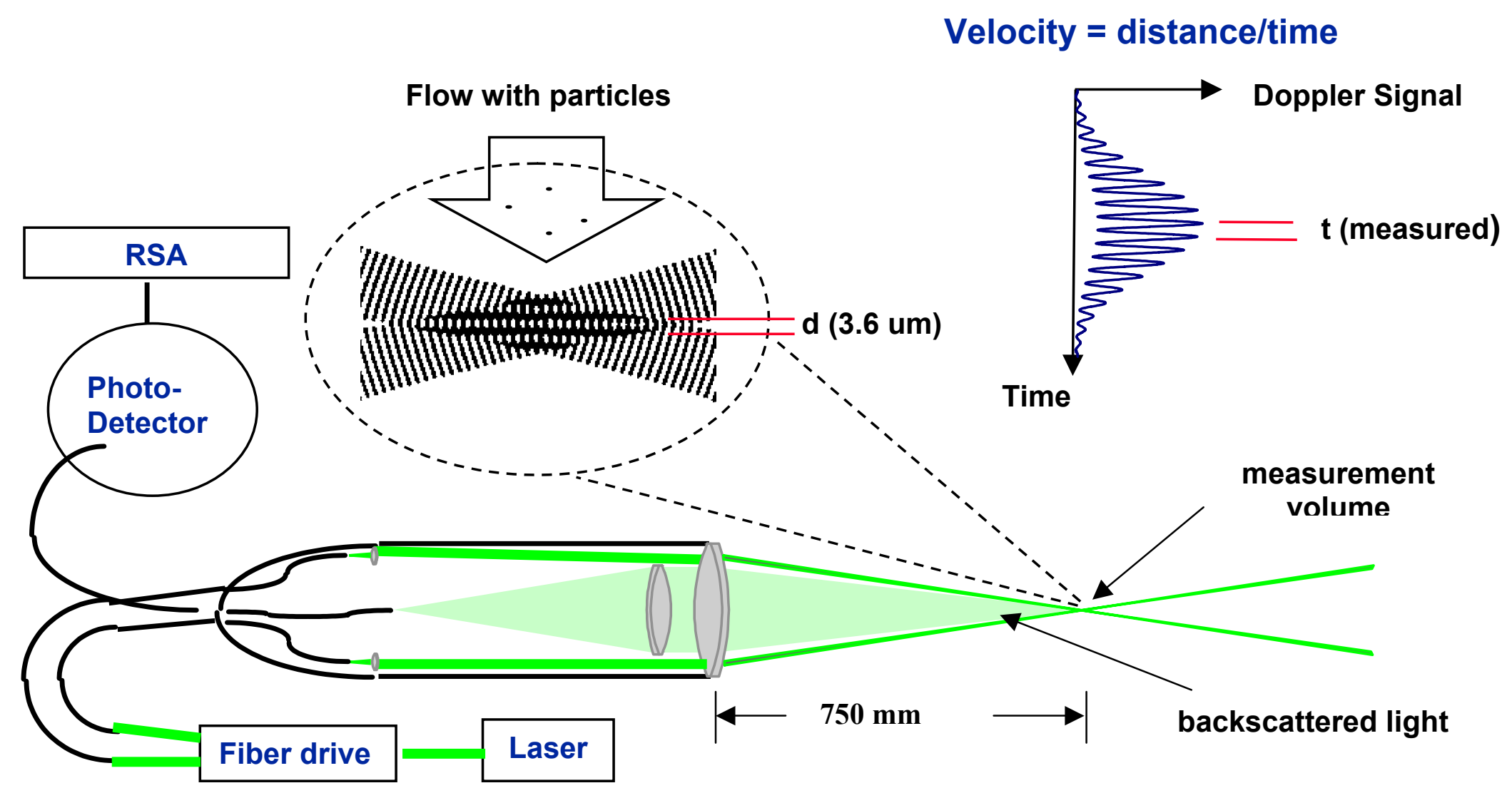

Figure 3.3 Basic operating principle of the LDV component of BILS, Dantec Inc. 


\subsubsection{Operating Principles of the Imaging component}

The measurement of particle size is based on the backscatter imaging technique. The diode laser from the transmitting probe illuminates the particle. The CCD camera that resides in the receiver probe images the particle onto a CCD camera using a $750 \mathrm{~mm}$ front lens as shown in Figure 3.4. A long pass filter is used to block the Ar-ion laser beam and other light sources. The maximum speed of the camera is 955 frames per second. The backscatter controller receives a trigger signal from the processor and then it activates the pixels to 'expose' mode. The controller fires the diode laser $50 \mathrm{~ns}$ later and $175 \mathrm{~ns}$ later the controller stops exposure and begins an image readout sequence by triggering the frame grabber to acquire the image data.

The backscatter imaging system has no 'stand-alone' operating mode, although the LDV system is able to take the data whether the backscatter controller is connected or not. The backscatter system operates in total synchronization with the RSA processors. The RSA acts as the 'master' to the backscatter controller and the controller doesn't trigger the laser diode unless the particle has been detected and validated by the RSA Fourier transform burst detector. The Backscatter software used is 'BackscaPP' and is supported by Windows NT application. It can analyze single as well as a series of images. These lenses provide approximately 1:1 imaging. An image of the particle is captured and sent to the computer via an interface board. Timing is controlled by the backscatter imaging controller. Generally, several thousands of images are grabbed in a single run and upon completion, both LDV and imaging data are saved on the hard drive. Statistical analysis of this data is done by post-processing software. 


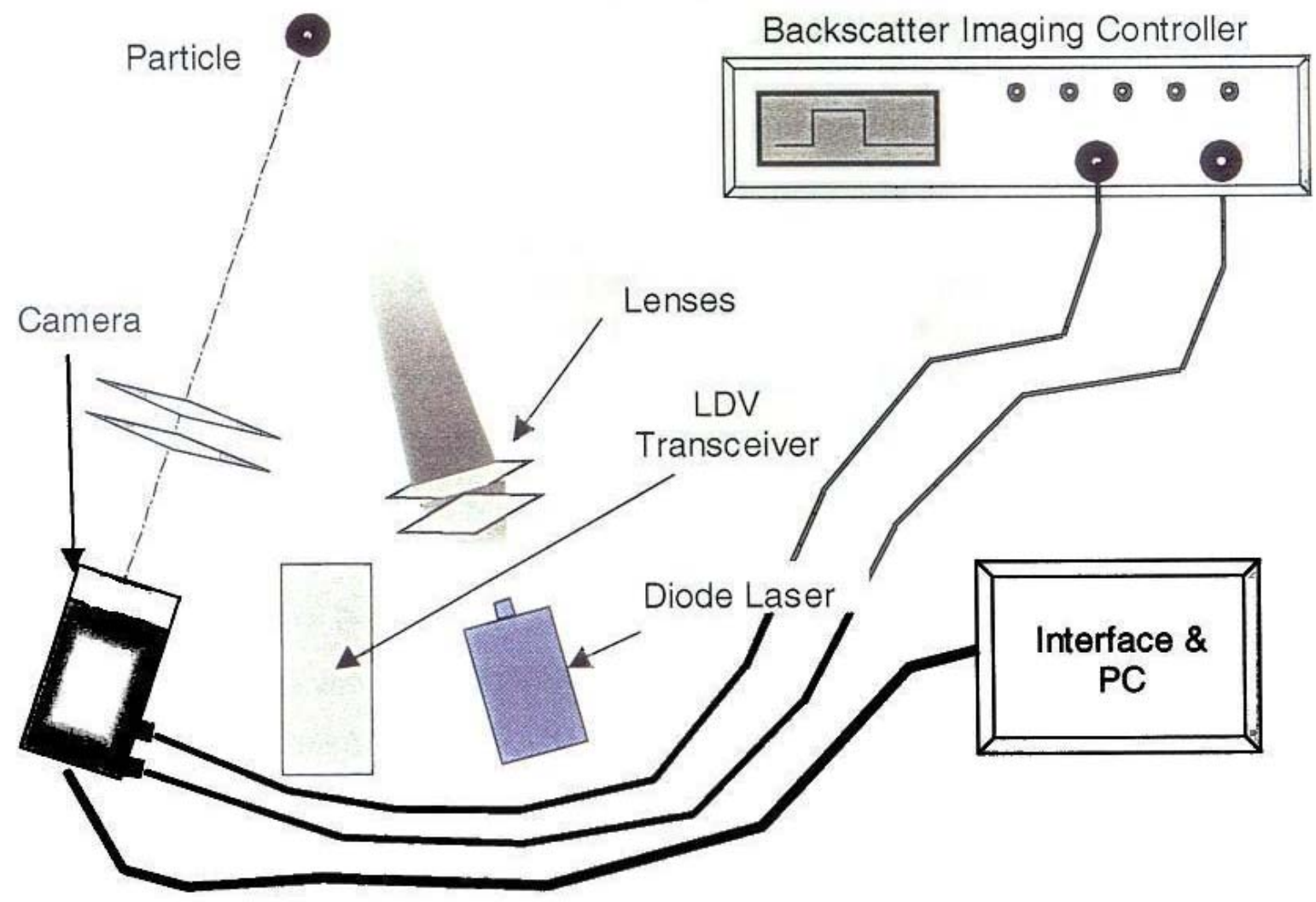

Figure 3.4 Layout of the Backscatter Imaging System, TSI Inc. Manual [2000b] 


\subsection{A summary of the Capabilities and Limitations of BILS}

BILS has the following features:

- Non-invasive and simultaneous measurement of two component velocity

- Imaging capability of nearly 1000 frames per second

- Measurement of particle circularity and aspect ratio

- Needs just one optical window access to the flow

- Provide frozen pictures and simultaneous velocity data, even if particles are moving at several hundred meters per second.

The limitations include:

- Doesn't work well on smooth surfaces as the glare spots spoil the information

- Particle size resolution and accuracy are limited by CCD pixel dimensions. Currently the lower size limit is $3 \mu \mathrm{m}$

- Particle shape information can be misleading since it is based on 2-D images, especially for particles having rod-like shape.

In summary, the BILS system can capture particle velocity and image data simultaneously. The high framing and capture rate will allow characterization of bursts or clusters of particles, which is important in the measurement of solids flux at the walls of CFBs. 


\section{Instrument Calibration and Validation}

\subsection{Velocity validation}

To validate the instrument's method of velocity measurement, the following setup was used. A stiff wire was attached to the rim of a rotating wheel whose rotation speed was known. The rate of rotation of the wheel was measured using a digistrobe. The velocity of the wire was calculated by knowing the radial distance of the wire from the center $(\mathrm{v}=\mathrm{r} \omega)$ and the rotation rate. The wire was attached perpendicular to the plane of the rotating wheel as shown in Figure 4.1. Each time the wire passed through the measurement volume, formed by the intersection of the lasers, the BILS measured and recorded a velocity datum point. This value was then compared to the theoretical value to validate the measurement method.

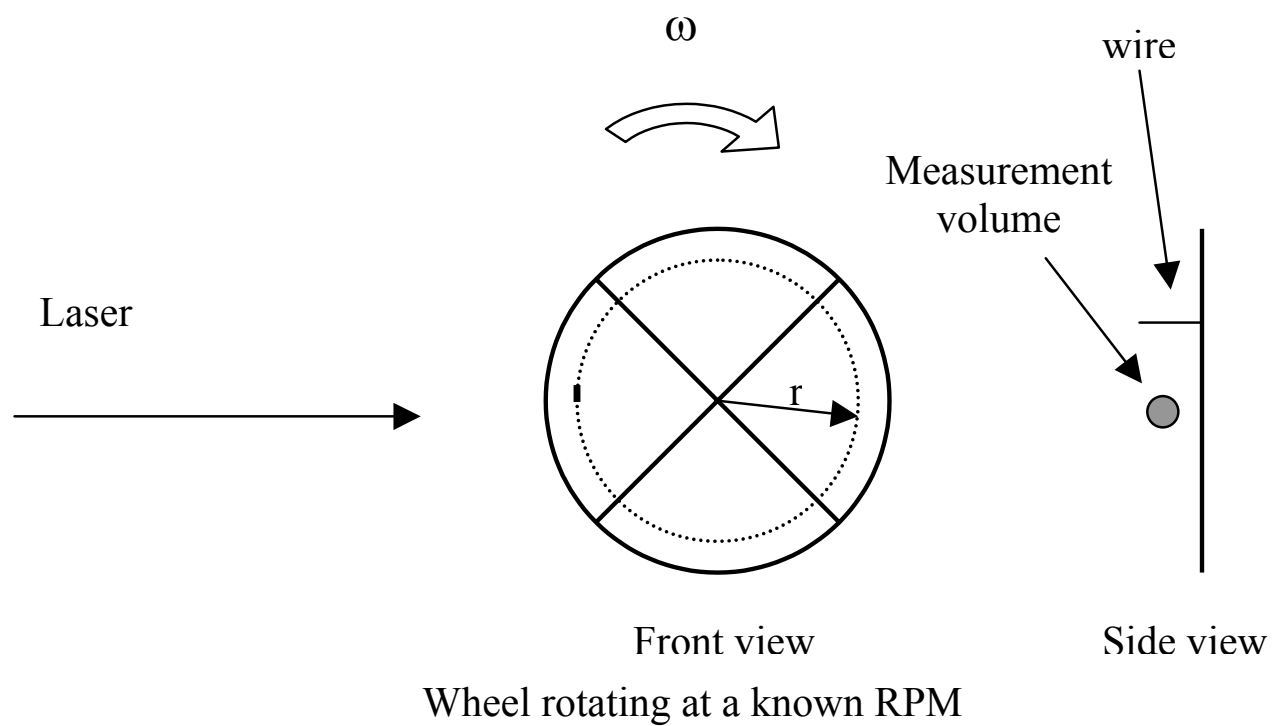

Figure 4.1 Set-up for instrument's data validation 
The first set of experiments was performed to study the effect of certain parameters on the velocity measured by the instrument. The parameters that were investigated were:

- The wire diameter - representative of the particle size

- Position of the wire in the measurement volume

- The rotation speed of the wheel

The experimental and the theoretical values were compared and a good match was observed, as shown in Figures 4.2 and 4.3. It was found that the position of the wire in the measurement volume did not have a significant effect on data obtained by the instrument, as shown in Figure 4.2. On comparison of the two data sets for different sizes of wire, it was observed that the wire diameter did not have any significant influence on the readings. This is illustrated in Figure 4.3. The runs were carried out in a random order to gauge the reproducibility of the instrument. The maximum difference between any two sets of values for the same rotation rate was $9 \%$ and in most cases was below $5 \%$. These tests validate the instrument's velocity measuring capacity and show that the measurements are reproducible. 


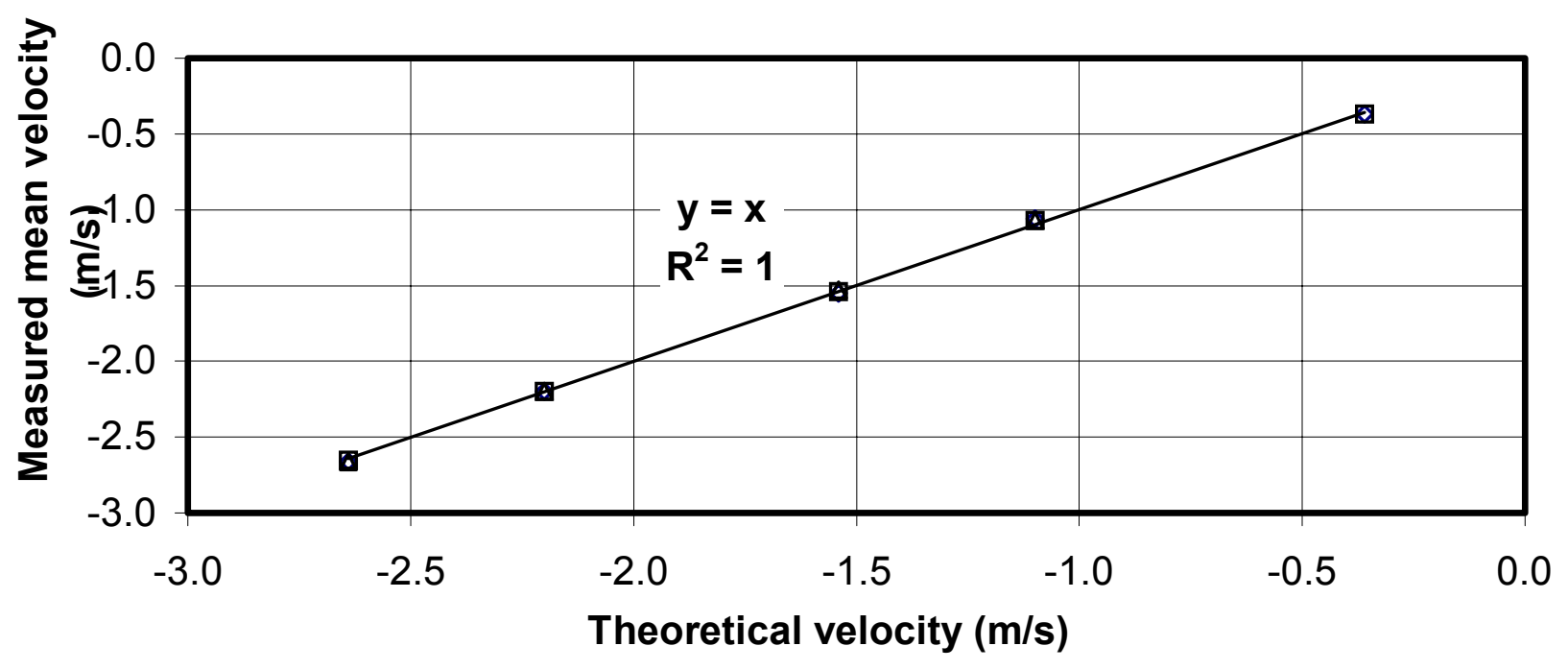
$\diamond$ Position 1
口 Position 2
$\Delta$ Position 3
- Linear (Theoretical values)

Figure 4.2 The effect of the position of wire in the measurement volume, for wire diameter $=0.5 \mathrm{~mm}$ 


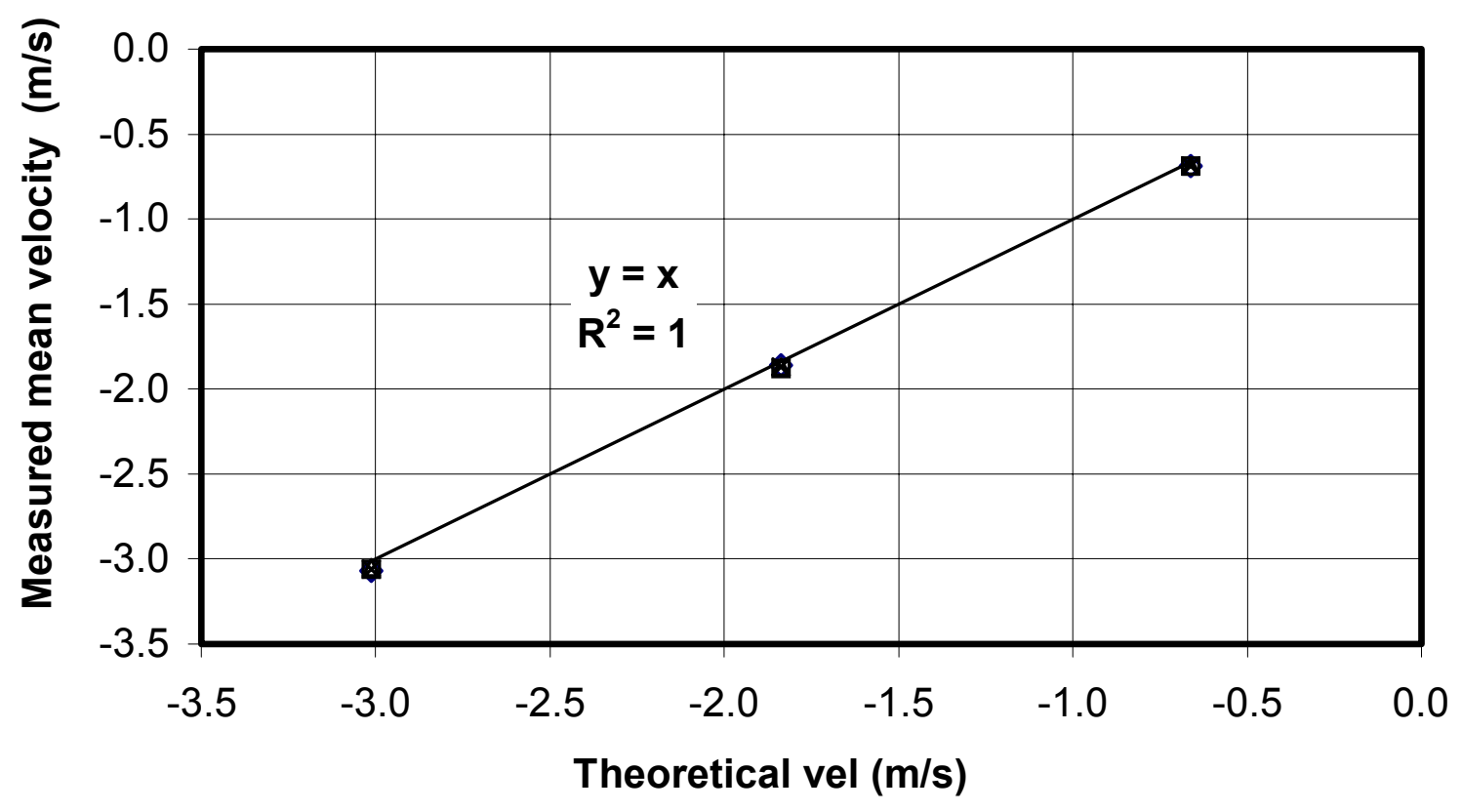
$\diamond$ Run 1, 1mm dia
- Run 2, $1 \mathrm{~mm}$ dia
$\Delta$ Run $1,0.5 \mathrm{~mm}$ dia
$\times$ Run 2, 0.5mm dia
_ Linear (Theoretical value)

Figure 4.3 Random runs with different wire diameters 


\subsection{Imaging calibration}

The imaging component is ready to use after aligning the imaging probe's measurement volume with the LDV measurement volume. The alignment has to be done with great accuracy to ensure that the camera takes simultaneous image of the particle whose velocity the LDV is recording. This was done using the previously described rotating disc to make sure that synchronized data were obtained for both the velocity and the imaging channels. The system was aligned and the camera focused when valid velocity data was obtained simultaneously with sharp images of the wire on the rotating disc. The calibration of the imaging component was required before accurate size information could be obtained. For this, the image of a known scale (1 division= $01 \mathrm{~mm})$, was used to provide the conversion factor from pixels to length in the BackscaPP imaging software. The image of the scale used is shown in Figure 4.4.

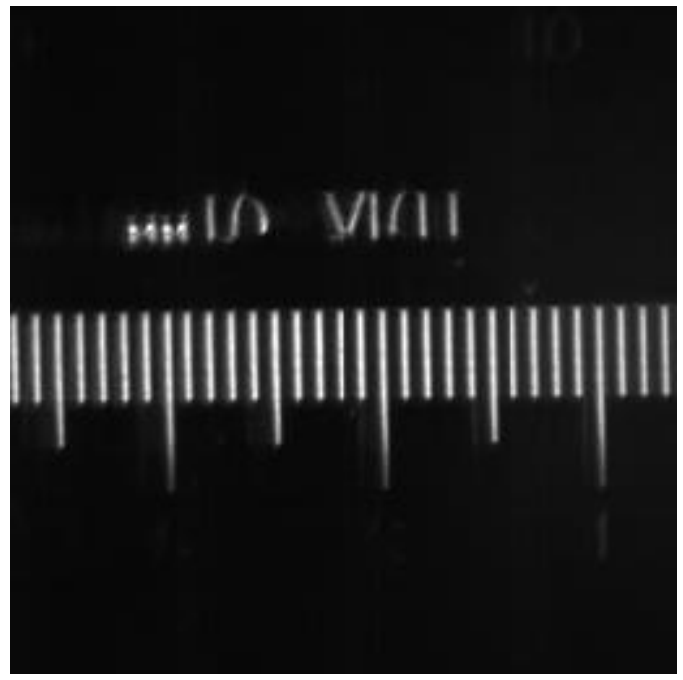

Figure 4.4 Target used for image calibration 


\subsection{Terminal velocity tests}

Further validation of the BILS system was made by measuring the terminal velocities and particle sizes and shapes of Nu-Pareil sugar spheres in air. The set up for these experiments is shown in Figure 4.5.

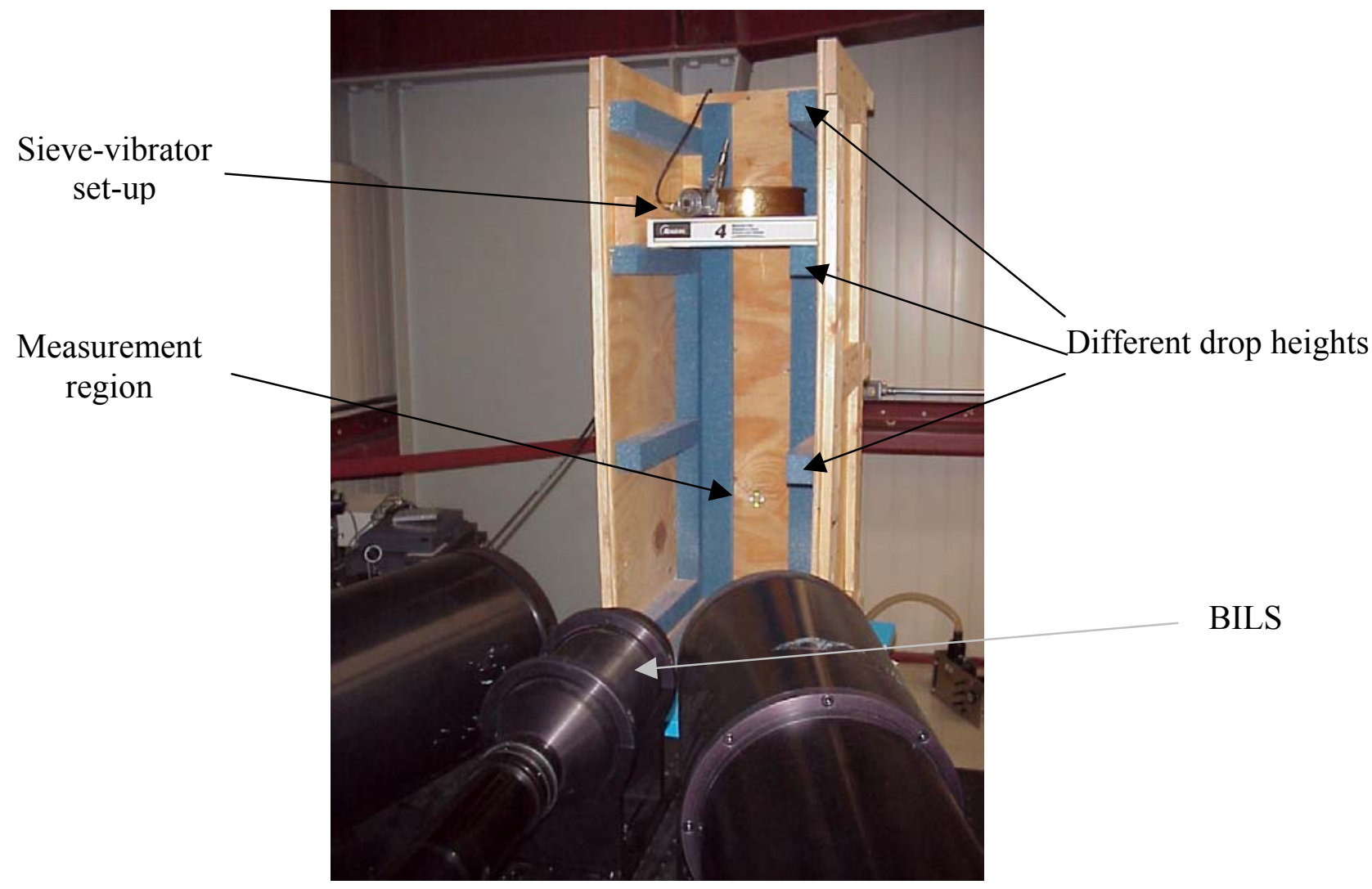

Figure 4.5 Set-up for terminal velocity measurements 
The Nu-pareil particles were metered using sieves with holes one size larger than the particles. A pneumatic vibrator was attached to the sieve to facilitate the flow of particles through the sieve as shown in Figure 4.6. The particles were dropped from different heights, as shown in Figure 4.5, until they reached their terminal velocity. The particles used for this study were Nu-Pareil sugar spheres with a particle density of $1.2 \mathrm{~g} / \mathrm{cc}$. The diameter of particles used ranged from 500 to 1200 microns. The reason for selecting this size range was that the size of the cork particles, used in the Circulating Fluidized Bed facility to be tested, was in this size range. In addition, the near-spherical shape of these particles allowed the comparison of the experimental results with predictions from the standard drag curve.

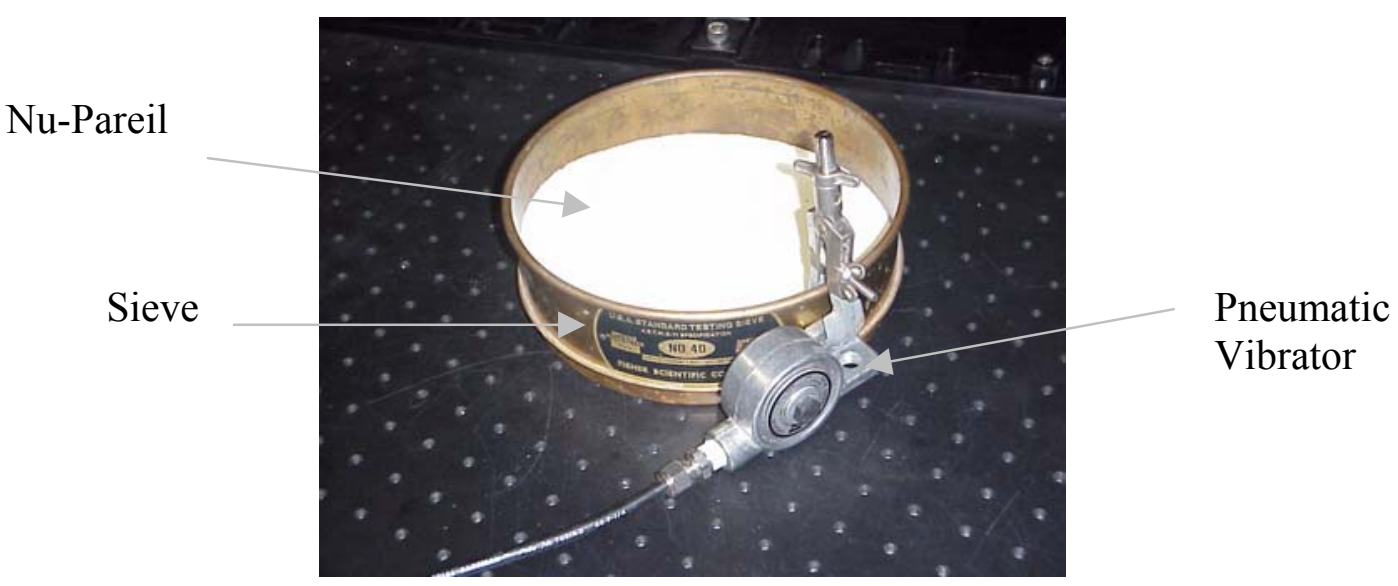

Figure 4.6 The sieve-vibrator arrangement 


\subsection{Safety Considerations}

The laser beam used in BILS is a class IV Ar ion laser with a peak power output of $750 \mathrm{~mW}$. Strict safety measures must be taken when operating a class IV laser because even the reflections of the beam from secondary surfaces can be harmful to the eyes. Direct exposure of the beam to the eyes can cause permanent blindness even when it is for a very short duration. A safety analysis was done at NETL, Morgantown, where the instrument was installed. The hazards associated with the operation were identified and proper mitigation steps were taken. The area where the instrument was set-up was enclosed, using appropriate safety curtains, to avoid any exposure to the beam reflections to those outside the work area. Safety goggles, appropriate for this class and type of laser, were required for the operator of the unit.

An interlocking device was also installed in such a way so that if the laser curtain is opened when the instrument is ' $\mathrm{ON}$ ', then the circuit breaks and a beam shutter in front of the laser beam is activated cutting the beam off. To get a beam from the probes and to record any readings, the laser curtains must be closed. The whole set-up for processing the data was placed outside this curtain-enclosed area. A warning light displaying three different modes of operation: 'SAFE', 'CAUTION' and 'DANGER' was placed outside the working area to indicate whether the laser is off, on standby or in use. 


\section{Results and Discussion}

A series of tests were conducted to measure the terminal velocities and the size of Nu-Pareil sugar spheres $\left(\rho_{s}=1.2 \mathrm{~g} / \mathrm{cc}\right)$ with the set-up described in Section 4.3. The effect of solids loading and particle size on the velocity of particles was studied. A typical velocity versus time graph generated during the runs is shown in Figure 5.1. Each point on the graph denotes a particle passing through the measurement volume. The images of the particles, as shown in Figure 5.2, were also stored. The BackscaPP software converts the particle image to a binary image, which is then used for the image analysis.

The LDV records real time velocity data if individual particles but the corresponding pictures of the particles grabbed by the camera are not always in focus. After completing a run, the data was analyzed and the out-of-focus images and images not entirely within the camera frame were discarded (shown in Figure 5.3). The remaining in-focus images and the corresponding velocity values were stored for further analysis.

The DATAVIEW software stored the velocity-time data. These data were then exported to the BackscaPP software that matched them with the corresponding images. The output file of the BackscaPP software contained information for each particle, as shown in Table 5.1. Thus simultaneous velocity and sizing information for each particle that passed through the measurement volume was obtained. 


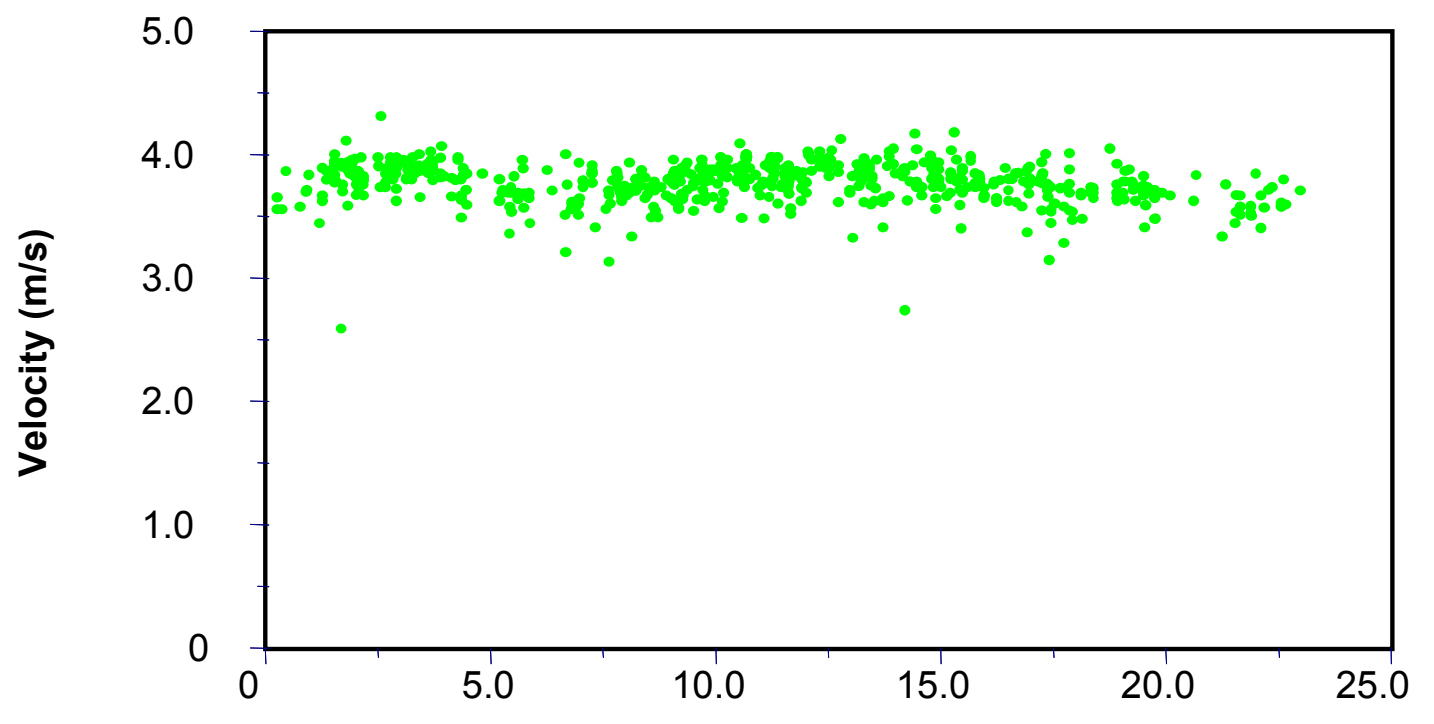

Time (s)

Figure 5.1 Typical velocity vs time data obtained from the DATAVIEW software 

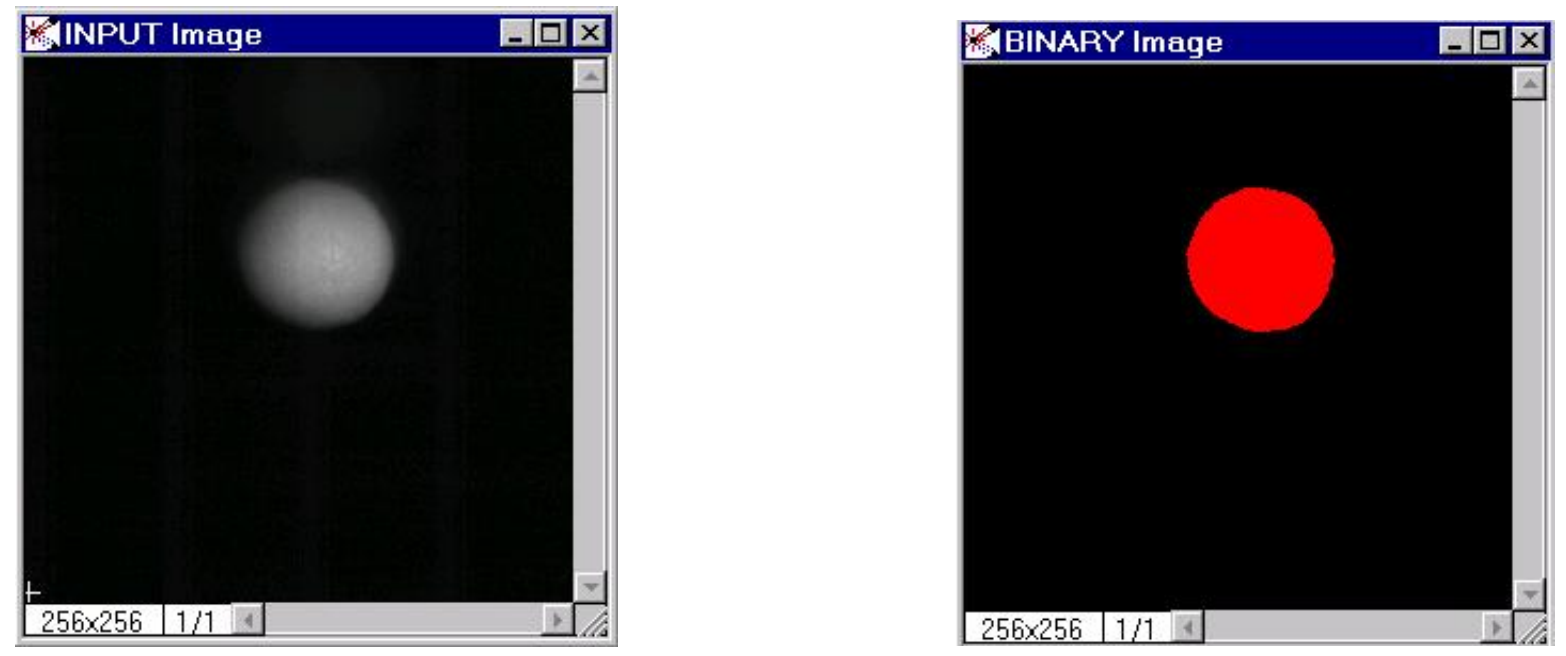

Figure 5.2 Image of a Nu-Pareil obtained from the camera and its corresponding binary image

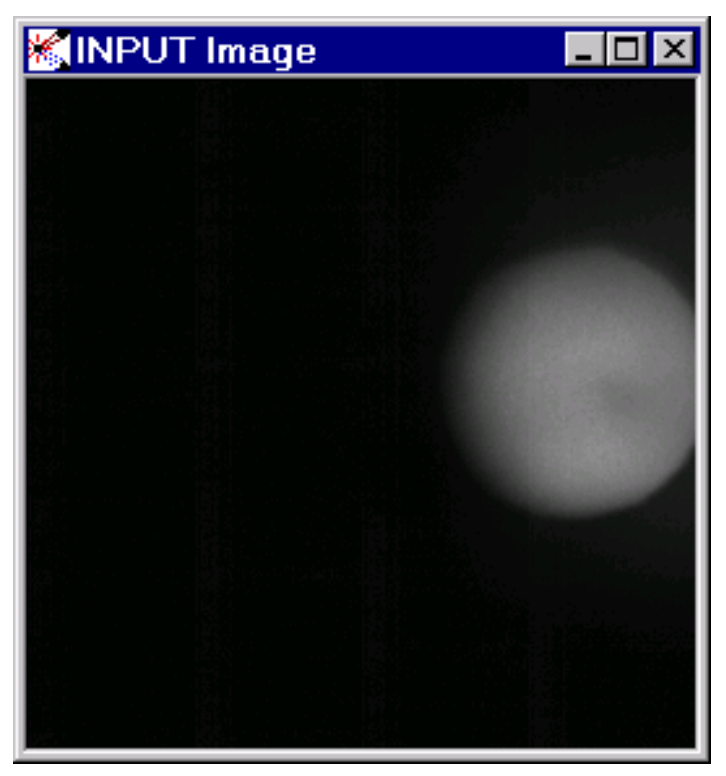

Figure 5.3 The image of a particle not completely within the field of view of camera 


\begin{tabular}{|c|c|}
\hline Area & Area of particle $\left(\mu \mathrm{m}^{2}\right)$ \\
\hline $\begin{array}{c}\text { Equivalent } \\
\text { Diameter }\end{array}$ & $\begin{array}{c}\text { Diameter of circle with the same area as that of } \\
\text { particle }(\mu \mathrm{m})\end{array}$ \\
\hline Circularity & $\begin{array}{c}\text { Ratio of measured perimeter to the perimeter of } \\
\text { equivalent circle }\end{array}$ \\
\hline Velocity Ch 1 & Vertical component of velocity $(\mathrm{m} / \mathrm{s})$ \\
\hline Velocity Ch 2 & Horizontal component of velocity $(\mathrm{m} / \mathrm{s})$ \\
\hline Width & Mean length of all horizontal chords $(\mu \mathrm{m})$ \\
\hline Height & Mean length of all vertical chords $(\mu \mathrm{m})$ \\
\hline Perimeter & Perimeter of particle $(\mu \mathrm{m})$ \\
\hline
\end{tabular}

Table 5.1 The main contents of the output file of the BackscaPP software 


\subsection{Effect of solids loading}

The first set of experiments was performed in order to study the variation in particle velocities as a function of the drop height and solids loading for different particle sizes, as shown in Figure 5.4. The solids loading was characterized qualitatively in terms of low and medium loading. The particle size cuts of Nu-Pareils used for this experiment were 500-600 $\mu \mathrm{m}$ and $600-700 \mu \mathrm{m}$. It was observed that the 500-600 $\mu \mathrm{m}$ size cut reached its terminal velocity for low loadings around a drop-height of $1 \mathrm{~m}$, as shown in Figure 5.4. The medium loadings had higher velocities than the low loadings. This was attributed to the fact that particles tend to agglomerate when the loading is increased and hence have an effective particle diameter greater than a single particle. Thus the height required to reach the terminal velocity was greater than that for a single particle. The particles tend to agglomerate to minimize the drag acting on them. It can be observed from the graph that a change in the solids loading caused a bigger shift in the curves in comparison to a change in the particle size.

Similar tests were conducted with four different solids loadings for two different particle sizes. The loadings were classified as low, medium, medium-high and high. The low loading case corresponds to essentially very dilute flow and no particle agglomeration. The use of the sieves to feed the particles helped to keep the particles separated. The high-loading case consisted of dumping a group of particles without using the sieve. The results for the 500-600 $\mu \mathrm{m}$ and 600-700 $\mu \mathrm{m}$ particle size cuts are shown in Figures 5.5 and 5.6. The figures clearly indicate that the mean velocity of particles increases with an increase in solids loading. The raw data is shown in Table A1.1 of Appendix I. 


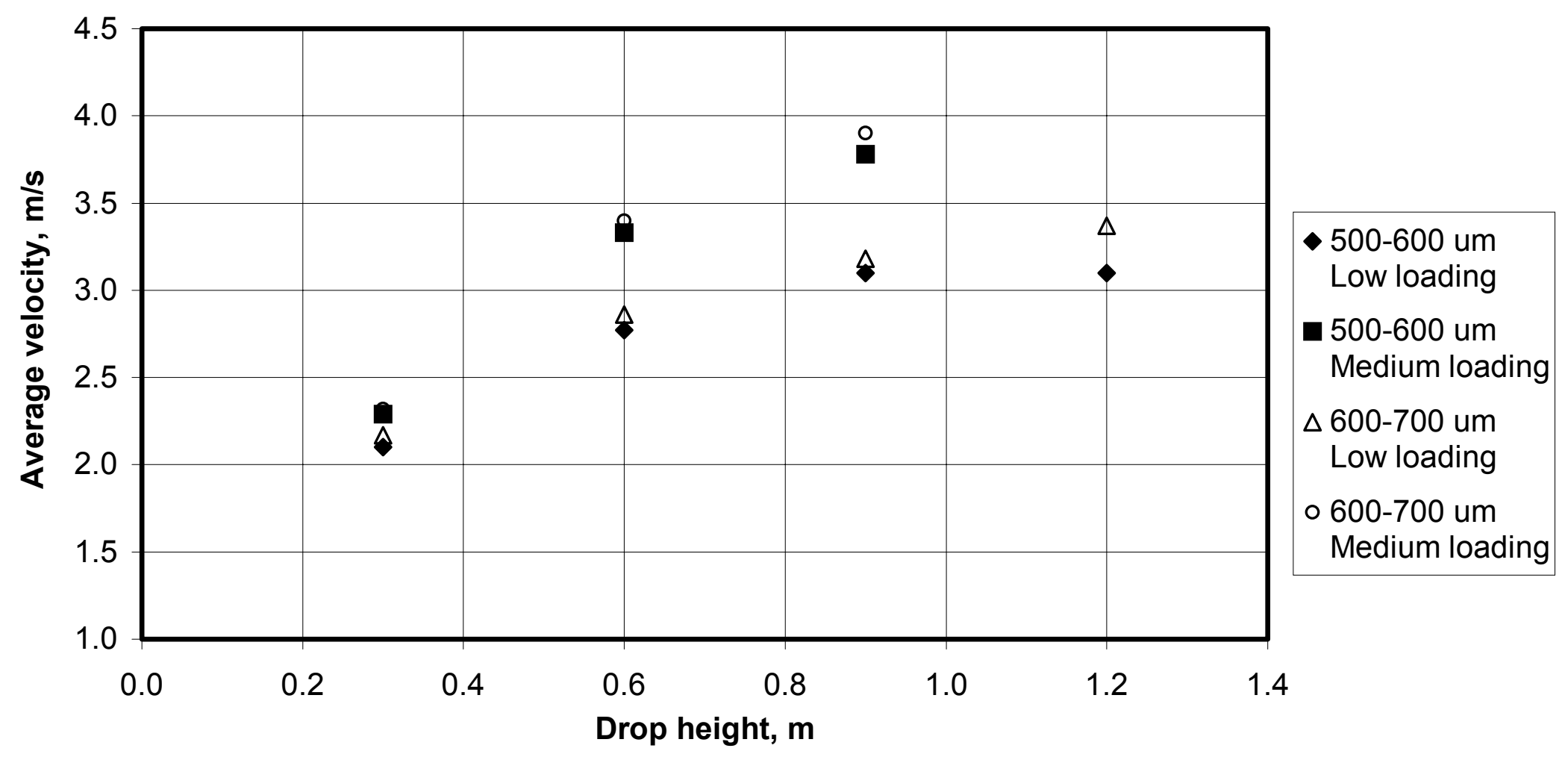

Figure 5.4 Variation of velocity with drop height and solids loading 


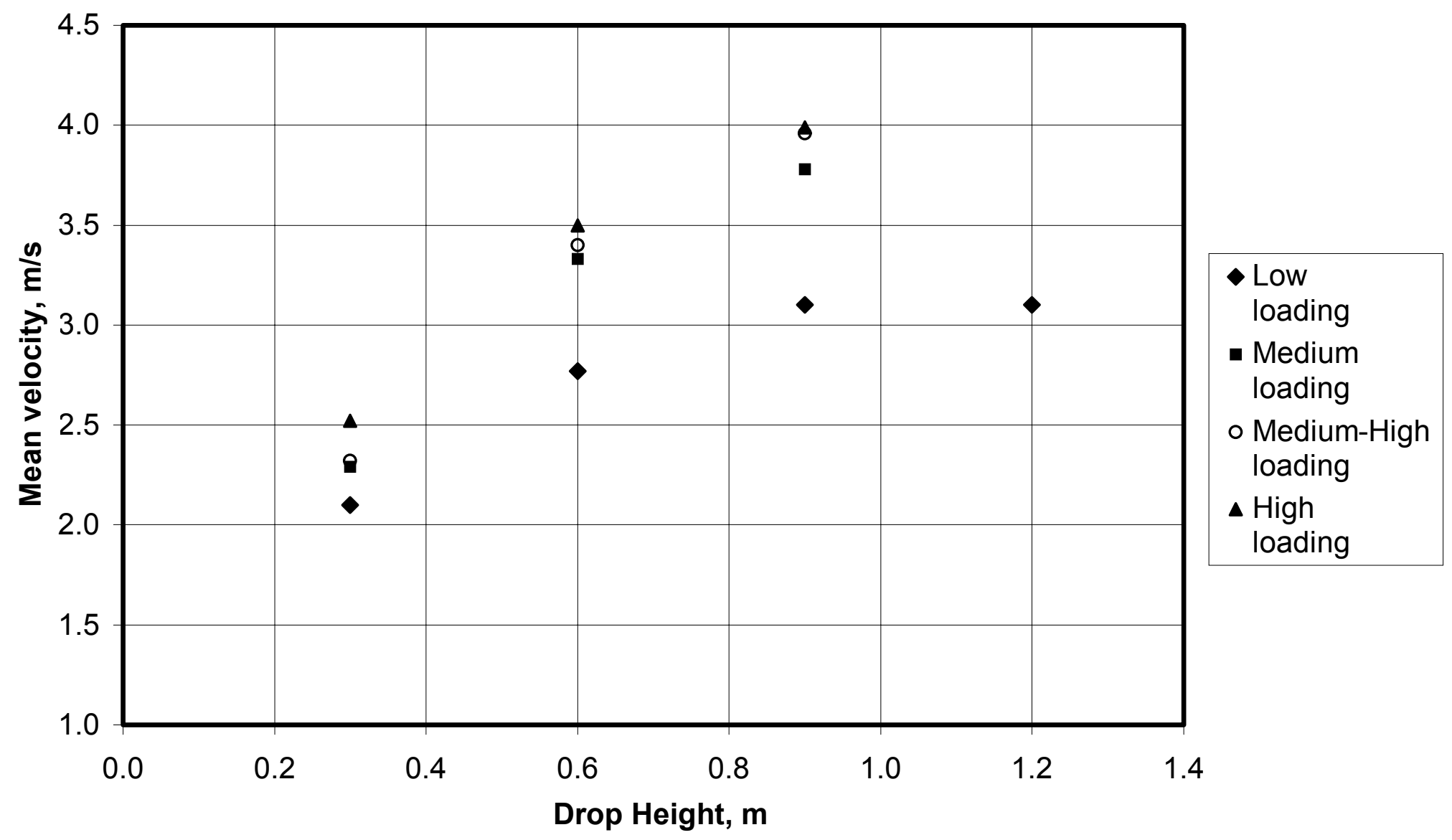

Figure 5.5 Velocity of 500-600 $\mu \mathrm{m}$ particles as a function of drop height and solids loading 


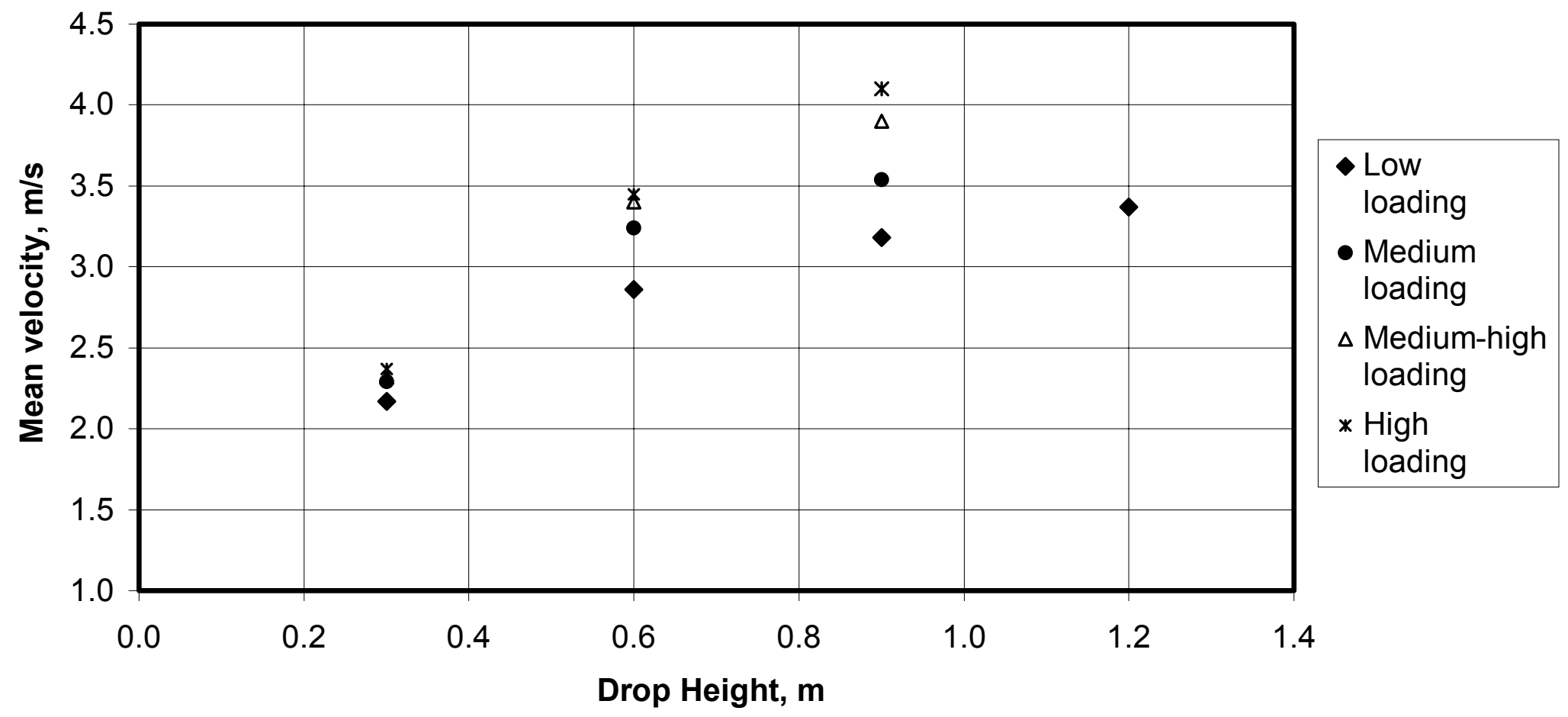

Figure 5.6 Velocity of 600-700 $\mu \mathrm{m}$ particles as a function of drop height and solids loading 


\subsection{Terminal velocity and particle size measurements}

A series of tests was conducted to measure the terminal velocities and particle sizes of the Nu-Pareils particles. These velocity values were then compared to those obtained from theory. The sizing information from the images was used to estimate the circularity of the particles. A statistical analysis of the data obtained is shown in Table 5.2. The runs were carried out at very low solids loading to minimize the effect of particle-particle interaction. This was verified from the images obtained. Two runs were conducted for each case. The bulk average stands for all the data points recorded by the LDV system whereas the mean velocity is the mean of only those particles that had images in focus. Thus, for the latter particles, both velocity and size information data were available. The values in the table indicate that the bulk and the mean velocity were very close to each other with a variability of less than $0.7 \%$. The standard deviations of the mean velocity are also tabulated. These are very low for the narrow size-cuts that have been used, thereby demonstrating the reproducibility of measurement by the instrument.

Figure 5.7 shows velocity versus particle diameter data for a particle size cut of $850-100 \mu \mathrm{m}$. Some variation was observed in the terminal velocity values obtained within a size cut, but for all cases the variation was less than $3 \%$. This can be attributed to the fact that even though care was taken to maintain a very dilute flow, there was still some particle to particle interaction. The diameter values, obtained from the image analysis, were in good agreement with the values obtained from sieve analysis of the particles. 


\begin{tabular}{|c|c|c|c|c|c|}
\hline $\begin{array}{c}\text { Particle } \\
\text { size }(\boldsymbol{\mu m})\end{array}$ & Run \# & $\begin{array}{c}\text { Bulk average } \\
\mathbf{( m / s )}\end{array}$ & $\begin{array}{c}\text { Mean } \\
\text { velocity } \\
\mathbf{( m / s})\end{array}$ & $\begin{array}{c}\text { Difference } \\
\mathbf{( \% )}\end{array}$ & $\begin{array}{c}\text { Standard } \\
\text { deviation } \\
\text { of } \mathbf{m e a n} \\
\text { velocity } \mathbf{( m / s )}\end{array}$ \\
\hline $1000-1200$ & 1 & 4.59 & 4.62 & 0.65 & 0.193 \\
\hline & 2 & 4.60 & 4.59 & 0.11 & 0.275 \\
\hline $850-1000$ & 1 & 4.45 & 4.47 & 0.45 & 0.305 \\
\hline & 2 & 4.47 & 4.45 & 0.45 & 0.284 \\
\hline $700-850$ & 1 & 3.80 & 3.81 & 0.26 & 0.270 \\
\hline & 2 & 3.77 & 3.78 & 0.27 & 0.237 \\
\hline $600-700$ & 1 & 3.35 & 3.37 & 0.60 & 0.264 \\
\hline & 2 & 3.33 & 3.33 & 0.00 & 0.201 \\
\hline $500-600$ & 1 & 3.06 & 3.08 & 0.65 & 0.315 \\
\hline & 2 & 3.09 & 3.08 & 0.32 & 0.315 \\
\hline
\end{tabular}

Table 5.2 Terminal velocity of Nu-Pareils for different particle size-cuts

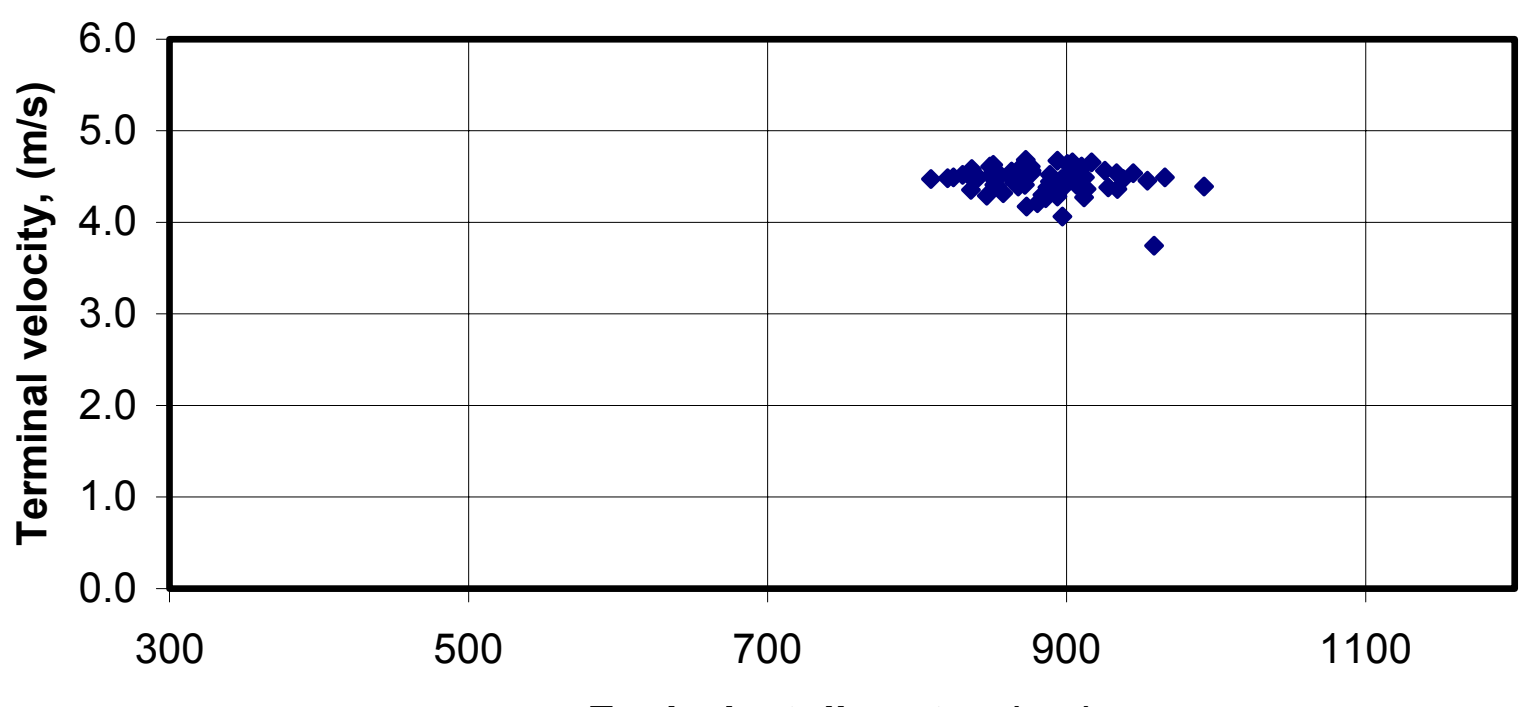

Equivalent diameter, (um)

Figure 5.7 Experimental terminal velocity versus particle size 
Haider and Levenspiel [1989] developed terminal velocity correlations for spherical and non-spherical particles. These were used to compute the theoretical terminal velocities of particles, which were then compared to those obtained from BILS. They defined two dimensionless numbers in their study: $u *$, the dimensionless terminal velocity and $d_{*}$, the dimensionless particle diameter. They developed a correlation for dimensionless terminal velocity as a function of dimensionless particle diameter and the sphericity of the particle (Ф), Equations (5.1) and (5.2).

$$
\begin{gathered}
u_{*}=\left[\frac{18}{d_{*}^{2}}+\frac{(2.3348-1.7439 \Phi)}{d_{*}^{0.5}}\right]^{-1} \quad \text { for } 0.5 \leq \Phi \leq 1 \\
d_{*}=d_{s p h}\left[\frac{g \rho_{f}\left(\rho_{s}-\rho_{f}\right)}{\mu^{2}}\right]^{1 / 3}
\end{gathered}
$$

where $d_{s p h}$ is the equivalent particle diameter, $\rho_{f}\left(=1.17 \mathrm{~kg} / \mathrm{m}^{3}\right)$ is the density of fluid (air in our case $), \rho_{s}\left(=1200 \mathrm{~kg} / \mathrm{m}^{3}\right)$ is the particle density, and $\mu_{f}\left(=1.85 \times 10^{-5} \mathrm{~kg} / \mathrm{m}-\mathrm{s}\right)$ is the air viscosity.

Equation (5.2) is used to estimate the dimensionless particle diameter, which is then used to estimate the theoretical dimensionless terminal velocity. The terminal velocity measured by BILS was converted to the experimental dimensionless terminal velocity using Equation (5.3).

$$
u_{*}=u_{t}\left[\frac{\rho_{f}^{2}}{g \mu\left(\rho_{s}-\rho_{f}\right)}\right]^{1 / 3}
$$


Figure 5.8 shows the experimental dimensionless terminal velocity $(u *)$ plotted against the experimental dimensionless diameter $\left(d_{*}\right)$. Each point on the graph denotes an individual measurement. The average values for velocity and diameter were calculated and plotted in Figure 5.9. Also shown are the error bars corresponding to two standard deviations about the mean value, which would cover a $95 \%$ confidence interval region. A repeat of the test is shown in Figure 5.10 and 5.11. The graph also suggests that there was little variation in the value of $u *$ within a size cut. This can be attributed to the fact that even though care was taken to make the flow very dilute, there was still some particle to particle interaction. An ideal case experiment (not very practical in this case) would be to drop individual particles one by one inside the measurement volume from a certain height. The experimental data for the current setup has been shown in Table A1.2 of Appendix.

The results obtained were in good agreement with the drag curve from Haider and Levenspiel [1989]. The theoretical curves shown on the graph are for sphericity value of 1 and 0.9 respectively. The data falls nearer to the curve with sphericity of 1 indicating that particles used have sphericity closer to 1 . The sphericity of the particles can be estimated using the imaging data and this is discussed in the next section. 


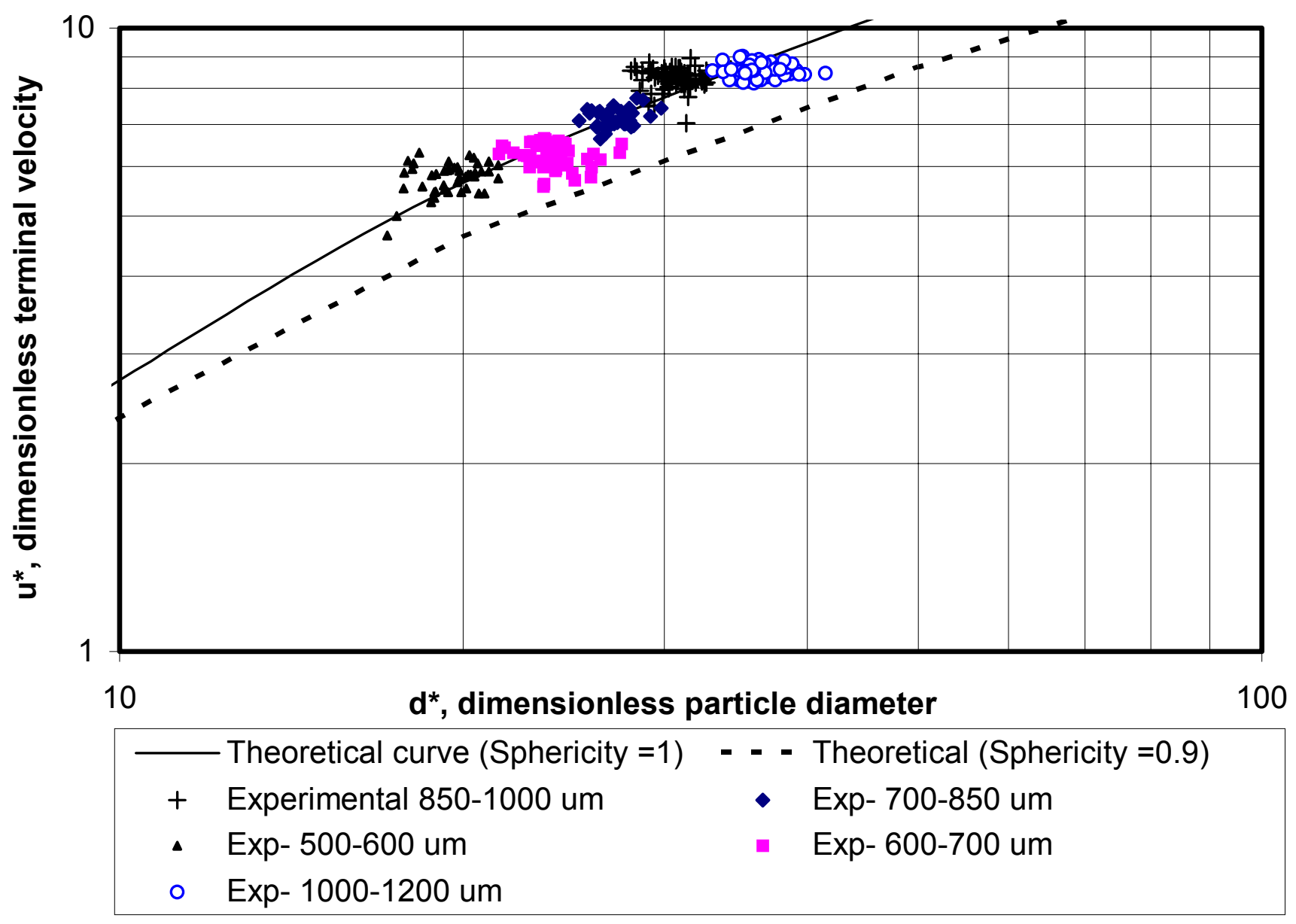

Figure 5.8 Run 1- Experimental dimensionless particle velocity vs dimensionless particle diameter 


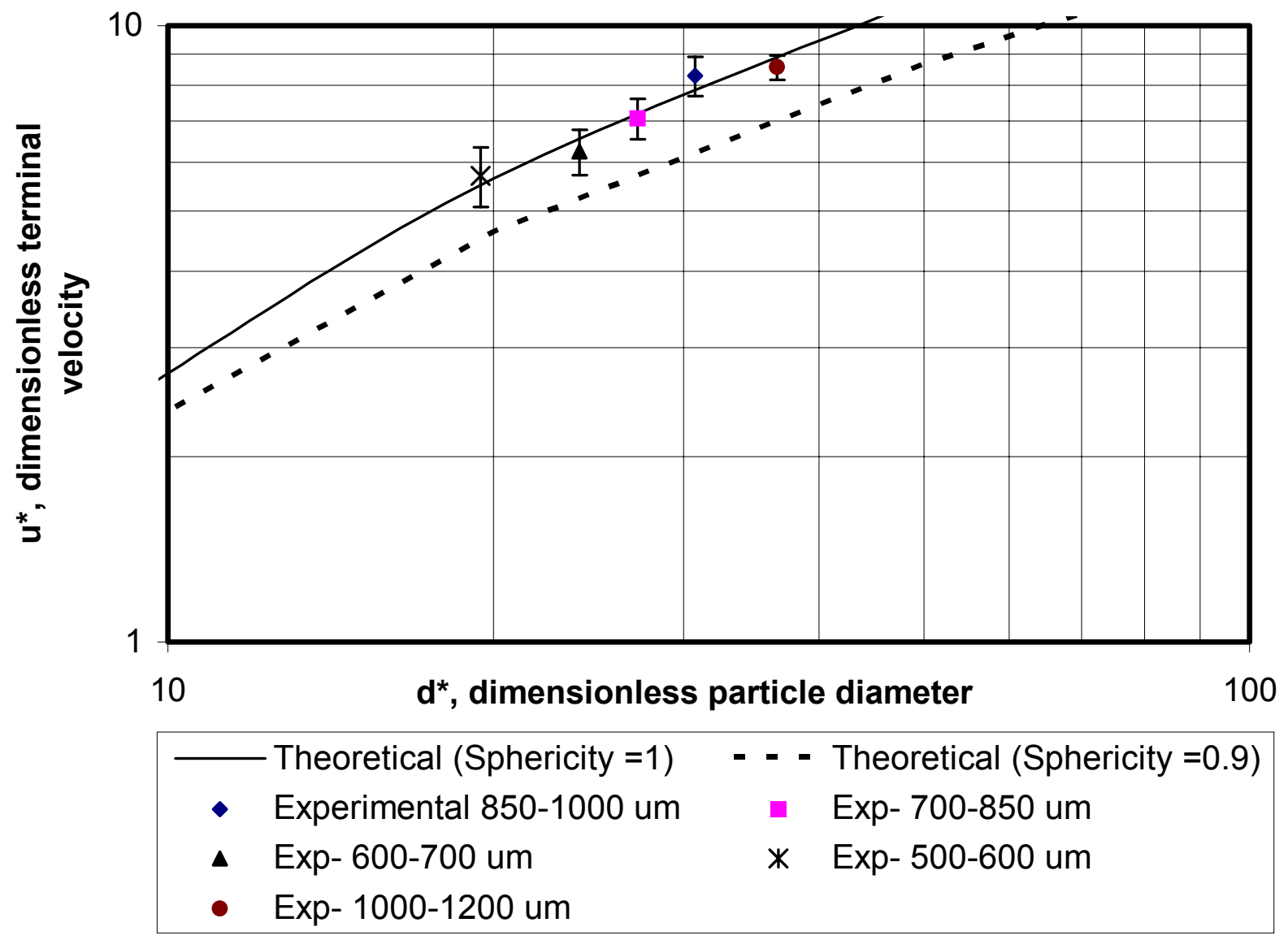

Figure 5.9 Run 1- Mean values and error bars (two standard deviations) 


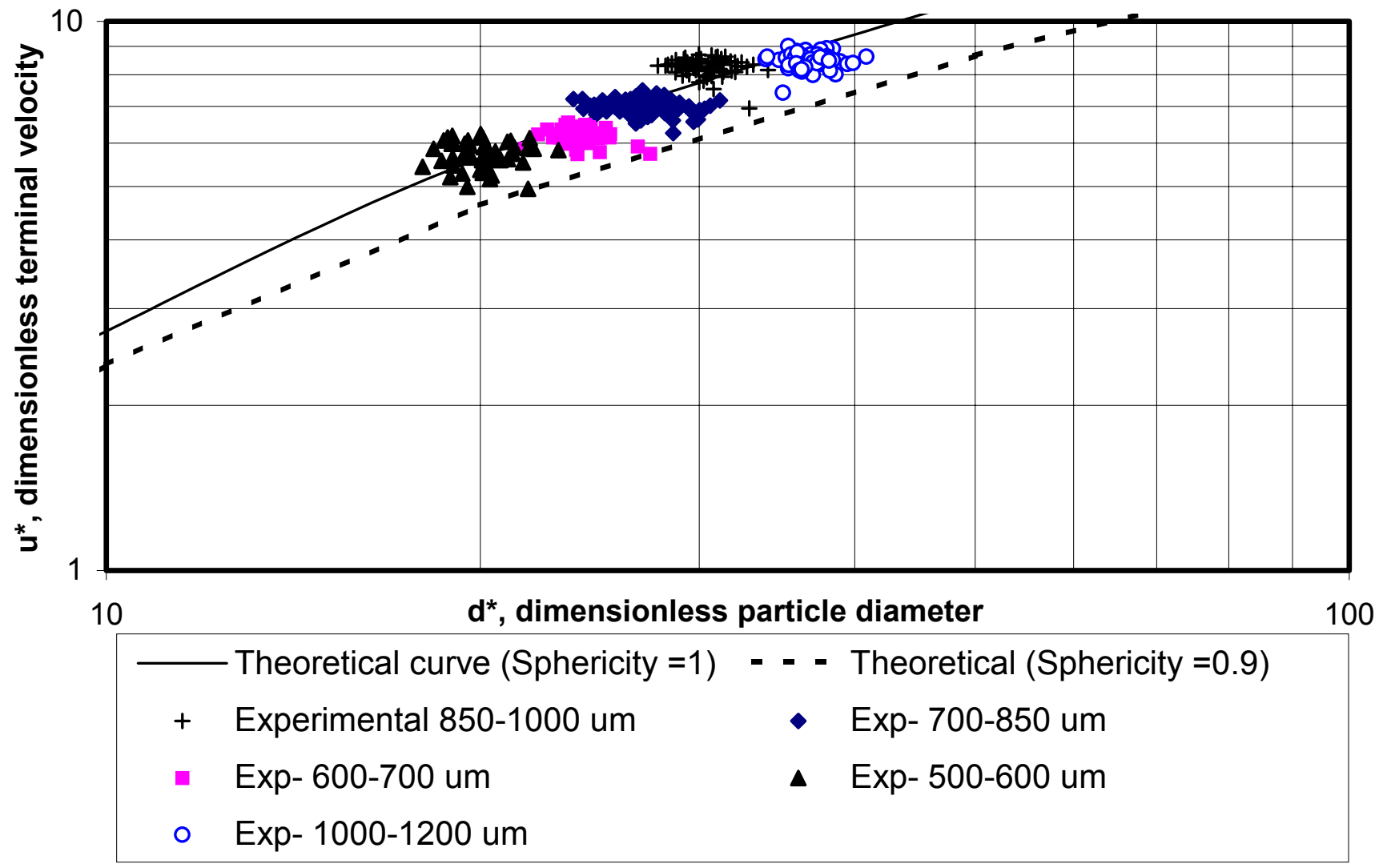

Figure 5.10 Run 2- Experimental dimensionless particle velocity vs dimensionless particle diameter 


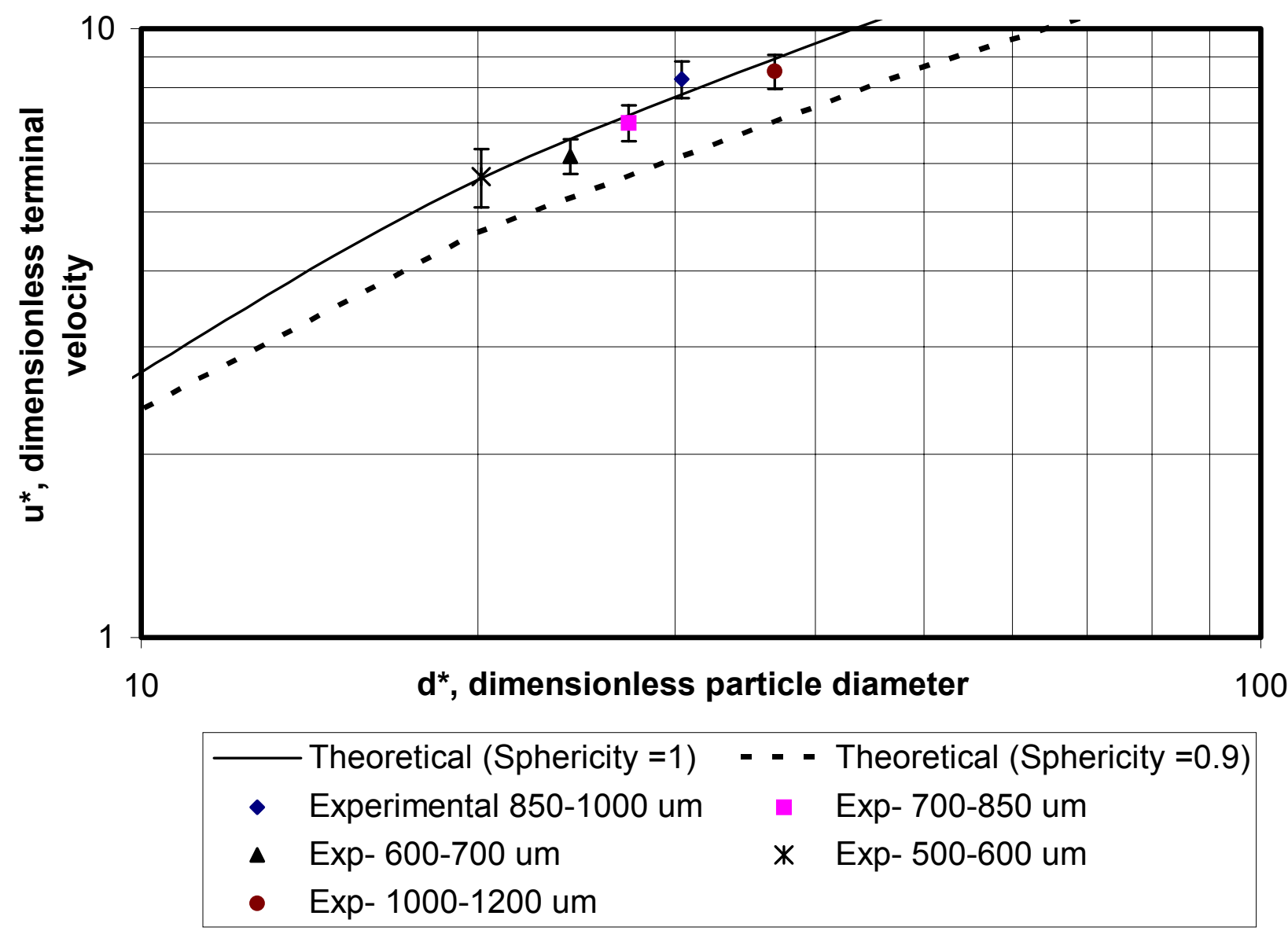

Figure 5.11 Run 2- Mean values and error bars (two standard deviations) 


\subsubsection{Sphericity calculations}

The sphericity of a particle $(\Phi)$ is given by Equation (5.4), where $s$ is the surface area of a sphere having the same volume as the particle and $S$ is the actual surface area of the particle.

$$
\Phi=\frac{S}{S}
$$

The imaging analysis software measures the projected area of the particle $\left(A_{\text {proj }}\right)$. Assuming that the particle is an ellipsoid, the actual surface area of the particle $(S)$ can be calculated by Equations (5.5) (for an oblate ellipsoid) and (5.6) (for a prolate ellipsoid). An oblate ellipsoid is generated by an ellipse rotating around its minor axis $(b)$ whereas a prolate ellipsoid is generated by an ellipse rotating around its major axis $(a)$. The values of the major and minor axis were obtained from Equations (5.9) and (5.10).

$$
\begin{aligned}
& S_{o}=2 \pi a^{2}\left[1+\left(1-e^{2}\right) a \tanh (e) / e\right] \\
& S_{p}=2 \pi b^{2}\left[1+(b / a)^{2} a \tanh (e) / e\right]
\end{aligned}
$$

where $e$ is the eccentricity and is given by $e=\sqrt{\left(1-b^{2} / a^{2}\right)}$

The imaging software evaluates the projected area $\left(A_{\text {proj }}\right)$ and the ellipsivity $(\varepsilon)$ of the particle. These were used to calculate the minor and major axis using the following equations.

$$
\begin{aligned}
& A_{p r o j}=\pi a b \\
& \varepsilon=\frac{b}{a} \times 100
\end{aligned}
$$


Combining Equations (5.7) and (5.8):

$$
\begin{aligned}
& a=\sqrt{\frac{100 A_{p r o j}}{\pi \varepsilon}} \\
& b=\sqrt{\frac{A_{p r o j} \varepsilon}{100 \pi}}
\end{aligned}
$$

The surface area of a sphere with the same volume as that of the particle $(s)$ was obtained by equating the volume of the ellipsoid to that of a sphere. An equivalent diameter $\left(d_{\text {equv }}\right)$ thus obtained was used to evaluate $s$. The results are summarized in Equations (5.11) and (5.12).

Volume of oblate spheroid $=(4 / 3) \pi a^{2} b$

Volume of equivalent sphere $=(\pi / 6) d_{\text {equv }}{ }^{3}$

Equations (5.11) and (5.12) combine to give:

$$
d_{\text {equv }}=2\left(a^{2} b\right)^{1 / 3}
$$

The equivalent surface area $s=\pi d_{\text {equv }}{ }^{2}$

Similar calculations were done assuming the particle to be a prolate ellipsoid, where

$$
\text { Volume of prolate ellipsoid }=(4 / 3) \pi a b^{2}
$$

For this case the equivalent diameter is given by:

$$
d_{\text {equv }}=2\left(a b^{2}\right)^{1 / 3}
$$

Using these equations both oblate and prolate sphericities were evaluated. These results have been tabulated in Table 5.3 for the runs given in Table 5.2. The results confirm that the sphericity of the particles used was close to $1(0.98<\Phi<0.99)$. 


\begin{tabular}{|c|c|c|c|}
\hline $\begin{array}{c}\text { Run } \\
\#\end{array}$ & $\begin{array}{c}\text { Particle } \\
\text { diameter } \\
(\boldsymbol{\mu m})\end{array}$ & $\begin{array}{c}\text { Oblate } \\
\text { Sphericity, } \Phi\end{array}$ & $\begin{array}{c}\text { Prolate } \\
\text { Sphericity, } \Phi\end{array}$ \\
\hline 1 & $1000-1200$ & 0.989 & 0.988 \\
\hline 2 & & 0.989 & 0.989 \\
\hline 1 & $850-1000$ & 0.993 & 0.993 \\
\hline 2 & & 0.992 & 0.992 \\
\hline 1 & $700-850$ & 0.991 & 0.991 \\
\hline 2 & & 0.992 & 0.992 \\
\hline 1 & $600-700$ & 0.989 & 0.989 \\
\hline 2 & & 0.991 & 0.991 \\
\hline 1 & $500-600$ & 0.984 & 0.984 \\
\hline 2 & & 0.984 & 0.985 \\
\hline
\end{tabular}

Table 5.3 Sphericity values for different particle size for two runs 


\subsection{Tests with cork material}

Using the set-up shown in Figure 4.5, some tests were carried out using cork material. This material is currently used in the cold flow circulating fluidized bed at NETL. The cork material was sieved to obtain different size cuts and terminal velocity tests were conducted for each cut. A typical graph obtained for a test run is shown in Figure 5.12. A much larger spread of data was observed in comparison to a similar graph for Nu-Pareils (Figure 5.7) and can be attributed to the non-uniform shape and density of the cork particles. The terminal velocity values, along with the standard deviations, for different size cuts of cork particles, are shown in Table 5.4. The mean velocity and the standard deviations were obtained for a sample of more than 50 data points.

The effect of solids loading on the velocity was tested on cork material for 3 different size cuts (Figure 5.13). Higher velocities were obtained as the particle size was increased. There was a significant change in the velocity data between the low and the high loadings. This was attributed to the clustering of cork particles.

Prior to moving the equipment to the $\mathrm{CFB}$, an experiment was conducted to investigate the effect of the presence of a curved glass surface placed between the BILS and the falling particle. This was accomplished by enclosing the set-up shown in Figure 4.7 in a glass section with the same curvature as that of the CFB. Cork material was dropped from the same height with and without the glass section. The results are shown in Figure 5.14 and indicated that there was no significant effect of the curvature of the glass surface on the velocity data obtained. Moreover, the vertical component of the velocity should not be affected by the curvature since the laser beam is incident at the center line of the riser wall. 


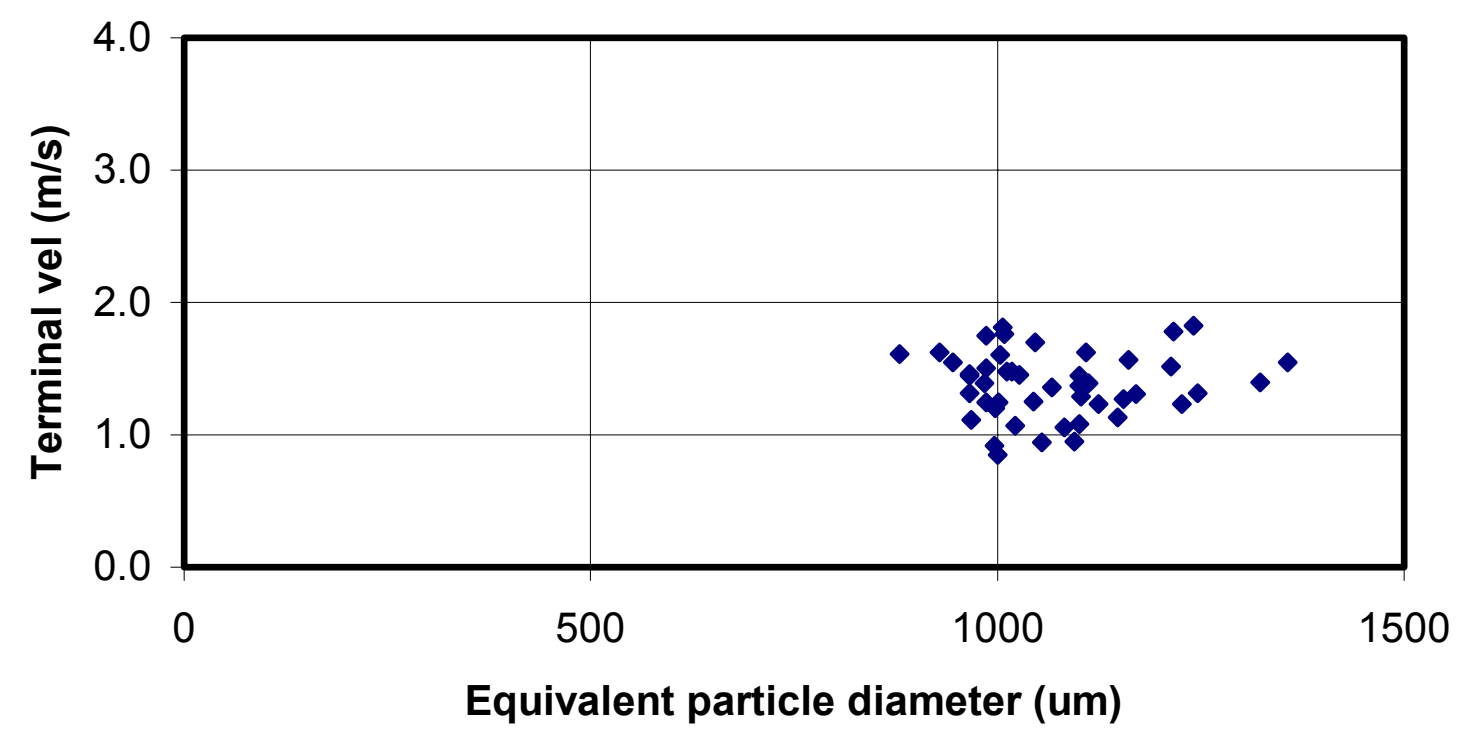

Figure 5.12 Terminal velocity of cork particles for particle size 1000$1200 \mu \mathrm{m}$

\begin{tabular}{|c|c|c|}
\hline Size $(\boldsymbol{\mu m})$ & $\begin{array}{c}\text { Mean Terminal velocity } \\
(\mathbf{m} / \mathbf{s})\end{array}$ & $\begin{array}{c}\text { Standard deviation } \\
(\mathbf{m} / \mathbf{s})\end{array}$ \\
\hline $700-850$ & 0.86 & 0.70 \\
\hline $850-1000$ & 0.95 & 0.70 \\
\hline $1000-1200$ & 1.38 & 0.85 \\
\hline
\end{tabular}

Table 5.4 Mean terminal velocities and standard deviations for different particle sizes of cork material 


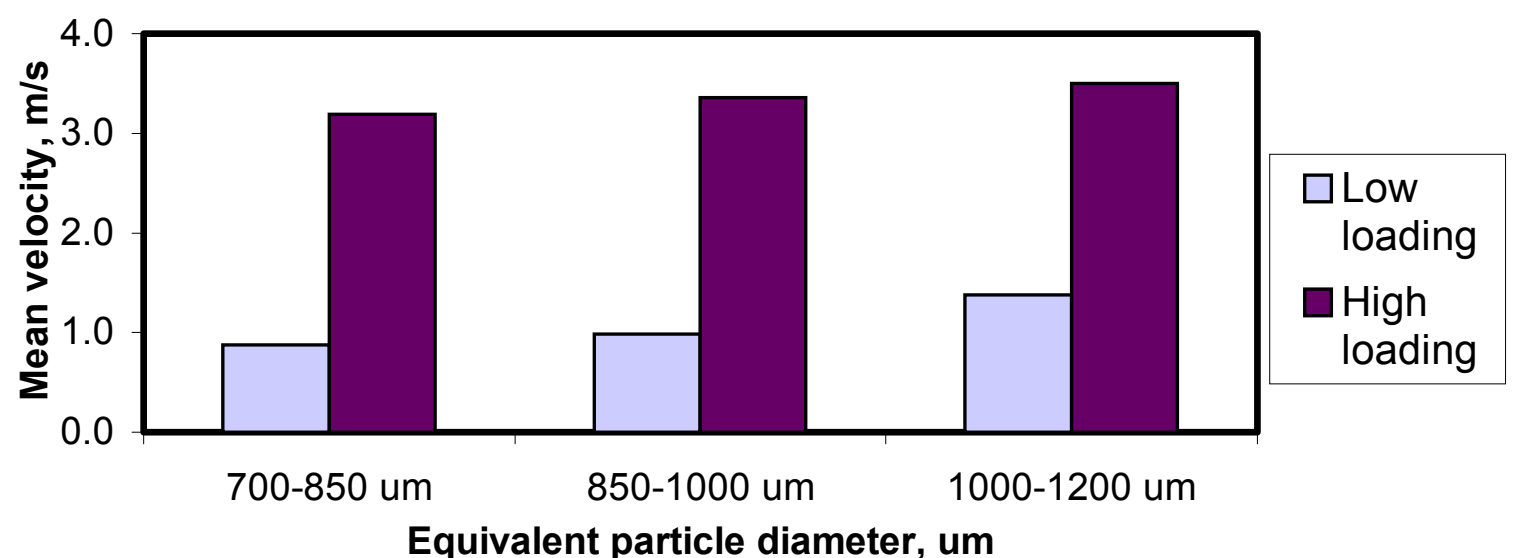

Figure 5.13 Velocity variation of cork particle with particle size and solids loading

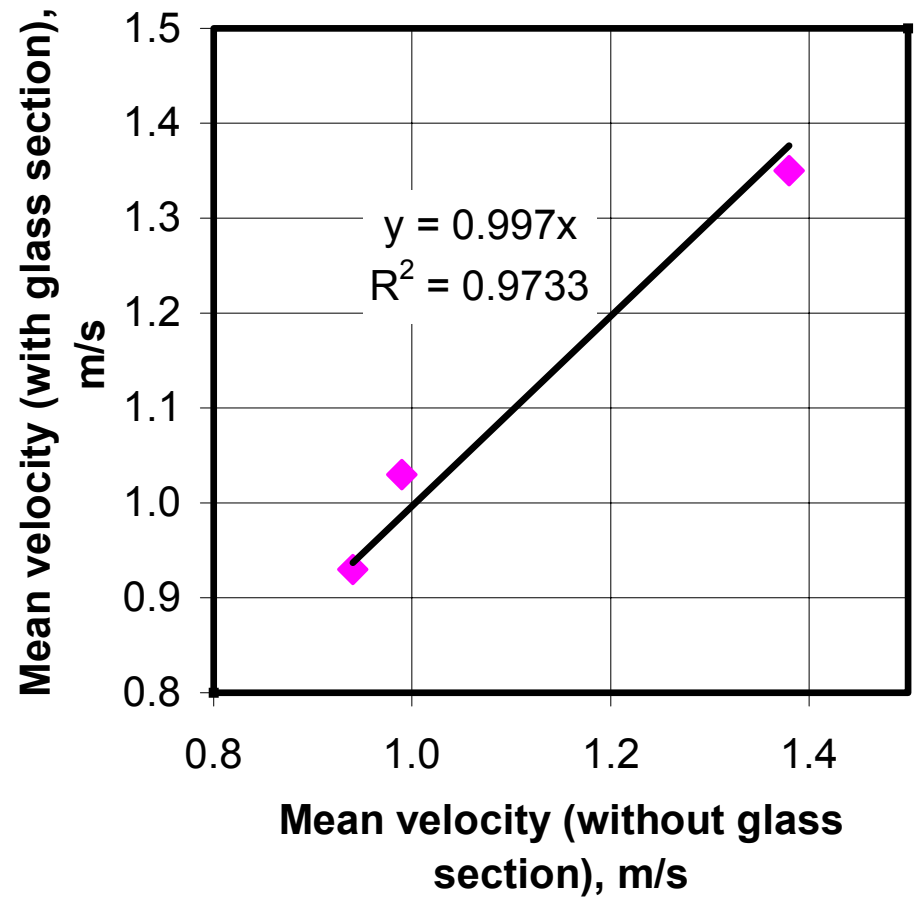

Figure 5.14 Comparison of velocity with and without glass section for three different particle sizes 


\section{Application to a Cold Flow Circulating Fluidized Bed (CFB)}

The results of the validation and calibration of the instrument showed that the instrument gives very repeatable and reliable measurements. As an application test of the instrument, it was then used to measure velocities of solid particles in the circulating fluidized bed. A test matrix was designed to ensure that a wide range of operating conditions, above the fast fluidized bed regime, Shadle et al., [2002], was covered. This matrix is shown in Table 6.1. A few runs were replicated to check the repeatability of the measurements. A spiral device, developed at NETL (National Energy Technology Laboratories, Morgantown), was used to measure the solids circulation rate, Ludlow et al., [2002]. All measurements were taken at steady state conditions.

\begin{tabular}{|c|c|c|}
\hline Run \# & $\begin{array}{c}\text { Superficial gas } \\
\text { velocity }(\mathbf{m} / \mathbf{s})\end{array}$ & $\begin{array}{c}\text { Solids circulation rate } \\
\mathbf{( k g / h r )}\end{array}$ \\
\hline 1 & 4.58 & 4491 \\
\hline 2 & 5.40 & 2722 \\
\hline 3 & 5.16 & 4005 \\
\hline 4 & 4.58 & 907 \\
\hline 5 & 3.99 & 4005 \\
\hline 6 & 5.16 & 1439 \\
\hline 7 & 4.58 & 2722 \\
\hline 8 & 3.99 & 1439 \\
\hline 9 & 3.75 & 2722 \\
\hline
\end{tabular}

Table 6.1 The experimental matrix of superficial gas velocities and solids circulation rates used in the CFB 


\subsection{Circulating Fluidized Bed Facility}

The experimental test facility used in this study is a Cold Flow Circulating Fluidized Bed (CFCFB), located at the National Energy Technology Laboratory (NETL), US Department of Energy, Morgantown. This system is described by Monazam et al., [2001]. A schematic diagram of this facility is shown in Figure 6.1. This unit is an atmospheric, cold-flow model of a CFB combustor. The riser is $30.5 \mathrm{~cm}$ I.D. and $15.2 \mathrm{~m}$ in height with a standpipe I.D. of $25.4 \mathrm{~cm}$. The CFB is instrumented with aeration flow control loops, differential pressure transmitters, load cells and a spiral device to measure the solids circulation rate. Solids are transported from the standpipe to the riser through a fully fluidized non-mechanical valve (loop-seal). Two staged cyclones capture the particles leaving the riser, which are then returned to the standpipe. The CFB walls are essentially made of metal with some sections made of plexiglass to allow for visual observation and provide clear optical access to instruments such as BILS.

The BILS instrument is set-up to take velocity measurements at a distance of $9 \mathrm{~m}$ from the bottom of the riser section. A vibration isolation system is used to prevent the vibrations caused by the CFB facility from influencing the system alignment. This is important for an optical set-up like BILS, where the laser power decreases significantly if the system is misaligned. A check on the laser power was done occasionally, using a power meter, to ensure that misalignment did not occur. A linear slide was set-up on this vibration isolation system. The optical table carrying the BILS instrument was placed on this linear slide. This system is shown in Figure 6.2. The linear slide enabled the BILS system to move radially in and out of the fluidized bed. It consists of a hand crank that rotates the screw, which in turn guides the movement of the slide. By knowing the pitch 
of the screw a measure of the linear distance moved can be found from the number of turns of the hand crank. A pre-calibrated counter is attached to the screw that converts the screw rotation value to a linear distance. The counter has an accuracy of two decimal places when displaying the distance in $\mathrm{mm}$. This set-up defines the radial position of the measurement volume in the bed. The BILS system sits on a platform resting on the supporting blocks. 


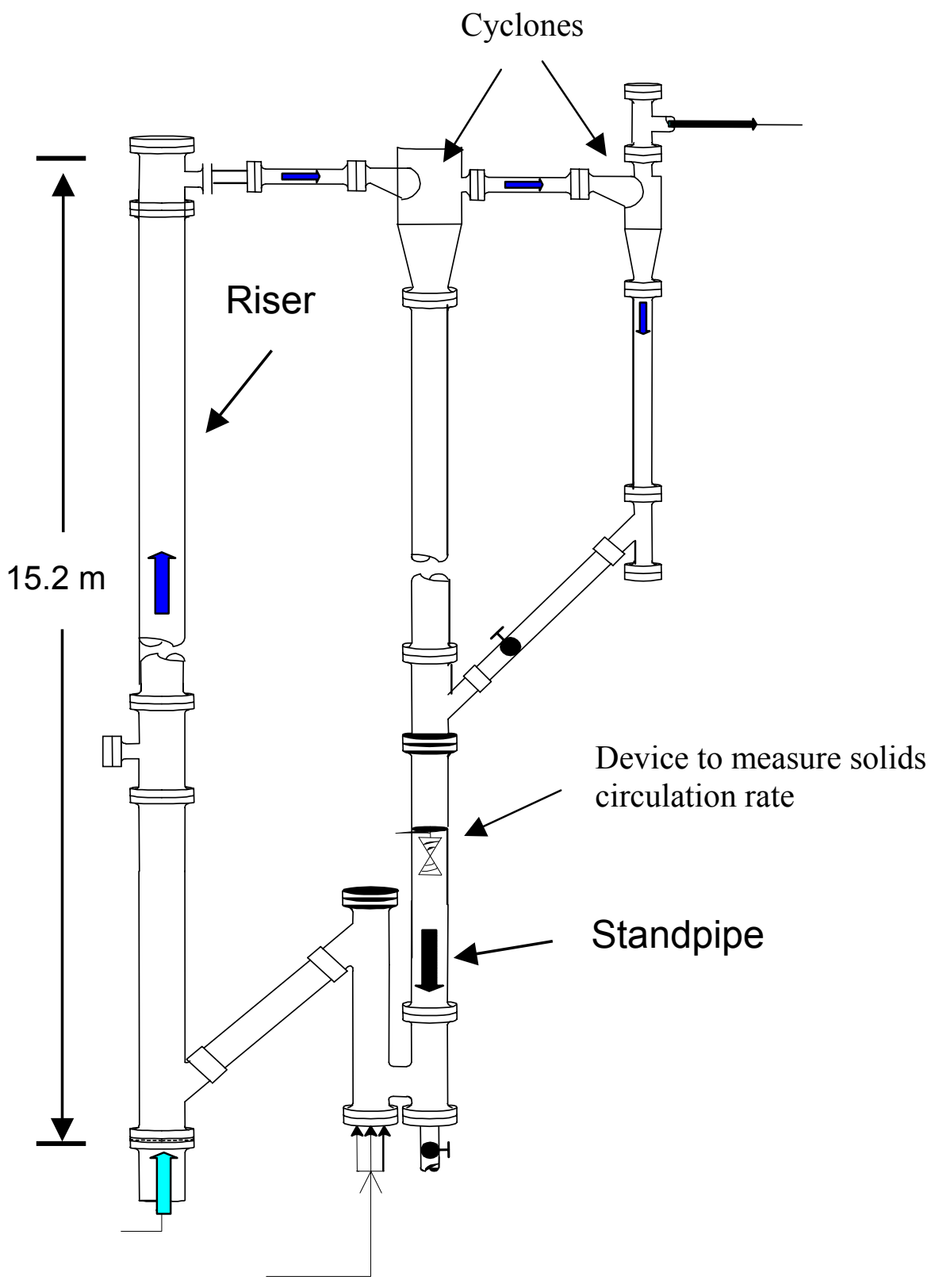

Figure 6.1 Circulating Fluidized Bed set-up at NETL, Morgantown 


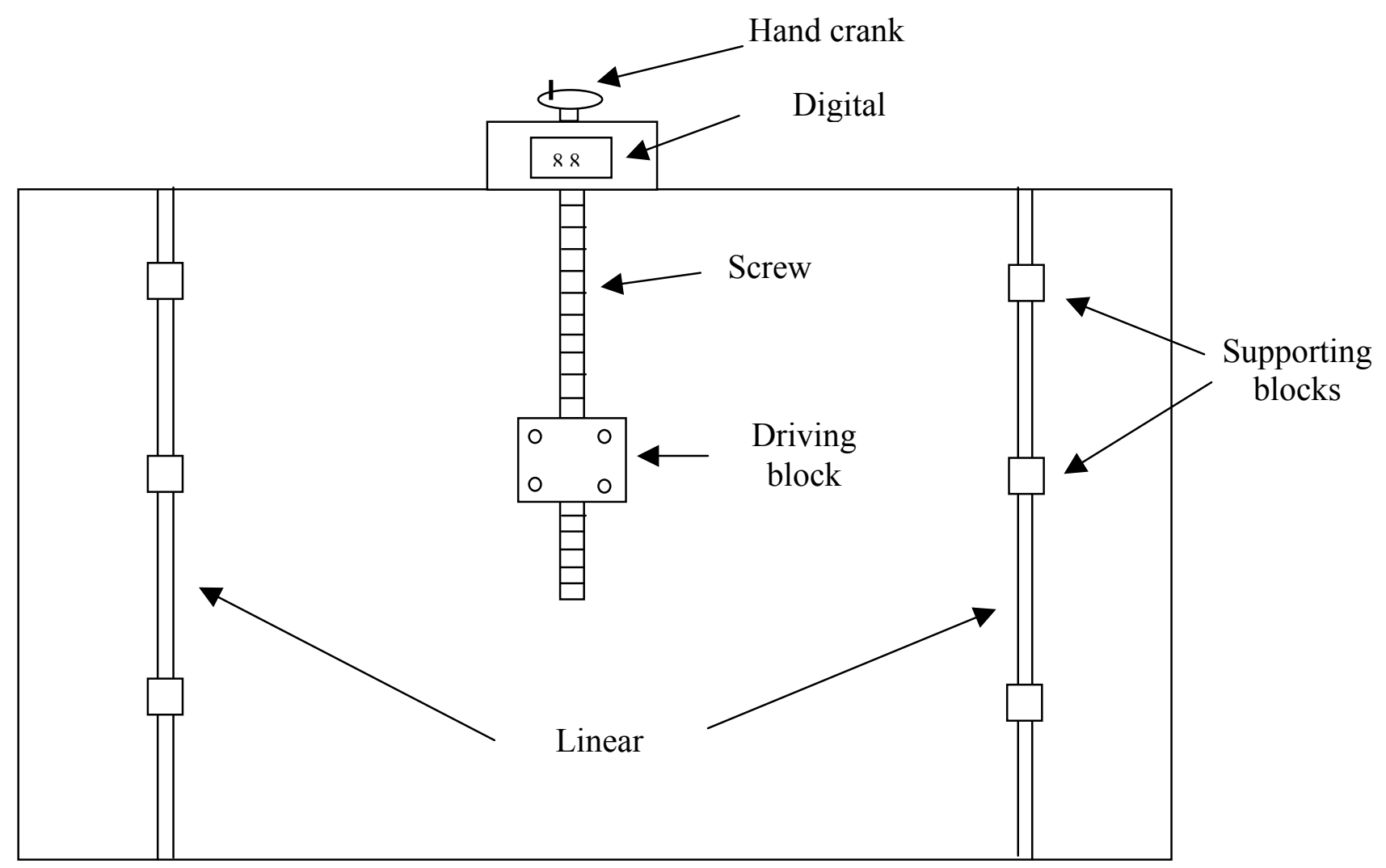

Figure 6.2 A sketch of the linear positioning system used in the set-up 


\subsubsection{Bed Materials and Properties}

The solid material used for circulation was cork with a nominal diameter of 1000 $\mu \mathrm{m}$. The size distribution of the cork material used is described by Shadle et al., [2002]. This material behaves as a Geldart type B particles for the operating conditions of this study, Gidaspow [1994]. Its bulk density is in the range of $88.1-107 \mathrm{~kg} / \mathrm{m}^{3}$ with a particle density of $189 \mathrm{~kg} / \mathrm{m}^{3}$. Solids volume fractions under vibrated and fluffed conditions were measured as 0.515 and 0.423 , respectively. The minimum fluidization velocity is 16.67 $\mathrm{cm} / \mathrm{sec}$. The internal angle of friction of the material has been estimated to be $74.3^{0}$. 


\subsection{Data reproducibility in the Circulating Fluidized Bed}

The LDV velocity data were recorded at different radial locations in the bed. The data were recorded until the mean velocity was found to be relatively stable. The acceptable data rate reduced as the LDV measurement volume was moved inside the bed. This phenomenon was attributed to the fact that the particles obstruct the path of the laser beam. For low solids circulation rates, the LDV was able to 'see' deeper into the CFB, in the sense that velocity data could be obtained. However, the velocity data were obtained for all the operating conditions under consideration near the wall. Runs 4 and 7, in Table 6.1, were repeated and the results are shown in Figures 6.3 and 6.4, respectively. The mean velocity values are plotted as a function of the measurement location, which is reported as the distance from the wall of the CFB.

Figure 6.3 indicates that for Run 4, which had a very dilute solids flow, the particles on the average were moving upwards even close to the wall. This result will be discussed in more detail in the next section. In Figure 6.4, the mean velocities were separated into negative and positive components, representing particles moving upwards and downwards, respectively. The graph shows that very close to the wall, the mean velocity was negative, indicating that the particles, in general, were moving downwards. The data demonstrated that the instrument's readings were reproducible. The raw data is tabulated in Table A2.1 of Appendix II. 


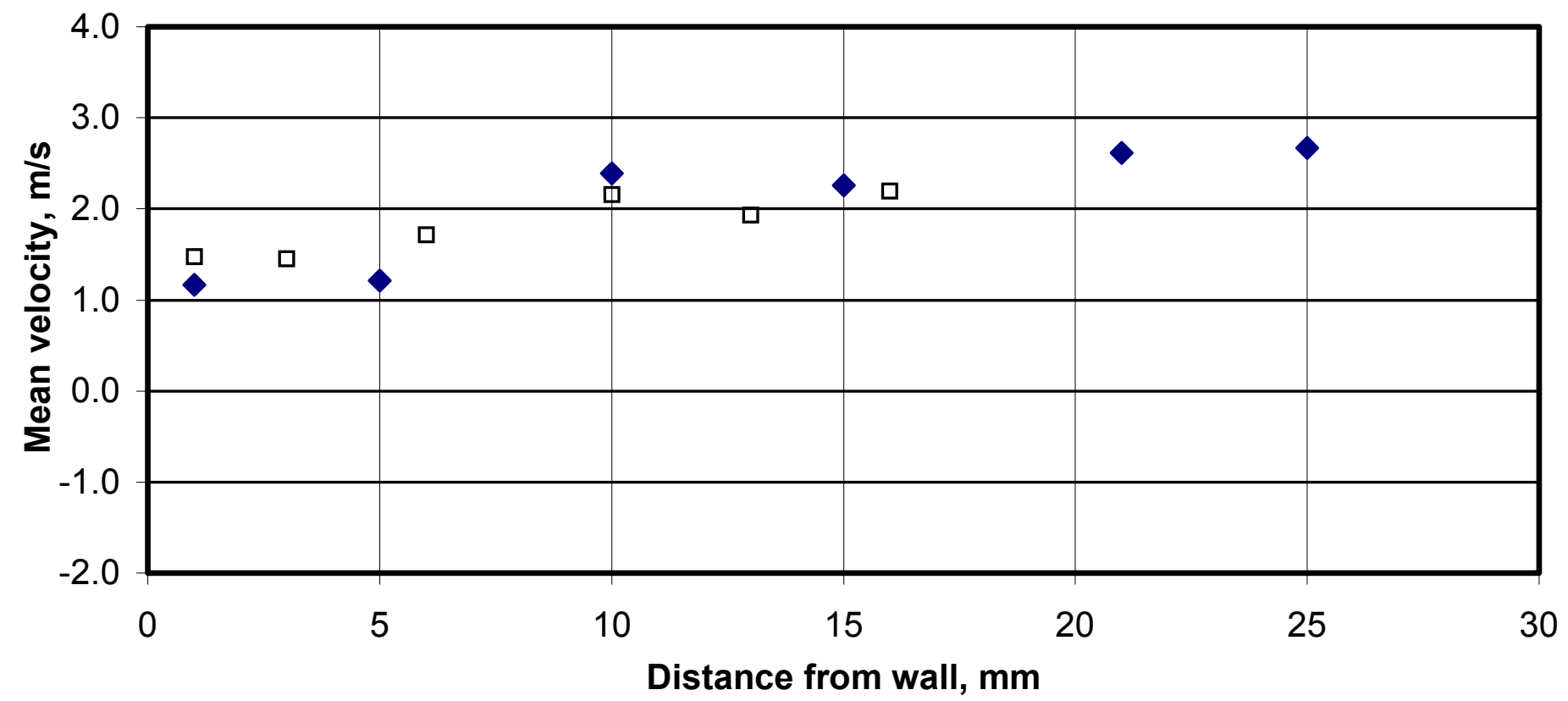

$\diamond$ Run $4 \quad$ a Repeat, Run 4

Figure 6.3 Mean velocity as a function of the measurement volume distance from the wall of the CFB,

Duplicate tests for the condition of Run $4, U_{g}=4.58 \mathrm{~m} / \mathrm{s}, M_{s}=907 \mathrm{~kg} / \mathrm{hr}$ 


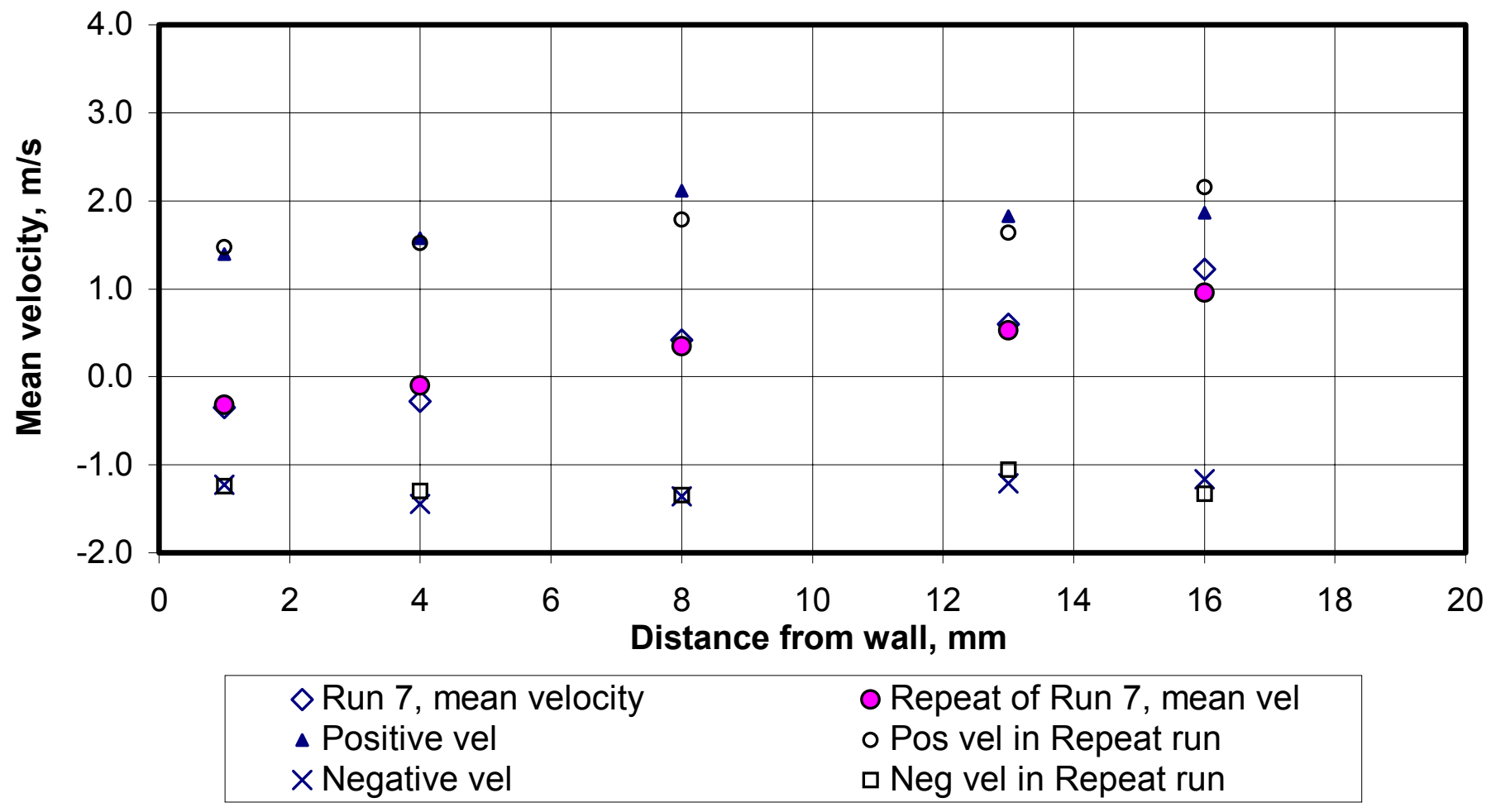

Figure 6.4 Mean velocity as a function of the measurement volume distance from the wall of the CFB, a repeat of Run 7, $U_{g}=4.58 \mathrm{~m} / \mathrm{s}$ and $M_{s}=2722 \mathrm{~kg} / \mathrm{hr}$ 


\subsection{Effect of solids circulation rate}

To study the effect of operating conditions on the solids velocity, either the solids circulation rate or superficial gas velocity was kept constant while the other was varied. Figure 6.5 shows the effect of solids circulation rate on the solids velocity profile, near the wall region. Here, the superficial gas velocity was kept constant at $4.58 \mathrm{~m} / \mathrm{s}$ (Run 1, 4 and 7). The graph shows that the mean velocity of solids shifted towards the negative direction with increasing circulation rates, indicating that more and more solids near the wall were moving downward. This is consistent with the core annular flow pattern expected in a riser and was confirmed by observation. At very high solids flow rate, nearly all particles seemed to be moving down near the wall region. For Run 4, which was the most dilute condition, there was no mean down-flow of particles, thus the coreannulus type of flow was not observed for this particular case. The maximum distance inside the bed, for which data could be recorded was about $2.5 \mathrm{~cm}$ for Run 4 (most dilute operating condition), $1.7 \mathrm{~cm}$ for Run 7, and $1.3 \mathrm{~cm}$ for Run 1 (the most dense case in the experimental matrix). In trying to take measurements further inside the bed the data rate became very low. This was caused by the particles obstructing the laser beam path. Some information may be obtained further inside the bed if the LDV is allowed longer sample times. This may be of interest in future studies with this instrument.

A similar analysis was carried out at a different superficial gas velocity for two different solids loading (Run 3 and Run 6). These results are shown in Figure 6.6. Again, for the very dilute case, the mean velocity near the wall was found to be always positive. 

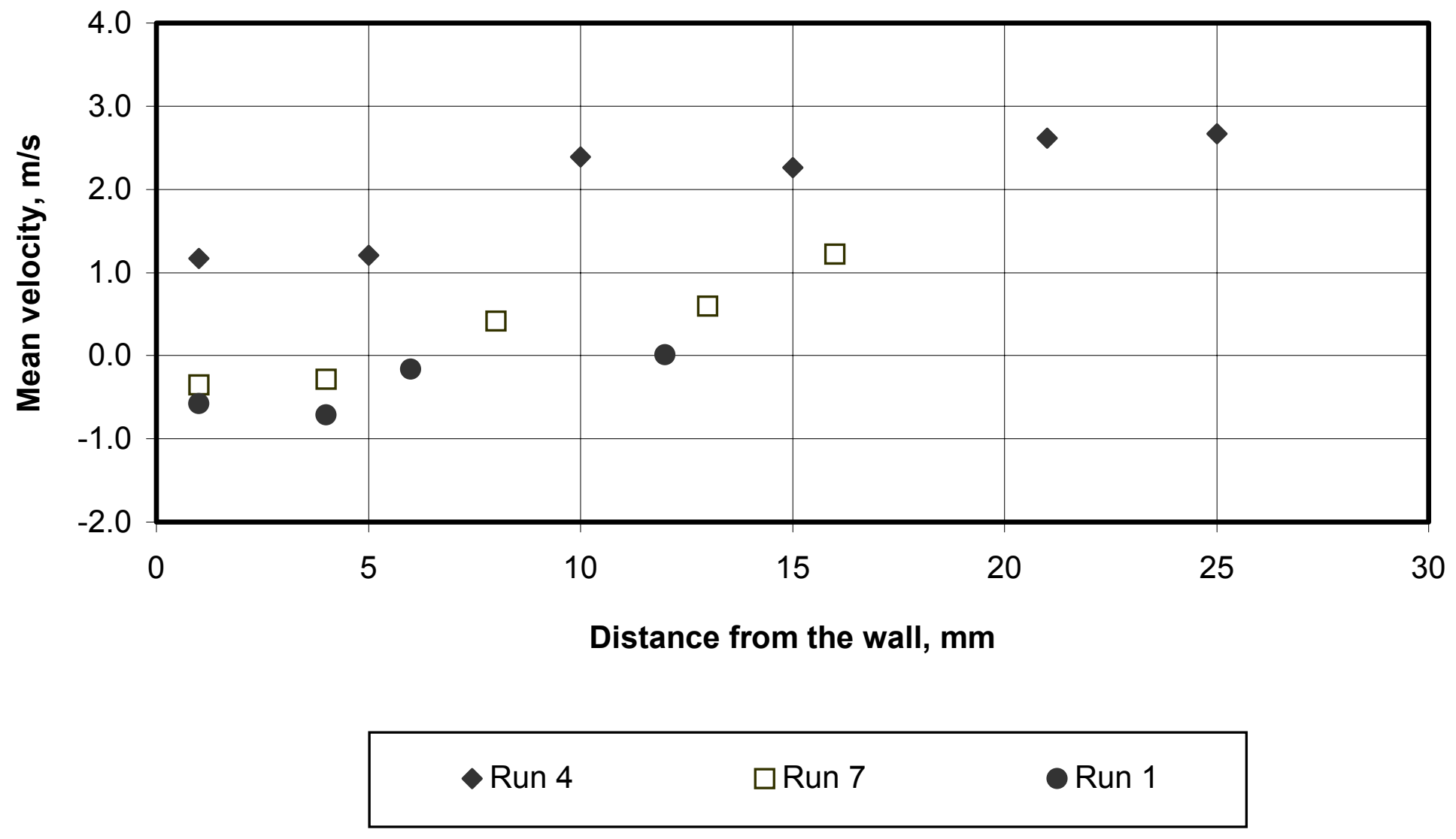

Figure 6.5 Effect of solids circulation rate on the mean velocity near the wall region for superficial gas velocity, $U_{g}=4.58 \mathrm{~m} / \mathrm{s}, M_{s}=907 \mathrm{~kg} / \mathrm{hr}(\operatorname{Run} 4), M_{s}=2722 \mathrm{~kg} / \mathrm{hr}(\operatorname{Run} 7), M_{s}=4491 \mathrm{~kg} / \mathrm{hr}(\operatorname{Run} 1)$ 


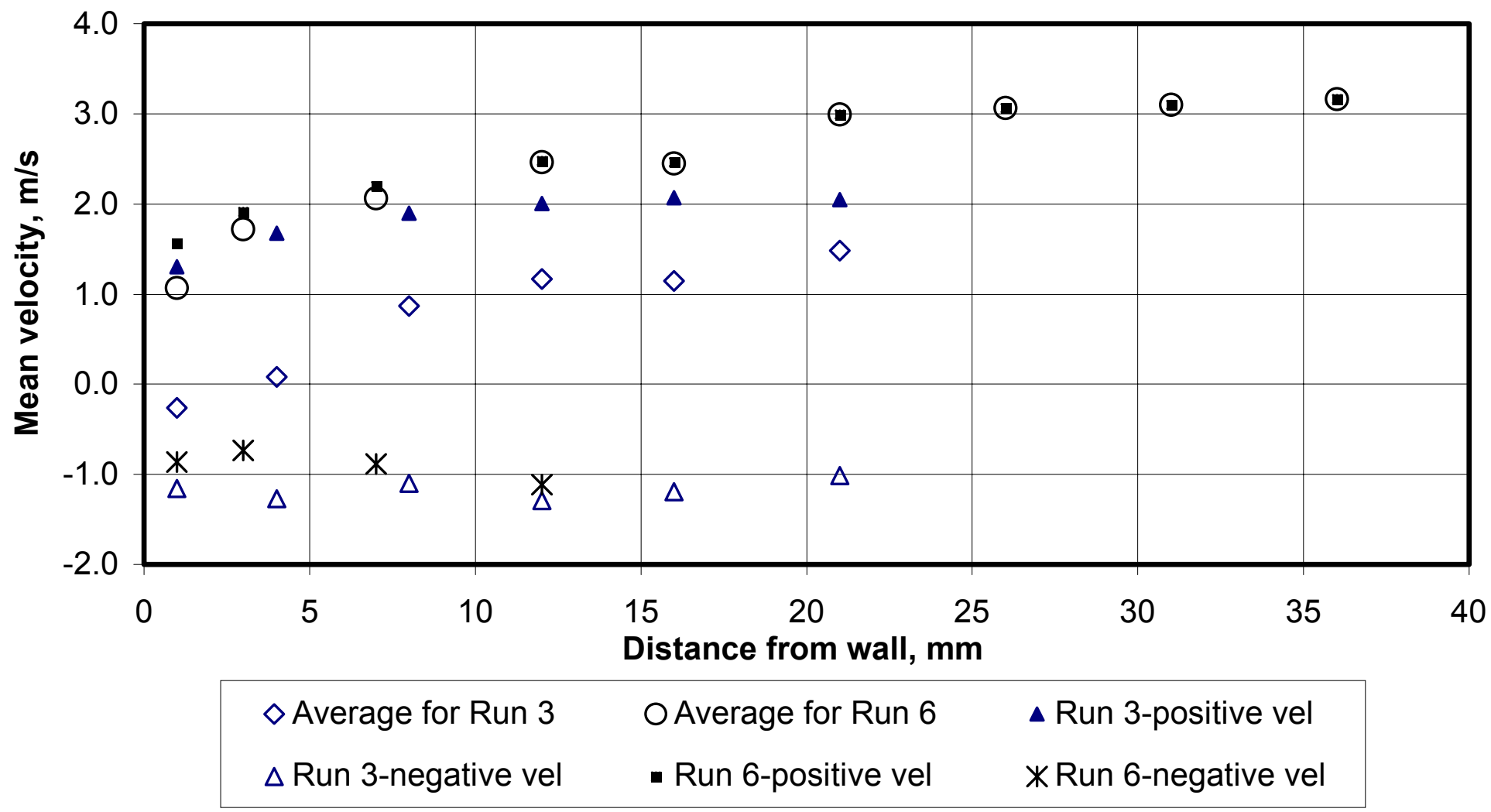

Figure 6.6 Effect of solids circulation rate on the mean velocity and positive and negative components, near the wall region for $U_{g}=5.16 \mathrm{~m} / \mathrm{s}: M_{s}=4005 \mathrm{~kg} / \mathrm{hr}(\operatorname{Run} 3), M_{s}=1439 \mathrm{~kg} / \mathrm{hr}$ (Run 6) 
The mean velocities of the particles moving up and down have been plotted separately. The graph shows that the upward solids velocity decreases and the downward solids velocity increases with increasing solids circulation rate. This was consistent with the result of Tadrist and Cattiuw [1993]. These results were attributed to the fact that an increase in the solids circulation rate caused the gas velocity near the walls to decrease. As seen in the Figure 6.6, the mean velocity of particles for Run 6 was downwards for the region very close to the wall. In addition, there were very few particles moving downwards for the more dilute case (Run 6), in comparison to the ones moving up. This is reflected by the fact that the solid mean velocity data almost overlaps that for the upward moving particles. As the LDV measuring volume was moved deeper inside the bed (radially), there were virtually no particles moving downwards for Run 6 . The mean negative velocity was found to be relatively insensitive to changes in solids circulation rate and superficial gas velocity.

\subsection{Effect of superficial gas velocity}

To study the effect of superficial gas velocity on the solids velocity profile near the wall, the solids circulation rate was kept constant. Figure 6.7 shows velocity profiles for three superficial gas velocities (Run 2, 7 and 9) at constant solids circulation rate. The results show that the mean solids velocity increased with increasing superficial gas velocity. For all of these cases, the mean solids velocity was downwards near the wall. Similar tests were conducted for a different solids circulation rate and data recorded for different superficial gas velocities. The results are shown in Figure 6.8. It can be seen from the graph that the velocities of the upward and downward moving particles increase 
with increasing superficial gas velocity. A similar test was carried out with the same superficial velocities but with a higher solids circulation rate. The mean velocity of particles was found to increase with increasing superficial gas velocity. The results are shown in Figure 6.9.

A statistical analysis of the data was done to study the significance of the operating variables $\left(U_{g}\right.$ and $M_{s}$ ) on the mean velocity of solids at the wall. It is shown in Table A2.2. The results show that the mean solids velocity at the wall was affected by both by solids circulation rate and superficial gas velocity. 


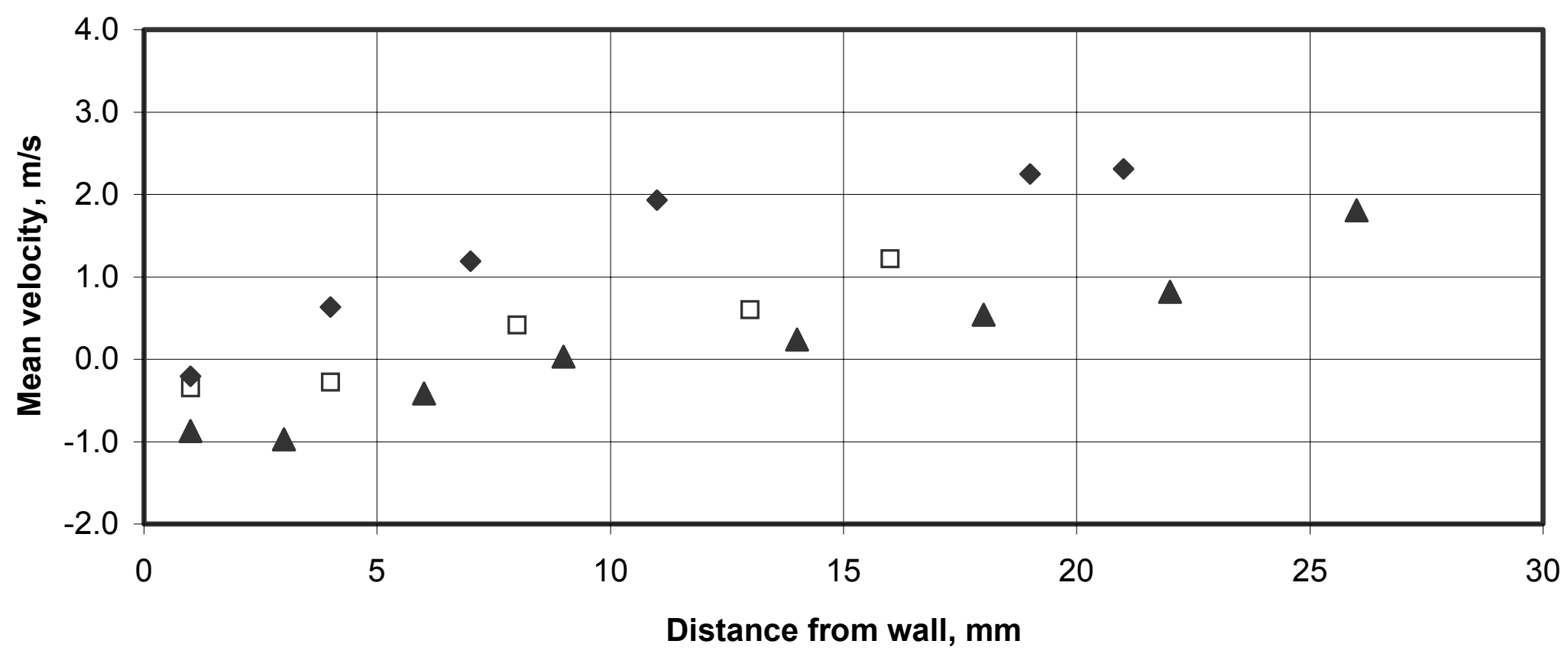

$\bullet$ Run $2 \quad \square$ Run $7 \quad \Delta$ Run 9

Figure 6.7 Effect of superficial gas velocity on the mean velocity near the wall region for solids circulation rate, $M_{s}=2722 \mathrm{~kg} / \mathrm{hr}: U_{g}=5.4 \mathrm{~m} / \mathrm{s}(\operatorname{Run} 2), U_{g}=4.58 \mathrm{~m} / \mathrm{s}(\operatorname{Run} 7), U_{g}=3.75 \mathrm{~m} / \mathrm{s}(\operatorname{Run} 9)$ 


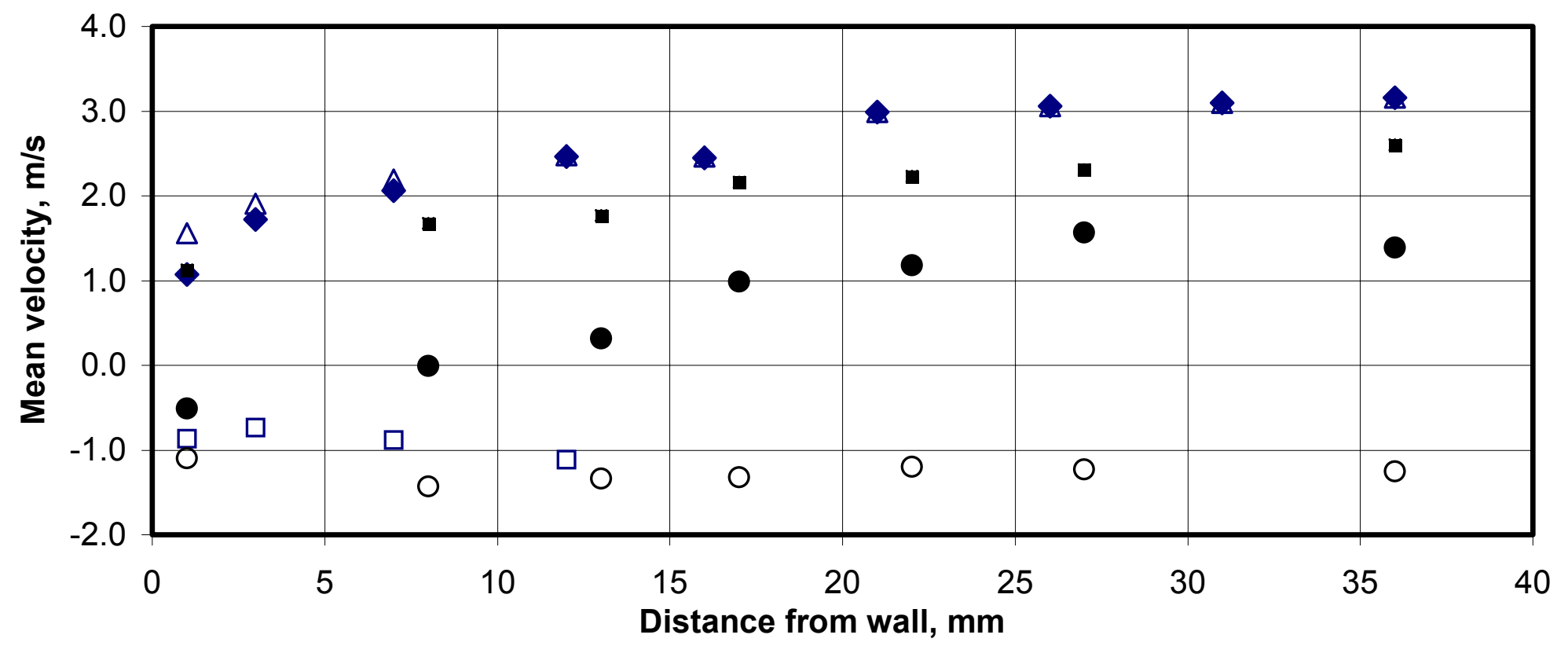
Run 6-mean vel
- Run 8-mean vel
$\triangle$ Run 6-positive vel
$\square$ Run 6-negative vel
- Run 8-positive vel ORun 8-negative vel

Figure 6.8 Effect of superficial gas velocity on the mean velocity near the wall region for solids circulation rate, $M_{s}=1439 \mathrm{~kg} / \mathrm{hr}: U_{g}=5.16 \mathrm{~m} / \mathrm{s}\left(\right.$ Run 6), $U_{g}=3.99 \mathrm{~m} / \mathrm{s}$ (Run 8) 


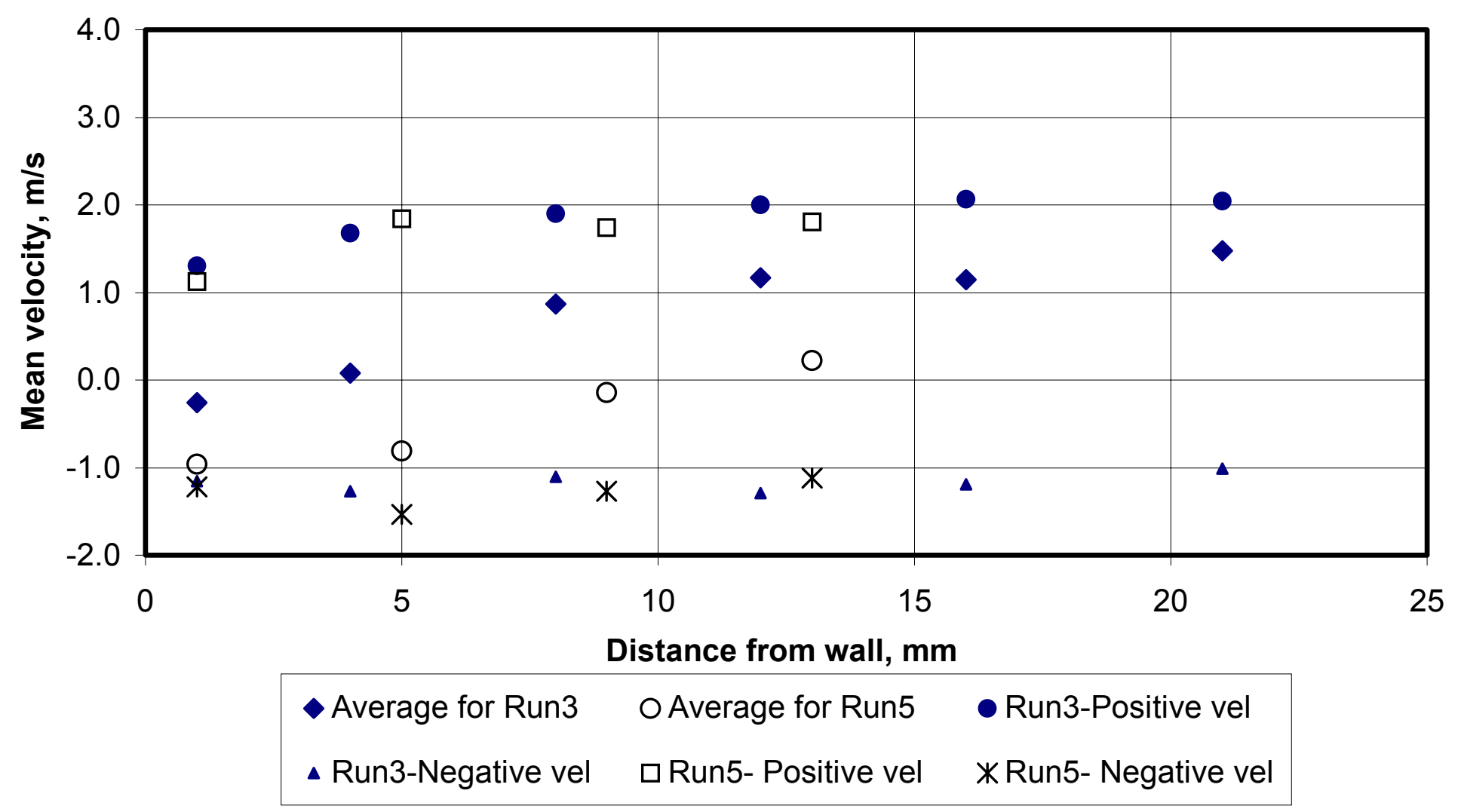

Figure 6.9 Effect of superficial gas velocity on the mean velocity near the wall region for solids circulation rate, $M_{s}=4005 \mathrm{~kg} / \mathrm{hr}: U_{g}=5.16 \mathrm{~m} / \mathrm{s}\left(\operatorname{Run~3)}, U_{g}=3.99 \mathrm{~m} / \mathrm{s}(\right.$ Run 5) 


\section{Conclusions and Significance}

It was important to test the ability of this prototype instrument to record velocity and images of particles before using it on a large scale fluidized bed, where a lot more noise in the signal was expected. A series of validation tests were carried out for that objective. The results from the first set of experiments showed that the velocity data obtained from BILS were successfully validated. This validation was achieved using a disc, rotating at a known angular frequency (measured by a digistrobe). The velocity was found to be very reproducible and was independent of the location of the wire inside the measurement volume. It was also found to be independent of the wire diameter. After calibration of the imaging part, using a target of known dimensions, experiments were conducted to record simultaneous terminal velocity and size of near-spherical, Nu-pareil sugar particles. The results were in good agreement with the drag curve, proposed by Haider and Levenspiel, 1988. Thus the operation of both the velocity and the imaging part of the system was successfully calibrated and validated.

The variation of particle velocity with drop height, as a function of particle size and solids loading, was also studied, qualitatively. The mean particle velocity was found to increase with increasing particle size and solids loading. The particles in the 500-600 $\mu \mathrm{m}$ size-cut were found to reach their terminal velocity, for very dilute flow, at a drop height of $1 \mathrm{~m}$. The sphericity of Nu-pareil particles was estimated using the images obtained. The particles were assumed to be ellipsoidal in shape and their calculated sphericity $(\Phi)$ was very close to $1(0.98<\Phi<0.99)$. 
The instrument's ability to record particle size and velocity near the wall region of the CFB facility at NETL, Morgantown, was tested, as a potential application for such a system. The particle velocity was measured successfully up to $3 \mathrm{~cm}$ inside the wall of the riser section, for a set of nine operating conditions, all of which were above the fastfluidized regime. Duplicates were carried out for two cases to test the reproducibility of the velocity data and the results showed very good repeatability. The results from the nine operating conditions show that the particle velocity, near the wall region, increases in the upward direction with increasing superficial gas velocity and in the downward direction with increasing solids circulation rate. The mean flow of particles adjacent to the wall was, in most cases, found to be downward. However, for the very dilute solids loading the mean flow was found to be upward, with only a few particles moving in the downward direction. This was consistent with visual observations. No meaningful particle images could be obtained due to the optical quality of the plexi-glass section of the CFB riser. A set of experiments was conducted to demonstrate that there was insignificant effect of the curvature of the window on the velocity measurements in the axial direction.

It was observed that the velocity data near the wall region could also be used to study the "clustering" phenomenon. To classify the "clusters" from the raw velocity-time data, there was a need to define a "cluster". Results obtained using certain criteria (discussed in Appendix III), show that the distribution of cluster velocity and cluster length was a function of the operating parameters of the CFB. An increased proportion of clusters were found to be moving in the downward direction with increasing solids circulation rate and with decreasing superficial gas velocity. The typical cluster velocity, 
at the wall, was in the range of $0.2-1 \mathrm{~m} / \mathrm{s}$ in the downward direction, for most of the operating conditions. The average cluster size was found to be about 2 to $4 \mathrm{~cm}$. Larger clusters were found near the wall in comparison to other radial locations. A more rigorous study needs to be done to determine the most appropriate criteria defining a cluster.

The particle velocities were obtained near the wall region in a non-intrusive way. The significance of this work lies in obtaining a solids flux profile across the entire cross section of the riser, using a momentum balance. To make such an analysis possible, the measurements from this study need to be coupled with some solids momentum pressure measurements. Also, the study on clustering will be of great significance in estimating the heat transfer at the walls of the riser. 


\section{Future Work}

In this study BILS was used to obtain particle velocity near the wall region of a CFB riser. The data was obtained up to $3 \mathrm{~cm}$ inside the wall. On moving further inside the bed, radially, the backscatter signal became weak and no meaningful data could be obtained. This signal can possibly be made stronger by replacing the current LDV lens by a shorter focal length lens. Presently, the focal length of the lens used is $750 \mathrm{~mm}$ and it appears that the curvature of the plexi-glass weakens the backscattered signal. By bringing the probe closer to the wall, the signal will be stronger when it reaches the probe.

For the current work, no particle images could be obtained inside the CFB riser because of the quality of optical window used at the riser wall. Replacement of the plexiglass used in this study by an optical-quality glass may enable the instrument to record particle images along with the velocity data. This can also help in understanding the 'clustering' phenomenon better.

The curvature effect of the plexi-glass section of the riser reduces the signal to noise ratio $(\mathrm{S} / \mathrm{N})$. This can be improved by having a flat window $(2 \mathrm{~cm} \mathrm{X} 2 \mathrm{~cm})$ allowing optical access to the flow at the measurement location. The current work shows the utility of the BILS in understanding the 'clustering' phenomenon at the walls. Although only preliminary results have been shown, a more rigorous analysis needs to be carried out. A computer code would be useful in order to study the effect of changes in the criteria on the cluster information obtained from the raw data. 


\section{Nomenclature}

\begin{tabular}{|c|c|}
\hline BILS & Backscatter Imaging LDV System \\
\hline CCD & Charged Coupled Devices \\
\hline CFB & Circulating Fluidized Bed \\
\hline CFCFB & Cold flow Circulating Fluidized Bed \\
\hline $\mathrm{FCC}$ & Fluidized Catalyst Cracker \\
\hline LDV & Laser Doppler Velocimeter \\
\hline $\mathrm{M}_{\mathrm{s}}$ & solids circulation rate, $\mathrm{kg} / \mathrm{hr}$ \\
\hline NETL & National Energy Technology Laboratory \\
\hline PDPA & Phase Doppler Particle Analyzer \\
\hline PMT & Photo Multiplier Tube \\
\hline $\mathrm{RCM}$ & Receiver Module \\
\hline RSA & Real-time System Analyzer \\
\hline $\mathrm{U}_{\mathrm{g}}$ & superficial Gas velocity, $\mathrm{m} / \mathrm{s}$ \\
\hline$\rho_{s}$ & solids density, $\mathrm{kg} / \mathrm{m}^{3}$ \\
\hline$\rho_{f}$ & density of fluid, $\mathrm{kg} / \mathrm{m}^{3}$ \\
\hline$\rho_{p}$ & particle density, $\mathrm{kg} / \mathrm{m}^{3}$ \\
\hline$\Phi$ & sphericity \\
\hline$\mu_{f}$ & viscosity of fluid, $\mathrm{kg} / \mathrm{m}-\mathrm{s}$ \\
\hline$d_{s p h}$ & equivalent particle diameter \\
\hline$d *$ & dimensionless particle diameter \\
\hline$g$ & acceleration due to gravity, $\mathrm{kg}-\mathrm{m} / \mathrm{s}^{2}$ \\
\hline & dimensionless terminal velocity \\
\hline
\end{tabular}




\section{References}

- Arastoopour H. and Shao S. (1996), Laser Doppler Anemometry: Applications in multiphase flow systems, Non-invasive Monitoring of Multiphase flows, 455-490

- Dantec Inc., www.dantec.com

- Durst F., Melling A. and Whitelaw J. (1981) Principles and practice of laser Doppler Anemometry, $2^{\text {nd }}$ edition

- Gidaspow, D. (1994), Multiphase Flow and Fluidization Continuum and Kinetic Theory Descriptions, San Diego, California, Academic Press Inc.

- Gidaspow, D., Tsuo, Y. and Luo, K. (1989), Computed and experimental cluster formation and velocity profiles in circulating fluidized beds, Fluidization VI, Engineering Foundation, NY, 81-88

- Griffith, A. and Louge, M. (1998), The scaling of cluster velocity at the wall of circulating fluidized bed risers, Chemical Engineering Science 53, 13, 2475-2477

- Haider, A. and Levenspiel, O. (1989), Drag coefficient and terminal velocity of spherical and nonspherical particles, Powder Technology 58, 63-70

- Kaufman, S. (1986), Fiberoptics in Laser Doppler Velocimetry, Lasers and Applications, Feb., 71-73

- Lim, K., Zhou, C., Grace, J., Lim, C. and Brereton, C. (1996), Cluster descending velocity at the wall of circulating fluidized bed risers, Proceedings of the fifth International Conference on Circulating Fluidized Beds, May28, Beijing, People's Republic of China 
- Ludlow, C., Shadle, L. and Syamlal, M. (2002), Development of Spiral Device for Measuring Solids Flow, Proceedings of the $7^{\text {th }}$ International Conference on Circulating Fluidized Beds held at Niagara Falls, Ontario, Canada

- Menon, R. (1982), Laser Doppler velocimetry: Performance and Applications, American Laboratory

- Monazum, E., Shadle, L. and Lawson, L. (2001), A transient method for determination of saturation carrying capacity, Powder Techonlogy 121, 205-212

- Monceaux, L. Azzi M., Molodtsof, Y. and Large, J.F. (1985), Overall and local characteristics of flow in a circulating fluidized bed, International Conference on Circulating Fluidized Beds, Halifax, Canada , 185-191

- Noymer, P. and Glicksman, L. (1998), Cluster motion and particle-convective heat transfer at the wall of a circulating fluidized bed, Int. J. Heat Mass transfer 41, 1, $147-158$

- Rhodes, M. and Geldart, D. (1986), The hydrodynamic of recirculating fluidized beds, Circulating Fluidized Bed Technology, ed. I.P. Basu, Pergamon Press, Toronto, 193200

- Rhodes, M., Mineo, H. and Hirama, T. (1992), Particle motion at the wall of a circulating fluidized bed, Powder Technology 70, 207-214

- Shadle, L., Monazum, E. and Mei, J. (2002), Circulating fluid bed operating regimes, Proceedings of the $7^{\text {th }}$ International Conference on Circulating Fluidized Beds held at Niagara Falls, Ontario, Canada, 255-262 
- Sharma, A., Tuzla, K., Matsen, J. and Chen, J. (2000), Parametric effects of particle size and gas velocity on cluster characteristics in fast fluidized beds, Powder Technology 111, 114-122

- Soong, C., Tuzla, K. and Chen, J. (1995), Experimental determination of cluster size and velocity in circulating fluidized bed, Fluidization VIII, 219-227

- Tadrist, L. and Cattiew, P. (1993), Analysis of two-phase flow in a circulating fluidized bed, Proceedings of the $4^{\text {th }}$ International Conference on Circulating Fluidized Beds, Pennsylvania, USA, 702-707

- Thompson H., and Stevenson W. (1978), Laser velocimetry and particle sizing, International workshop on Laser Velocimetry, $3^{\text {rd }}$, Purdue University, July 11-13

- TSI Inc. 2000a, Backscatter Imaging LDV System, Hardware, Software and Analysis: Users Manual

- TSI Inc. 2000b, Phase Doppler Particle Analyzer (PDPA): Operations Manual

- Tsuji Y., Morikawa Y. and Shiomi H. (1984), LDV measurements of an air-solid flow in a vertical pipe, J. Fluid Mech. 139, 417-434

- Van den Moortel, T., Azario, E., Santini, R. and Tadrist, L. (1998), Experimental analysis of the gas-particle flow in a circulating fluidized bed using a phase Doppler particle analyzer, Chem. Eng. Sc. 53, 10, 1883-1899

- Van den Moortel, T. and Tadrist, L. (2002), Flow structures in a circulating fluidized bed, Circulating Fluidized Bed Technology VII, Proceedings of the $7^{\text {th }}$ International Conference on Circulating Fluidized Beds held at Niagara Falls, Ontario, Canada, May 5-8, 217-224 
- Wang, Y., Wei, F., Wang, Z., Jin, Y. and Yu, Z. (1998), Radial profiles of solids concentration and velocity in a very fine particle $(36 \mu \mathrm{m})$ riser, Powder Technology 96, 262-266

- Wei, F., Lin, H., Cheng, Y., Wang, Z. and Jin, Y. (1998), Profiles of particle velocity and solids fraction in a high-density riser, Powder Technology 100, 183-189

- Zhou, J., Grace, J., Lim, C. and Brereton, C. (1995), Particle velocity profiles in a circulating fluidized bed riser of square cross-section, Chemical Engineering Science $\mathbf{5 0}, 2,237-244$

- Zhu, J., Li, G., Qin, A., Li, F., Zhang, H. and Yang, Y. (2001), Direct measurements of particle velocities in gas-solids suspension flow using a novel five-fiber optical probe, Powder Technology 115, 184-192 


\section{Appendix I}

Variation in velocity of $\mathrm{Nu}$-Pareils with drop height, solids loading and particle size

\begin{tabular}{|c|c|c|c|c|c|}
\hline \multirow{2}{*}{$\begin{array}{c}\text { Size cut } \\
(\boldsymbol{\mu m})\end{array}$} & $\begin{array}{c}\text { Drop } \\
\text { Height }(\mathbf{m})\end{array}$ & \multicolumn{4}{|c|}{ Mean velocity $(\mathbf{m} / \mathbf{s})$} \\
\cline { 3 - 6 } & & $\begin{array}{c}\text { Low } \\
\text { loading }\end{array}$ & $\begin{array}{c}\text { Medium } \\
\text { Loading }\end{array}$ & $\begin{array}{c}\text { Medium-High } \\
\text { Loading }\end{array}$ & $\begin{array}{c}\text { High } \\
\text { Loading }\end{array}$ \\
\hline $500-600$ & 0.3 & 2.1 & 2.29 & 2.32 & 2.52 \\
\hline & 0.6 & 2.77 & 3.33 & 3.4 & 3.5 \\
\hline & 0.9 & 3.1 & 3.78 & 3.96 & 3.99 \\
\hline & 1.2 & 3.1 & - & - & - \\
\hline $600-700$ & 0.3 & 2.17 & 2.29 & 2.32 & 2.37 \\
\hline & 0.6 & 2.86 & 3.24 & 3.4 & 3.45 \\
\hline & 0.9 & 3.18 & 3.54 & 3.9 & 4.1 \\
\hline & 1.2 & 3.37 & - & - & - \\
\hline
\end{tabular}

Table A1.1 Velocity data corresponding to Figures 5.4, 5.5 and 5.6

The difference in solids loading in the above experiment is brought about by using a sieve of different size and also by altering the vibration rate of the pneumatic vibrator. 


\begin{tabular}{|c|c|c|c|}
\hline Run \# & $\begin{array}{c}\text { Particle size }(\boldsymbol{\mu m}) \\
\text { (sieve analysis) }\end{array}$ & $\begin{array}{c}\text { Mean terminal } \\
\text { velocity }(\mathbf{m} / \mathbf{s}) \\
\text { (experimental) }\end{array}$ & $\begin{array}{c}\text { Mean particle } \\
\text { diameter }(\boldsymbol{\mu m}) \\
\text { (experimental) }\end{array}$ \\
\hline 1 & $1000-1200$ & 4.62 & 1064.7 \\
\hline 2 & & 4.59 & 1072.4 \\
\hline 1 & $850-1000$ & 4.47 & 894.9 \\
\hline 2 & & 4.45 & 885.2 \\
\hline 1 & $700-850$ & 3.81 & 791.3 \\
\hline 2 & & 3.78 & 793.9 \\
\hline 1 & $600-700$ & 3.37 & 699.1 \\
\hline 2 & & 3.33 & 700.8 \\
\hline 1 & $500-600$ & 308 & 566.7 \\
\hline 2 & & 3.08 & 586.2 \\
\hline
\end{tabular}

Table A1.2 Experimental data for terminal velocity and particle diameter of Nu-Pareils of different particle size-cuts 


\section{Appendix II}

\section{Solids velocity data near the wall of the CFB riser}

\begin{tabular}{|c|c|c|c|c|}
\hline \multirow[b]{2}{*}{$\operatorname{Run}$ \# $^{*}$} & \multirow{2}{*}{$\begin{array}{l}\text { Distance } \\
\text { from wall } \\
(\mathrm{mm})\end{array}$} & \multicolumn{2}{|c|}{ Mean velocity $(\mathrm{m} / \mathrm{s})$} & \multirow{2}{*}{$\begin{array}{c}\text { Mean } \\
\text { velocity } \\
\text { (m/s) } \\
\text { (weighted) }\end{array}$} \\
\hline & & $\begin{array}{l}\text { Negative velocity } \\
\text { (Downward) }\end{array}$ & $\begin{array}{l}\text { Positive velocity } \\
\text { (Upward) }\end{array}$ & \\
\hline \multirow[t]{4}{*}{1} & 1 & -1.43 & 1.46 & -0.58 \\
\hline & 4 & -1.37 & 1.50 & -0.71 \\
\hline & 6 & -1.32 & 1.66 & -0.16 \\
\hline & 12 & -1.15 & 1.55 & 0.01 \\
\hline \multirow[t]{6}{*}{2} & 1 & -1.10 & 1.32 & -0.21 \\
\hline & 4 & -1.24 & 1.73 & 0.63 \\
\hline & 7 & -1.13 & 1.95 & 1.19 \\
\hline & 11 & -1.13 & 2.38 & 1.93 \\
\hline & 19 & -1.25 & 2.44 & 2.25 \\
\hline & 21 & -1.57 & 2.47 & 2.31 \\
\hline \multirow[t]{6}{*}{3} & 1 & -1.16 & 1.30 & -0.26 \\
\hline & 4 & -1.27 & 1.67 & 0.08 \\
\hline & 8 & -1.10 & 1.90 & 0.87 \\
\hline & 12 & -1.29 & 2.00 & 1.17 \\
\hline & 16 & -1.19 & 2.07 & 1.15 \\
\hline & 21 & -1.01 & 2.05 & 1.48 \\
\hline \multirow[t]{7}{*}{4} & 1 & -0.70 & 1.58 & 1.17 \\
\hline & 5 & -0.90 & 1.66 & 1.21 \\
\hline & 10 & -0.80 & 2.42 & 2.39 \\
\hline & 15 & -0.64 & 2.32 & 2.26 \\
\hline & 21 & $* *$ & 2.62 & 2.62 \\
\hline & 25 & $* *$ & 2.67 & 2.67 \\
\hline & 31 & $* *$ & 2.78 & 2.78 \\
\hline \multirow[t]{4}{*}{5} & 1 & -1.22 & 1.13 & -0.96 \\
\hline & 5 & -1.53 & 1.84 & -0.81 \\
\hline & 9 & -1.27 & 1.74 & -0.14 \\
\hline & 13 & -1.12 & 1.81 & 0.22 \\
\hline \multirow[t]{9}{*}{6} & 1 & -0.87 & 1.56 & 1.07 \\
\hline & 3 & -0.74 & 1.91 & 1.72 \\
\hline & 7 & -0.88 & 2.19 & 2.06 \\
\hline & 12 & -1.11 & 2.48 & 2.46 \\
\hline & 16 & $* *$ & 2.46 & 2.45 \\
\hline & 21 & $* *$ & 2.99 & 2.99 \\
\hline & 26 & $* *$ & 3.06 & 3.06 \\
\hline & 31 & $* *$ & 3.10 & 3.10 \\
\hline & 36 & $* *$ & 3.16 & 3.16 \\
\hline
\end{tabular}




\begin{tabular}{|c|c|c|c|c|}
\hline \multirow[b]{2}{*}{ Run \# * } & \multirow{2}{*}{$\begin{array}{l}\text { Distance } \\
\text { from wall } \\
(\mathbf{m m})\end{array}$} & \multicolumn{2}{|c|}{ Mean velocity $(\mathrm{m} / \mathrm{s})$} & \multirow{2}{*}{$\begin{array}{c}\text { Mean } \\
\text { velocity } \\
(\mathbf{m} / \mathbf{s}) \\
\text { (weighted) }\end{array}$} \\
\hline & & $\begin{array}{c}\text { Negative } \\
\text { velocity } \\
\text { (Downward) }\end{array}$ & $\begin{array}{l}\text { Positive } \\
\text { velocity } \\
\text { (Upward) }\end{array}$ & \\
\hline \multirow[t]{5}{*}{7} & 1 & -1.23 & 1.40 & -0.35 \\
\hline & 4 & -1.44 & 1.58 & -0.28 \\
\hline & 8 & -1.36 & 2.12 & 0.42 \\
\hline & 13 & -1.21 & 1.82 & 0.60 \\
\hline & 16 & -1.16 & 1.87 & 1.22 \\
\hline \multirow[t]{5}{*}{ Repeat (run 7) } & 1 & -1.24 & 1.47 & $\begin{array}{l}-0.32 \\
\end{array}$ \\
\hline & 4 & -1.30 & 1.52 & -0.10 \\
\hline & 8 & -1.35 & 1.78 & 0.35 \\
\hline & 13 & -1.05 & 1.64 & 0.53 \\
\hline & 16 & -1.33 & 2.15 & 0.96 \\
\hline \multirow[t]{7}{*}{8} & 1 & -1.10 & 1.13 & -0.51 \\
\hline & 8 & -1.43 & 1.68 & -0.01 \\
\hline & 13 & -1.34 & 1.77 & 0.32 \\
\hline & 17 & -1.32 & 2.16 & 0.99 \\
\hline & 22 & -1.20 & 2.23 & 1.18 \\
\hline & 27 & -1.23 & 2.31 & 1.57 \\
\hline & 36 & -1.25 & 2.60 & 1.39 \\
\hline \multirow[t]{8}{*}{9} & 1 & -1.11 & 1.07 & -0.87 \\
\hline & 3 & -1.40 & 1.42 & $\begin{array}{l}-0.97 \\
\end{array}$ \\
\hline & 6 & -1.44 & 1.48 & -0.42 \\
\hline & 9 & -1.40 & 1.80 & 0.03 \\
\hline & 14 & -1.18 & 1.51 & 0.24 \\
\hline & 18 & -1.18 & 1.84 & 0.54 \\
\hline & 22 & -1.28 & 2.14 & 0.82 \\
\hline & 26 & $\begin{array}{l}-0.79 \\
\end{array}$ & 2.24 & 1.81 \\
\hline
\end{tabular}

* For the corresponding operating conditions refer to Table 6.1

** Insignificant number of particles moving in this direction relative to the whole data set

Table A2.1 Mean velocities of particles as a function of distance inside

the riser wall for various operating conditions 
A statistical analysis was done to examine the dependence of solids circulation rate $\left(M_{S}\right)$ and superficial gas velocity $\left(U_{g}\right)$ on the mean velocity of solids at the wall. The significance values indicate that the mean velocity was affected both by solids circulation rate and superficial gas velocity at the wall. A significance value less than 0.05 indicate strong dependence.

\begin{tabular}{|c|c|c|c|c|c|}
\hline \multicolumn{6}{|c|}{$\begin{array}{l}\text { Tests of Between-Subjects Effects } \\
\text { Dependent Variable: Mean solids velocity at wall }\end{array}$} \\
\hline Source & Type I Sum of Squares & df & Mean Square & $\mathbf{F}$ & Sig. \\
\hline Corrected Model & 4.503(a) & 5 & .901 & 12.376 & .015 \\
\hline Intercept & .331 & 1 & .331 & 4.552 & .100 \\
\hline$U_{g}$ & 1.291 & 1 & 1.291 & 17.736 & .014 \\
\hline$M_{s}$ & 2.263 & 1 & 2.263 & 31.097 & .005 \\
\hline$U_{g} * U_{g}$ & .332 & 1 & .332 & 4.565 & .099 \\
\hline$M_{s} * M_{s}$ & .424 & 1 & .424 & 5.820 & .073 \\
\hline$U_{g} * M_{s}$ & 194 & 1 & .194 & 2.660 & .178 \\
\hline Error & 291 & 4 & 7.277E-02 & & \\
\hline Total & 5.125 & 10 & & & \\
\hline Corrected Total & 4.794 & 9 & & & \\
\hline \multicolumn{6}{|c|}{ a R Squared $=.939($ Adjusted R Squared $=.863)$} \\
\hline
\end{tabular}

Table A2.2 Dependence of solids velocity on superficial gas velocity and solids circulation rate, at the wall- A statistical study 


\section{Appendix III}

\section{Results on Solids 'Clusters'}

It was observed that from the data collected for the various operating regimes, some useful information could be obtained regarding the cluster formation near the walls of the riser. This information is useful in characterizing the 'clusters' and understanding the mechanics of heat transfer at the walls of the bed.

Figure A3.1 shows the velocity versus time graph obtained at the wall for two sets of operating conditions. Cluster behavior was seen to occur when a large amount of data occurs over a very narrow time period indicating that a 'swarm' of particles passed through the LDV measuring volume. It is clear from the graph that particles tend to form more clusters during dense flow. The main question posed in such a study is "How to define a cluster?". A set of criteria was required to distinguish the presence of clusters within the raw velocity data. Although a more rigorous analysis needs to be done, the results from a preliminary analysis are discussed here. These have shown good agreement with the kind of behavior expected near the wall of the bed.

A cluster in the raw data, was identified when all of the following criteria were satisfied:

- The difference in time between two successive particle measurements was less than $20 \mathrm{~ms}$ and greater than $0.1 \mathrm{~ms}$

- The direction of the flow of particles does not change within a cluster

- There were at least 4 and at the maximum 15 particle measurements obtained for a cluster

- The length of a cluster was greater than $0.5 \mathrm{~cm}$ 


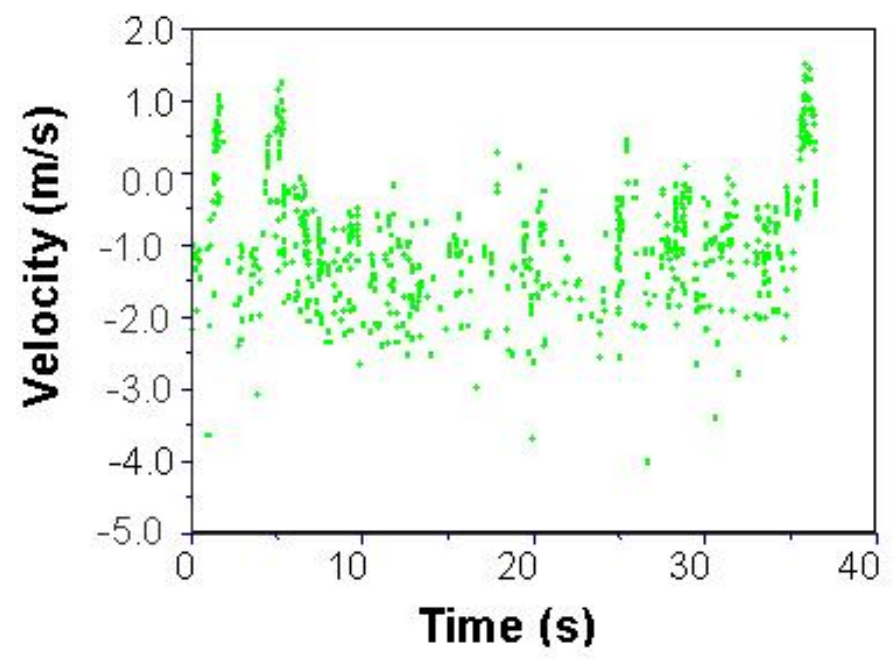

Dilute flow: Less clustering

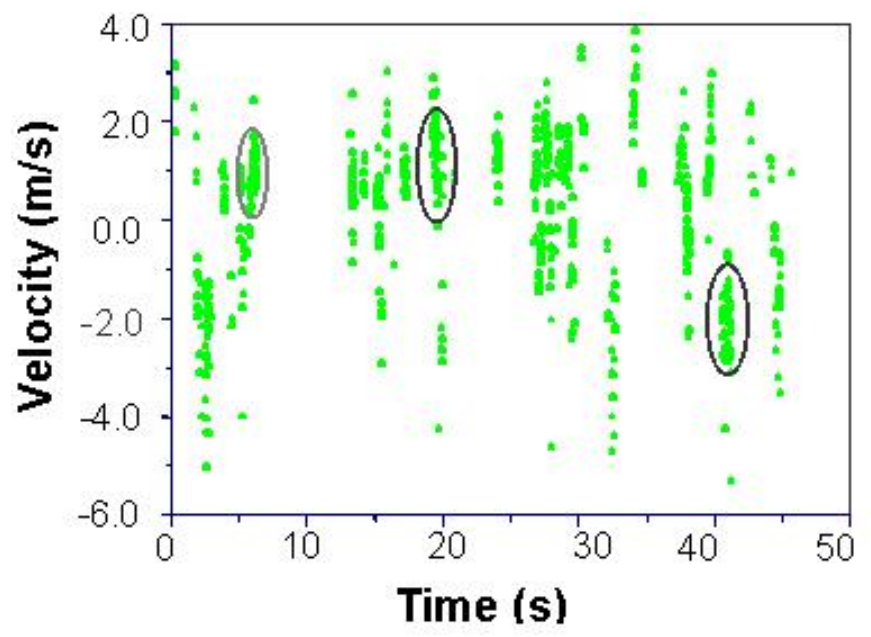

Dense flow: More clustering

Figure A3.1 Clustering of particles for the dense and dilute solids loading 
These criteria were developed based on the results obtained by varying the criteria and comparing the results with work done in the past, and accounting for changes due to the CFB material and the measurement method used in this study.

Using the above criteria, the raw data was analyzed, and the mean cluster velocity and length of clusters were derived. The cluster velocity was defined to be the mean velocity of the particles in a cluster. The length of a cluster was obtained by multiplying the cluster velocity with the time for which that cluster was present in the measurement volume of the LDV. Figure A3.2 shows the velocity of clusters at two radial locations, at the wall and $3 \mathrm{~mm}$ inside the wall for $M_{s}=6000 \mathrm{~kg} / \mathrm{hr}$ and $U_{g}=5.5 \mathrm{~m} / \mathrm{s}$. The frequency distribution shows that at the wall, the proportion of the clusters moving down was much more than those moving up. On moving $3 \mathrm{~mm}$ inside the bed, the proportion of clusters moving down decreases. This is consistent with the fact that the flow is core annular and more particles tend to move down at the wall in comparison to any other location. Also, for the same run time, more clusters were obtained at the wall in comparison to the location $3 \mathrm{~mm}$ inside the wall. A similar comparison is shown in Figure A3.3 for a different operating condition. A similar change in the velocity distribution was obtained for that case. The average velocity of the clusters, for the various operating conditions studied, was found to lie in the range of $0.2-1 \mathrm{~m} / \mathrm{s}$, with most of them around the $1 \mathrm{~m} / \mathrm{s}$ value. This is consistent with the results of previous researchers, which are summarized in Table 2.1. 


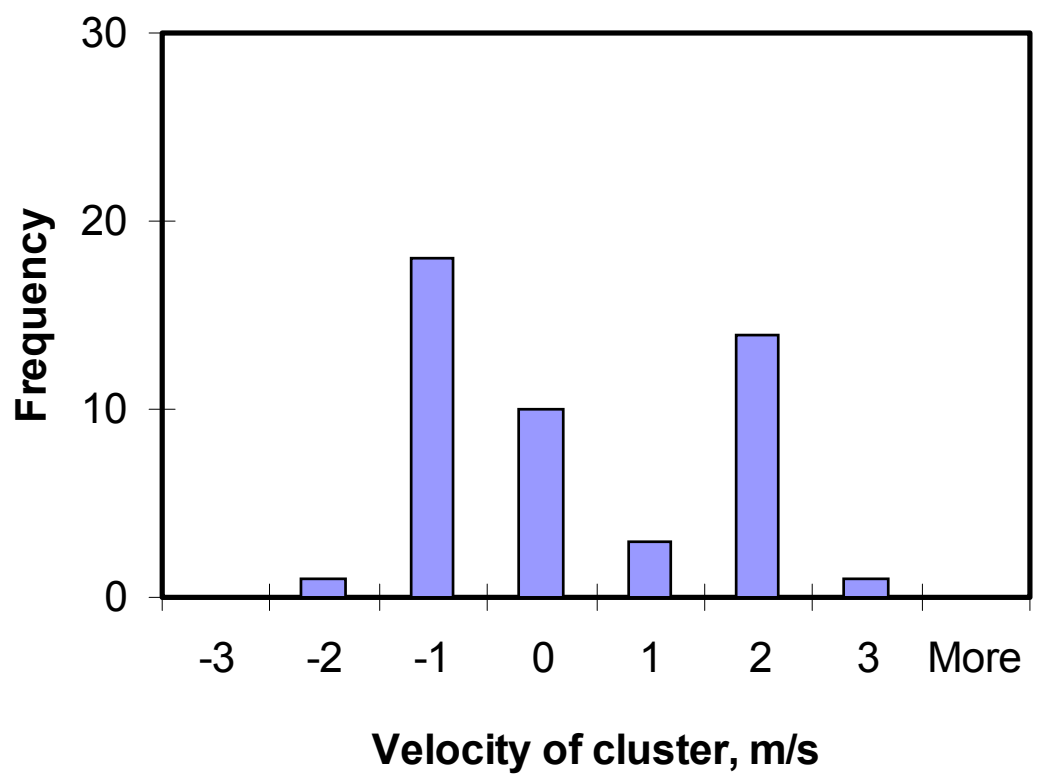

Measurement at the wall

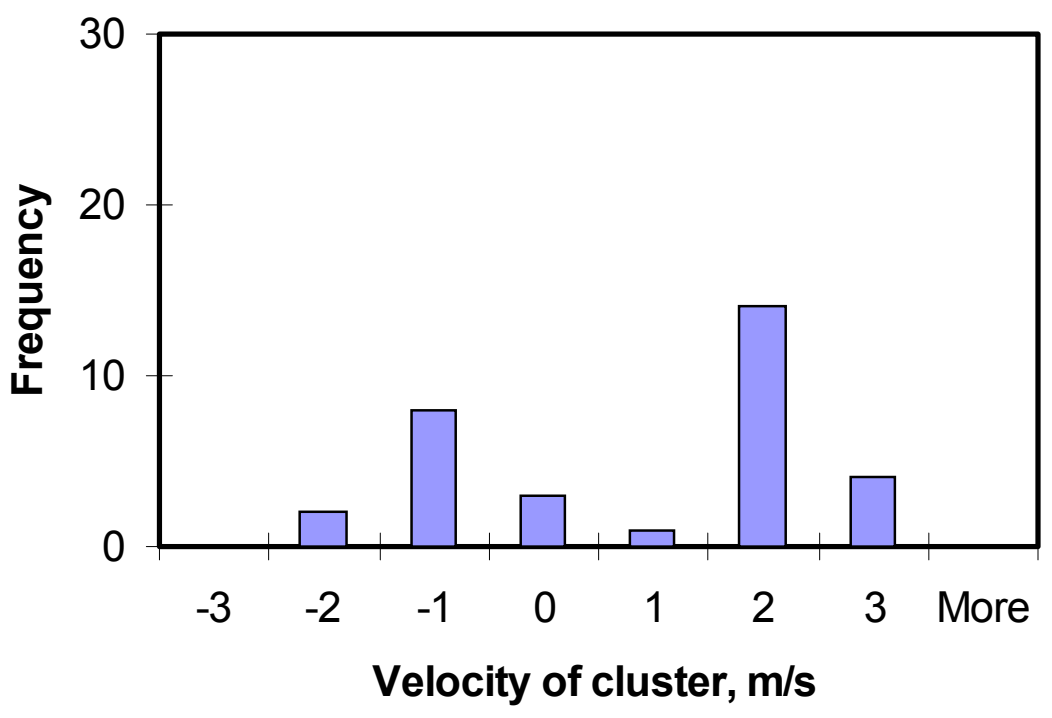

Measurement $3 \mathrm{~mm}$ inside the wall

Figure A3.2 Variation of cluster velocity distribution with radial

location for $M_{s}=6000 \mathrm{~kg} / \mathrm{hr}, U_{g}=5.5 \mathrm{~m} / \mathrm{s}$ 


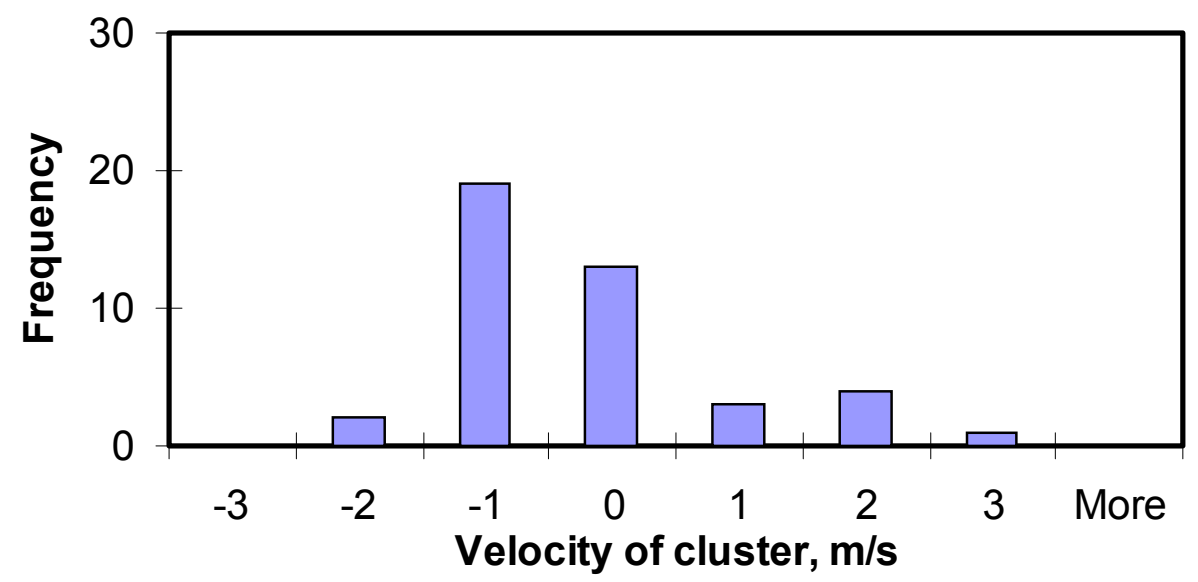

Measurement at the wall

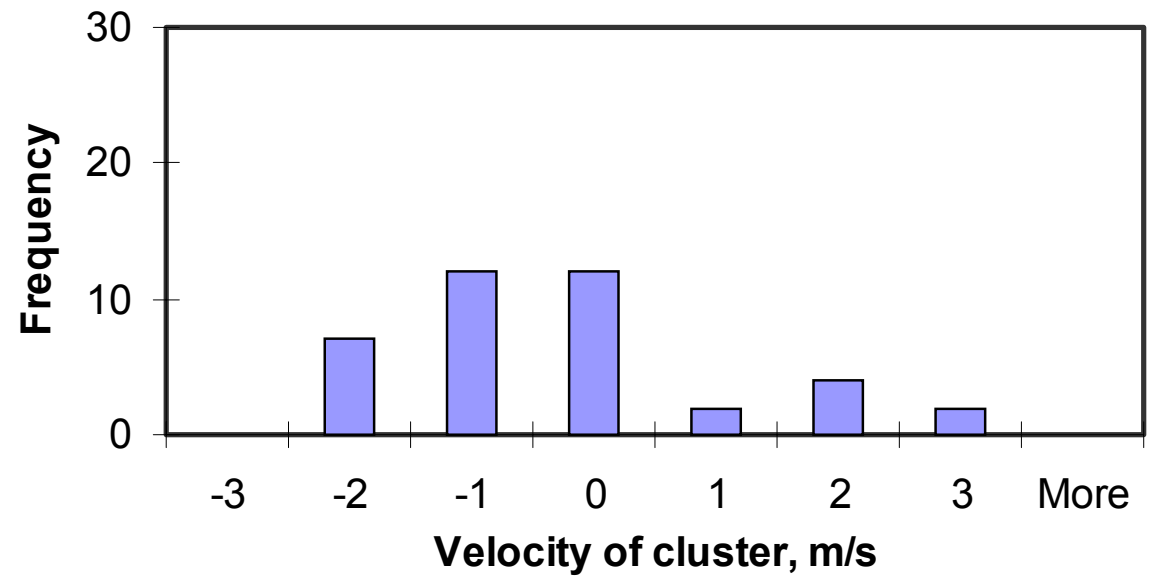

Measurement $3 \mathrm{~mm}$ inside the wall

Figure A3.3 Variation of cluster velocity distribution with radial location for $M_{s}=6000 \mathrm{~kg} / \mathrm{hr}, U_{g}=4.6 \mathrm{~m} / \mathrm{s}$ 
Figure A3.4 shows the variation in cluster length distribution with the change in radial location, for two radial locations, at the wall and $3 \mathrm{~mm}$ inside the wall. It was observed that the proportion of bigger clusters was greater at the wall in comparison to 3 $\mathrm{mm}$ inside the wall. The majority of clusters, for the various operating conditions studied, were $0.5-4 \mathrm{~cm}$ in length with the average cluster size ranging between $2-4 \mathrm{~cm}$. The average cluster size is consistent with the results reported in Soong et al., [1995] and Gidaspow et al., [1989].

The effect of operating variables on the cluster velocity distributions was also studied. Figure A3.5 shows a comparison of the three different solids circulation rates at the wall. It was observed that the clusters have a tendency to move in the downward direction with an increase in the solids circulation rate. This is consistent with the core annular kind of flow expected in the CFB riser. The number of clusters, for the same amount of time, was found to increase with an increase in the solids circulation rate. Figure A3.6 shows the variation with superficial gas velocity at the wall. The solids circulation rate was kept constant at $6000 \mathrm{~kg} / \mathrm{hr}$ for this study. As seen from the graph, the clusters had a tendency to move in the downward direction with decreasing superficial gas velocity. For the lowest superficial gas velocity, $U_{g}=3.8 \mathrm{~m} / \mathrm{s}$, almost all the clusters were found to be moving in the downward direction. The variation of the cluster velocity distribution with solids circulation rate was studied by keeping the superficial gas velocity and other operating parameters constant. 


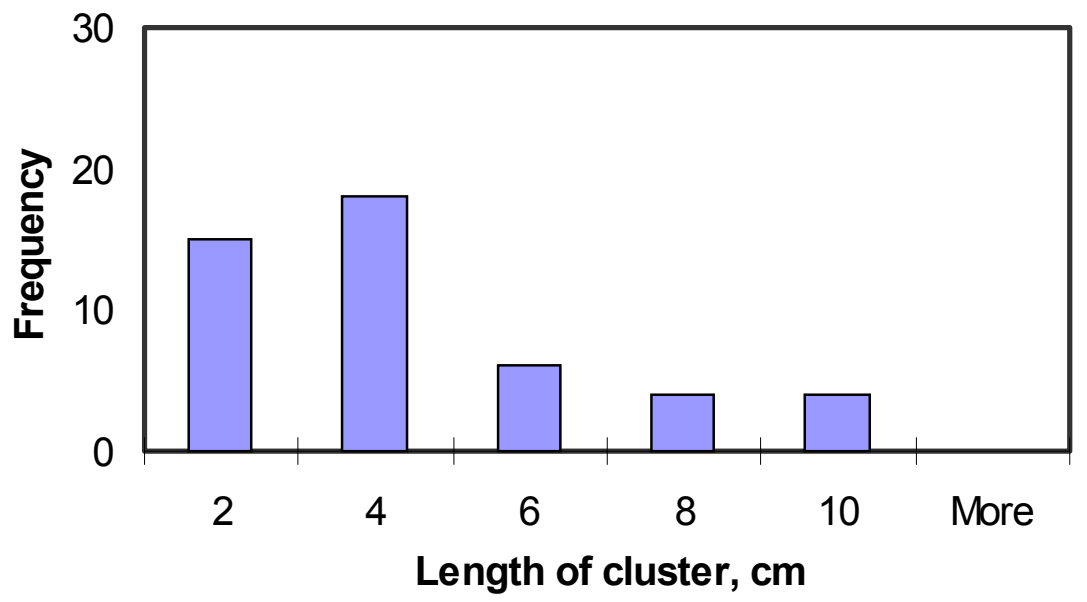

Measurement at the wall

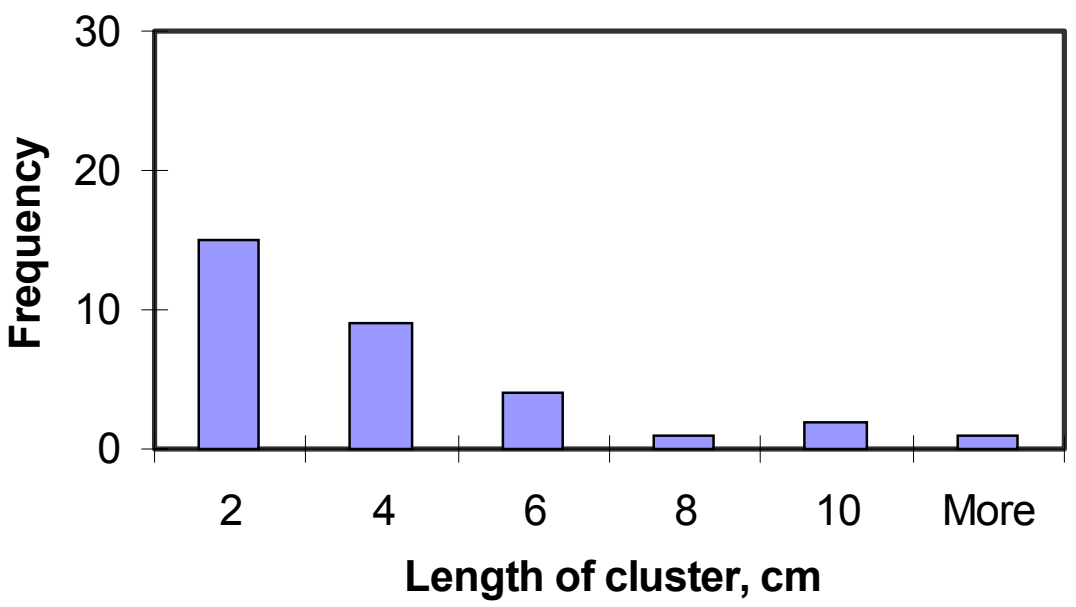

Measurement $3 \mathrm{~mm}$ inside the wall

Figure A3.4 Variation of cluster length distribution with radial location for $M_{s}=6000 \mathrm{~kg} / \mathrm{hr}, U_{g}=4.6 \mathrm{~m} / \mathrm{s}$ 


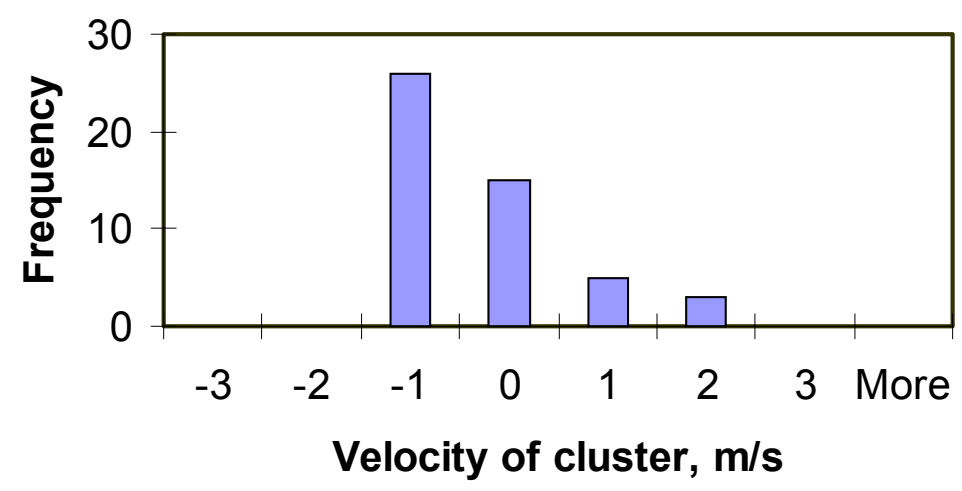

$$
M_{s}=10000 \mathrm{~kg} / \mathrm{hr}
$$

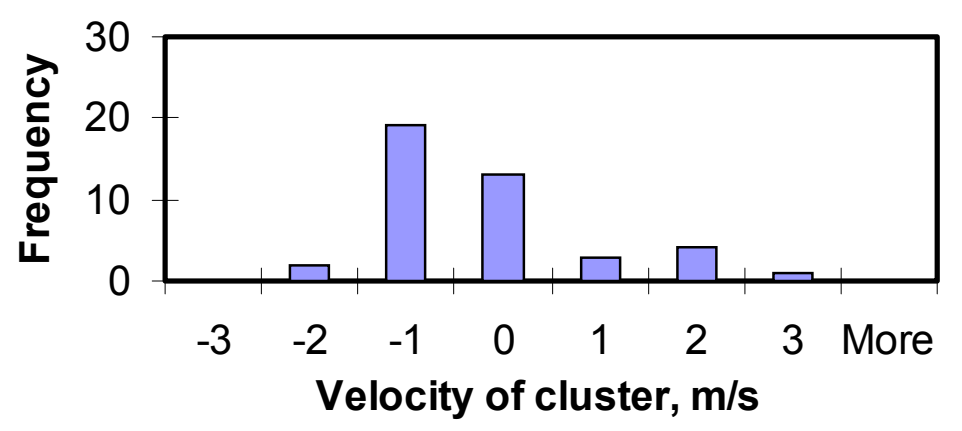

$M_{s}=6000 \mathrm{~kg} / \mathrm{hr}$

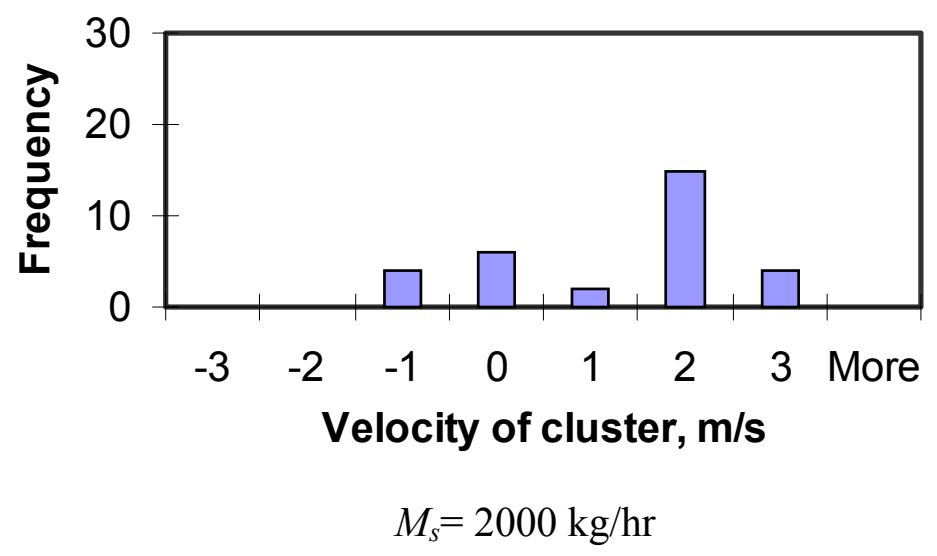

Figure A3.5 Variation of cluster velocity distribution with solids circulation rate for $U_{g}=4.6 \mathrm{~m} / \mathrm{s}$, at the wall of the riser 


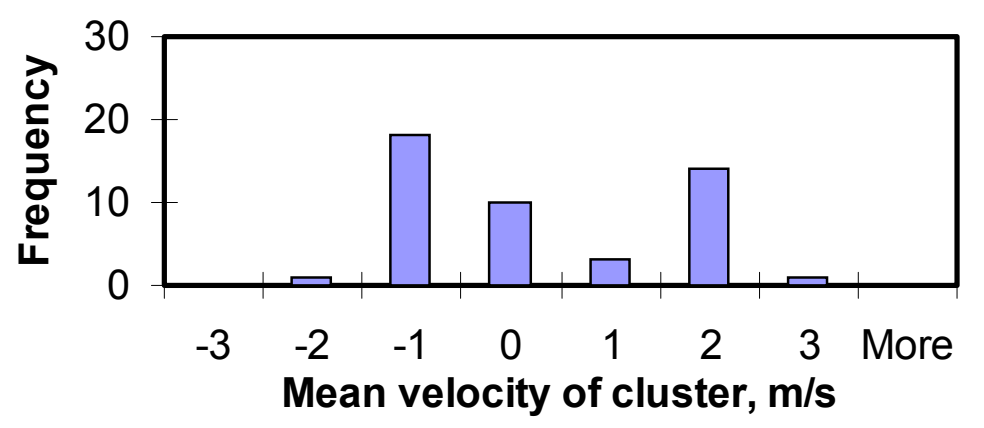

$$
U_{g}=5.5 \mathrm{~m} / \mathrm{s}
$$

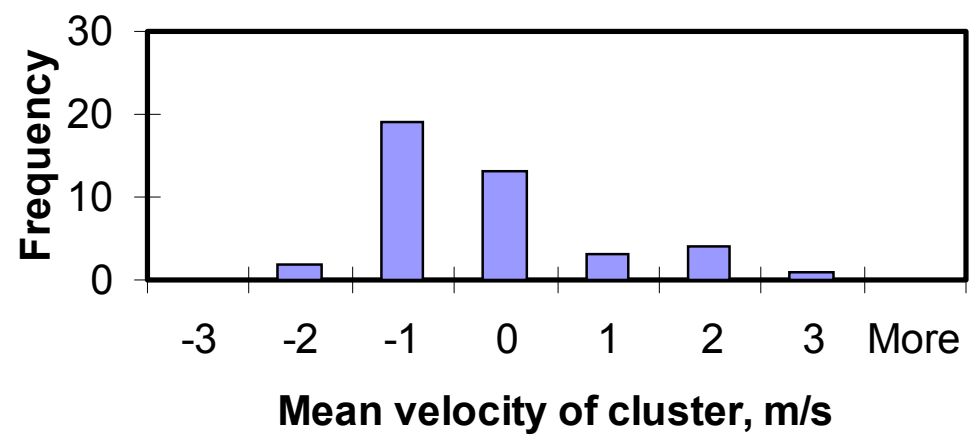

$$
U_{g}=4.6 \mathrm{~m} / \mathrm{s}
$$

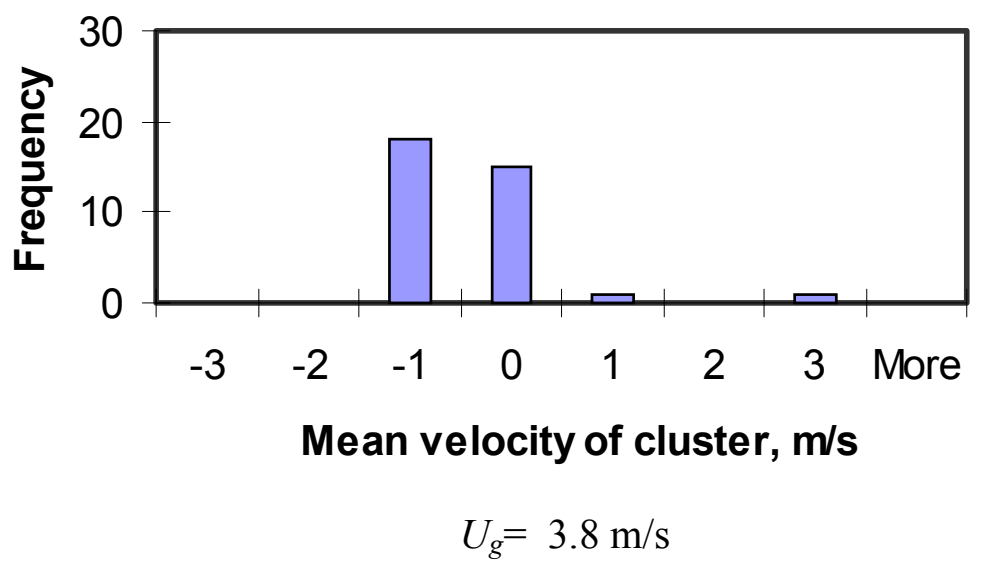

Figure A3.6 Variation of cluster velocity distribution with superficial gas velocity for $M_{s}=6000 \mathrm{~kg} / \mathrm{hr}$, at the wall of the riser 